
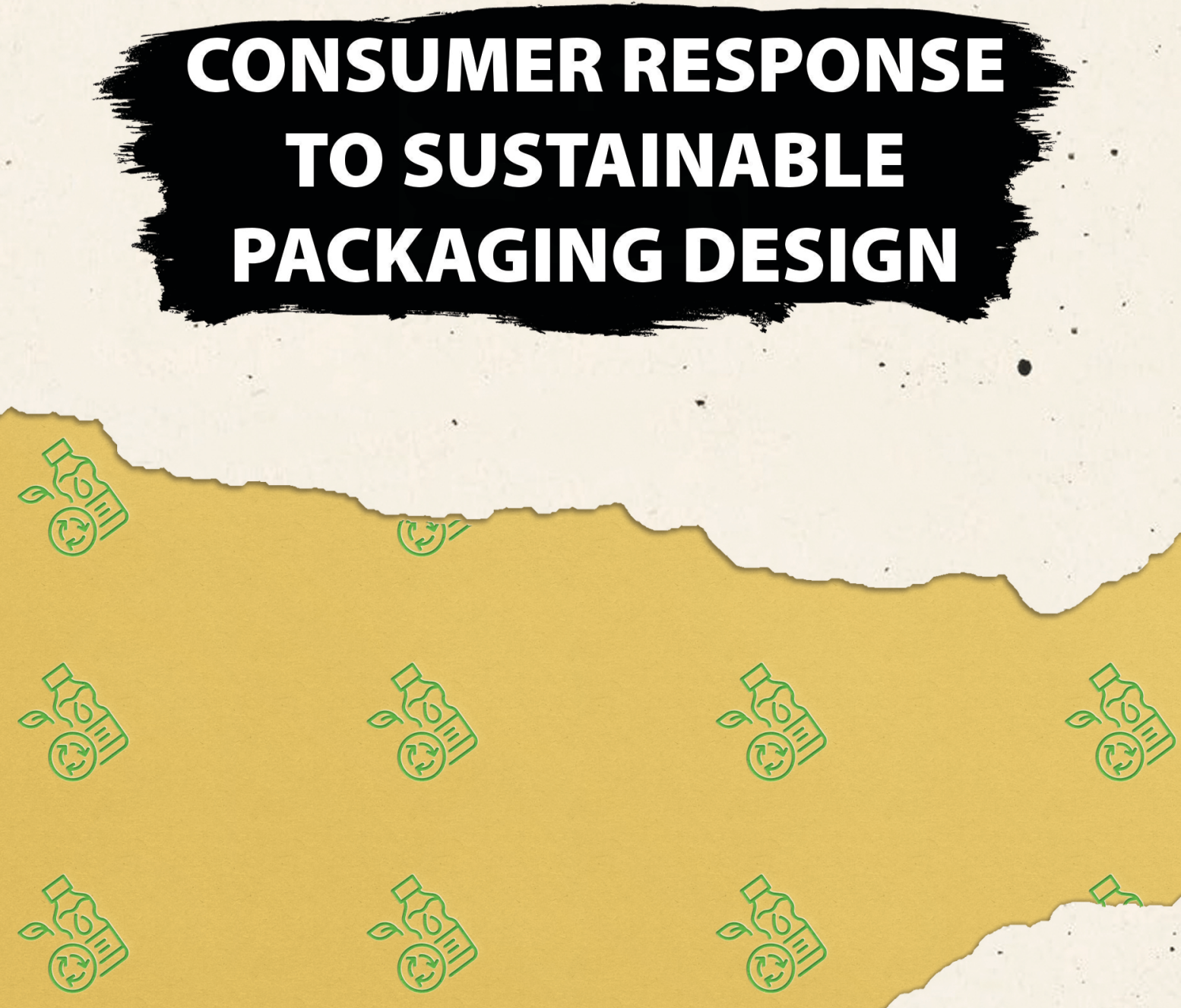

NIGEL D. STEENIS 


\section{Propositions}

1. Green marketing's myopic view on positioning contributes to failure rates of sustainably packaged products. (this thesis)

2. Consumer sustainability perceptions are a poor predictor of expert assessments of environmental impacts. (this thesis)

3. A key challenge of multidisciplinary scientific research is that it is expected to conform to the norms and practices of multiple disciplines.

4. Dutch ecosystems cannot be fully restored without the return of the wolf.

5. Fast-fashion is the adversary of sustainability.

6. Virtual loot boxes turn games of skill into games of chance.

Propositions belonging to the thesis, entitled:

Consumer response to sustainable packaging design

Nigel Desmond Steenis

Wageningen, Tuesday 5 November 2019 


\section{CONSUMER RESPONSE TO SUSTAINABLE PACKAGING DESIGN}

Nigel Desmond Steenis 


\section{Thesis committee}

\section{Promotor}

Prof. Dr. J.C.M. van Trijp

Professor of Marketing and Consumer Behaviour

Wageningen University \& Research

\section{Co-promotor}

Dr. H.W.I. van Herpen

Associate professor, Marketing and Consumer Behaviour Group

Wageningen University \& Research

Dr. I.A.C.M van der Lans

Assistant professor, Marketing and Consumer Behaviour Group

Wageningen University \& Research

\section{Other members}

Prof. Dr. G. Spaargaren, Wageningen University \& Research

Prof. Dr. E.G. Smit, University of Amsterdam

Prof. Dr. J.P.L. Schoormans, TU Delft

Prof. Dr. J. Henseler, University of Twente

This research was conducted under the auspices of the Wageningen School of Social Sciences (WASS). 


\title{
CONSUMER RESPONSE TO SUSTAINABLE PACKAGING DESIGN
}

\author{
Nigel Desmond Steenis
}

Thesis

submitted in fulfilment of the requirements for the degree of doctor

at Wageningen University

by the authority of the Rector Magnificus,

Prof. Dr A.P.J. Mol

in the presence of the Thesis Committee appointed by the Academic Board to be defended in public

on Tuesday 5 November 2019

at 1.30 p.m. in the Aula. 
Nigel Desmond Steenis

Consumer response to sustainable packaging design,

191 pages

PhD Thesis, Wageningen University, Wageningen, the Netherlands (2019) With references, with summary in English

ISBN: 978-94-6395-140-1

DOI: https://doi.org/10.18174/501664 


\section{CONTENTS}

CHAPTER 1 General Introduction

CHAPTER 2 Consumer response to packaging design: The role of packaging materials and graphics in sustainability perceptions and product evaluations

CHAPTER 3 Effects of sustainable design strategies on consumer preferences for redesigned packaging

CHAPTER 4 Partially green, wholly deceptive? How consumers respond to (in)consistently sustainable packaged products in the presence of sustainability claims

CHAPTER 5 Making it macho: Using 'gendered' packaging designs to increase consumer preferences for sustainably packaged products

CHAPTER 6 General Discussion

References 



\section{CHAPTER 1}

General introduction 


\subsection{Background}

\subsubsection{Packaging \& the environment}

Packaging is a pervasive element of modern consumption. The global consumer packaging market is worth an estimated total of US\$400b (EY, 2013), yet it is also associated with a significant environmental burden.. In 2012, container and packaging waste formed the largest category of municipal solid waste in the US, constituting 30\% of the total municipal solid waste (EPA, 2014). EU citizens in 2015 on average generated $166.3 \mathrm{~kg}$ of packaging waste per inhabitant, and $41 \%$ of this packaging waste consisted of paper and cardboard packaging, followed by $19 \%$ for both glass and plastics, 16\% wood and 5\% metal packaging (Eurostat, 2018).

Packaging is often perceived by consumers as a 'necessary evil' that is prominently associated with environmental degradation (Lindh, Olsson, \& Williams, 2016; Lindh, Williams, Olsson, \& Wikström, 2016). Packaging is highly visible and its waste is often difficult for consumers to avoid. The pervasiveness of packaging causes it to contribute to a variety of environmental problems including global warming and climate change, the depletion of resources, acidification and high energy and water consumption (Bohlmann, 2004; Ligthart \& Ansems, 2018). At the same time, packaging also fulfils a number of positive environmental (and economical) roles such as preventing product losses and facilitating efficient logistics.

The development of sustainable packaging has been one of the major topics of attention by policy-makers, environmental lobbyists, consumers and the industry alike (Brisson, 1993; Sonneveld, James, Fitzpatrick, \& Lewis, 2005). Sustainable packaging is defined by the Sustainable Packaging Coalition (a packaging industry collaborative), as packaging that is sourced responsibly, designed to be effective and safe throughout its life cycle, meets market criteria for performance and cost, is made entirely using renewable energy, and once used, is recycled efficiently to provide a valuable resource for subsequent generations (SPC, 2011). In order to actualize sustainable packaging along these criteria, sustainable packaging needs to be designed to have desirable effects on consumer behavior (Magnier \& Crié, 2015; Nordin \& Selke, 2010). This is important as more sustainable packaging designs may lead to (un)intended changes in consumer perception, evaluation and choice of packaged products. 


\subsubsection{Marketing roles of packaging}

Despite the generally negative view on packaging in light of the environment, packaging fulfils a number of key roles in consumer markets and their corresponding supply-chains. From a marketing perspective, primary packaging plays a pivoting role in the product benefit proposition and communication thereof. This primary packaging is defined as the packaging that surrounds the product in the retail environment (e.g., the bottle surrounding soda drink), and is also referred to as sales packaging, retail packaging or consumer packaging. The marketing role of packaging is of great importance for highly competitive Fast Moving Consumer Goods (FMCG), which are defined as single (or limited) use, low priced consumer products. They consist to a large extent of food products and other daily-use consumer goods (Simms \& Trott, 2010). Primary packaging can convey specific product benefits (Magnier, Schoormans, \& Mugge, 2016; Underwood, 2003), generate brand impressions (Orth, Campana, \& Malkewitz, 2010; Orth \& Malkewitz, 2008), differentiate the product in the retail environment (Orth \& Crouch, 2014) and guide consumer categorization processes (Garaus \& Halkias, 2019; Schoormans \& Robben, 1997).

These marketing roles of packaging are important because they often cannot be fulfilled by the product contained within the packaging. The product contents often lack ability to express themselves at the point of purchase. Packaging therefore serves as 'the silent salesman' (Rod, 1990) as it allows consumers to generate specific product impressions. These impressions may originate from deliberate packaging design decisions by marketers, but can also occur purely by virtue of the packaging's appearance. Packaging design has a major influence in guiding consumer choice for packaged products as a whole because its design generates expectations about the qualities of the product contained within (Underwood, 2003). Even small changes in packaging design can have far reaching consequences for product sales.

\subsubsection{Sustainable packaging \& the consumer challenge}

From a consumer marketing perspective, the successful introduction of more sustainable packaging alternatives requires that sustainably packaged products are designed to outperform conventionally packaged options in terms of environmental performance, but also in terms of consumer acceptance (i.e., preferences and purchases). 
Consumer acceptance is key for sustainable packaging because its effective environmental improvements rely on consumers opting to choose for more sustainably packaged products. In other words, if sustainably packaged products are not preferred in the consumer marketplace, a lack of consumer adoption would marginalize its actual environmental contributions. This implies that sustainable packaging design must consider both the functional aspects of sustainable design (improving the environmental impact of packaging), as well as consider what such packaging designs signal to consumers, intentionally or otherwise. Therefore, this thesis focusses on understanding the processes underlying consumer response to sustainable packaging design. It is subsequently considered how this packaging can be designed and positioned such to improve consumer response to sustainably packaged products. The next section outlines a theoretical framework to study the influence of sustainable packaging design and its positioning on consumer response.

\subsection{Theoretical framework: Consumer response to sustainable packaging}

The way in which consumers respond to sustainable packaging designs can be viewed as the result of an inference making process wherein consumers utilize the cues of packaging design to ultimately respond in terms of packaged product perceptions, beliefs, attitudes (as evaluative judgments), purchase intentions and choices. Cues are therein considered as characteristics of the packaging with the potential to signal some property of the packaged product. A theoretical framework outlining this process is displayed in Figure 1.1 This framework combines insights from theoretical models related to cue utilization and inference-making (Kardes, Posavac, \& Cronley, 2004; Olson, 1978; Olson \& Jacoby, 1972; Steenkamp, 1990) and product design (Bloch, 1995). The framework considers the consumer process as a subject-object interaction (Brunswik, 1955), relying on consumers' subjective processing and evaluation of 'objective' packaging designs. In the next sections, the framework's concepts are discussed and knowledge gaps are highlighted.

\subsubsection{Subject-object interactions and inference-making processes}

In line with previous conceptualizations (Bloch, 1995; Golder, Mitra, \& Moorman, 2012; Mitra \& Golder, 2006; Steenkamp, 1990) the object (i.e., sustainable packaging) is the 'starting point' of the framework. It is described as the physical design, or as an objectively produced state that is the outcome of various design processes, goals and constraints (Bloch, 1995; Golder et al., 2012). This physical design contains an 
array of cues perceptible through the senses (Steenkamp, 1990), and consumers' perception and evaluation of this physical design depends on their mental processing of the cues provided by the design. These types of processes therefore are a psychophysical subject-object interaction because they are considered to be neither fully subjective (i.e., an exclusively psychological process) nor fully objective (i.e., a subject-free physical process).

In order to make sense of packaging designs, consumers must first perceive and acquire cues of the design (Olson, 1978; Steenkamp, 1990). While cues themselves are considered as 'objective' elements, cue perception relies on the subjective processing of these cues. Therefore, the cue perception stage posits that (1) consumers may not always perceive all cues resulting from the designed packaging and (2) that consumers are heterogeneous in terms of their perception of those cues, that is, different consumers may come to different conclusions on the basis of the same cues (Golder et al., 2012; Steenkamp, 1990). These cues can (theoretically) be diagnostic for the true environmental impacts (e.g., packaging materials differ in environmental impacts). Moreover, consumers can also utilize cues that often do not have effects on true environmental impacts but that serve primarily as signals for consumers (e.g., packaging colors). Apart from cues stemming directly from the packaging's physical design, other cues are likely to also be present in retail environments (e.g., cues from advertisements, price labels and displays).

Following the cue perception stage, consumers form evaluations (beliefs) about the packaged product through informational routes or implicit inferential routes (Fishbein \& Ajzen, 1975; Steenkamp, 1990). The informational route is relatively straightforward and includes consumer evaluations based on explicit information such as on-package labels and advertisement texts (e.g., a textual on-package claim stating that packaging has environmental benefits). Inferential routes are based on mental schemata stored in memory regarding the perceived relationship between a cue and benefit(s) (Steenkamp, 1990).

The inferential route is of particular interest for sustainable packaging design as it can lead to inferences based on packaging's physical form (e.g., graphics, shapes and packaging types). These effects are interesting because packaging cues are often non-diagnostic for the benefits of the product contained within the packaging, such as a food product's taste or a cleaning agent's potency. With regards to the theoretical framework, we term benefits related to product contents contained within the packaging as product benefits. For example, the use of the color green on 
packaging is often associated with sustainability (Pancer, McShane, \& Noseworthy, 2017), which in turn may lead consumers to infer that the product contained within is sustainable. Other examples include how packaging design influences perceived (Fenko, De Vries, \& Van Rompay, 2018) and experienced (Becker, Van Rompay, Schifferstein, \& Galetzka, 2011) taste intensities for food products, as well as price and quality perceptions (Orth et al., 2010).

\subsubsection{Inference-making and (sustainable) packaging design}

The inferential route to form product evaluations is especially important for sustainable packaging design because packaging sustainability is a credence benefit, which consumers cannot reliably assess even after consumption (Vermeir $\&$ Verbeke, 2006). Hence, consumers must rely to a comparatively great extent on cues available on the packaging and its retail environment to form an idea of sustainability benefits. Sustainable packaging design also constitutes an important element in generating overall impressions of sustainability of the packaged product, its cues can also lead to inferences with regard to other product benefits. To investigate the consumer inference-making processes, the theoretical framework outlines four types of inferences to be examined in the empirical chapters.

First, the use of sustainable packaging design (cues) can directly prompt consumers to evaluate the packaging's sustainability, which can affect consumer attitudes and purchase behaviors. These effects are considered inferential when they are based on the processing of implicit cues, for example when consumer perceived sustainability is based on packaging material. In such a case, the sustainability evaluation is derived from pre-existing mental schemata. Alternatively, these evaluations can also be formed on the basis of explicit information, for example when consumers are confronted with textual sustainability claims about sustainability benefits. In order to form sustainability perceptions based on inference, consumers can rely on a variety of packaging cues. It is however important to recognize that the sustainability perceptions arising from packaging cue inferences need not be accurate compared to the true environmental impacts of packaging. This occurs when consumer perception of a packaging material's environmental impacts does not line up with more objective assessments thereof. The credence nature of sustainability provides no clear evidence to consumers for refuting or validating beliefs based on inferences from sustainable packaging design cues. The degree to which consumers' lay-inferences align with objective assessments of packaging sustainability, as well as the diagnosticity of the cues they 
use, is therefore an important element in understanding consumer response to sustainable packaging, yet research regarding these relationships is scarce.

The second type of inference considers the more incidental effect when consumers use packaging sustainability cues to infer about product sustainability. For example, a sustainable(-looking) packaging may lead consumers to believe that the product contained within is also sustainable in some way.

The third type of inference considers that consumers utilize sustainable packaging cues to infer about other packaging and product benefits besides sustainability. Consumers are posited to do so because the concept of sustainability is cognitively associated with various other benefits (Luchs, Walker Naylor, Irwin, \& Raghunathan, 2010). Even when packaging is designed to only be (visibly) more sustainable, its signaling function is likely to cause consumers to infer about (other) packaged product benefits as well. For example, sustainable packaging appearances can lead consumers to infer a higher product quality and naturalness of food products (Magnier et al., 2016). Sustainable packaging is also positively associated with greater health benefits (e.g., avoids the use of toxic substances), and the reduction of superfluous packaging material can in some cases provide additional convenience and economic cost benefits (Magnier \& Crié, 2015). At the same time, sustainable packaging is associated with potential sacrifices, for example in terms of perceived product performance and quality (Lin \& Chang, 2012; Pancer et al., 2017). These incidental benefit inferences are important because such other benefits can be more determinant for consumer purchase behavior than sustainability benefits. 


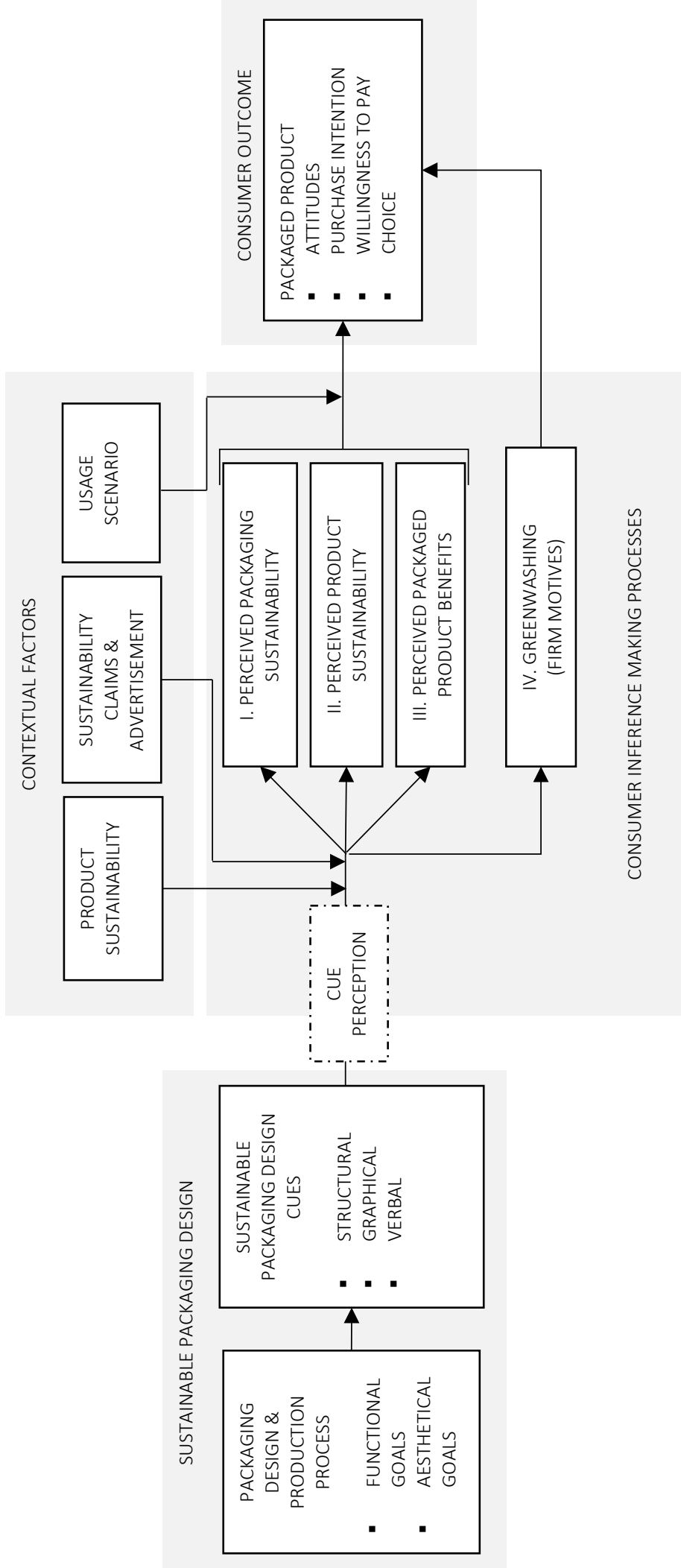


Last, the fourth type of inference considers that consumers may also take into account perceived (firm) motives (De Vries, Terwel, Ellemers, \& Daamen, 2015; Friestad \& Wright, 1994; Nyilasy, Gangadharbatla, \& Paladino, 2014), and that this evaluation can be integrated into the consumer response to the sustainably packaged product, even if this evaluation does not necessarily affect its benefits (as with the other inferences). Specifically, packaging sustainability improvements may be subject to perceptions of greenwashing (as a form of consumer deception) causing consumers to doubt the sincerity of the producing firm's motives. These impressions could for example derive from the use of sustainability cues in ways that consumers perceive as misleading (Magnier \& Crié, 2015), or from deceptive firm claims (Nyilasy et al., 2014), which could hamper the adoption of more sustainable offerings.

\subsubsection{Sustainable packaging cues}

The specific nature of consumer evaluations with regard to a sustainably packaged product depends on the available cues which in turn are the outcome of various functional and/or aesthetical design goals (Bloch, 1995). A conceptual distinction is made between cues of the product and cues of the packaging. Product cues pertain to the core product, and could for example consist of its color or the mouthfeel of a food product. Packaging design cues are extrinsic to the product and entail for example the physical size dimensions, color and texture of the package. Some cues can vary in their classification depending on where they are located. For example, price cues can be considered a packaging cue when price is labelled on the package, yet when the price is given on a supermarket shelf it is a retail environment cue (not part of the physical packaging form).

Extant research has generally classified packaging cues along three archetypes: structural, graphical and verbal (Magnier \& Crié, 2015; Underwood, 2003). Structural cues pertain directly to the physical characteristics of the packaging (Magnier \& Crié, 2015), and may be designed (e.g., material types, shapes, sizes) to meet functional demands (e.g., providing a certain degree of environmental sustainability or microbial protection) and/or for aesthetic reasons (e.g., to convey brand personality or specific consumer benefits). Graphical cues relate to visuals, abstract icons/labels, color palettes, and so forth (Magnier \& Crié, 2015). They are most commonly used for aesthetic design goals and provide non-verbal consumer information. Both structural and graphical cues are implicit in nature because they require 
interpretation from the consumers' side to convey specific meanings. Hence, they influence consumer response through the inferential belief formation process.

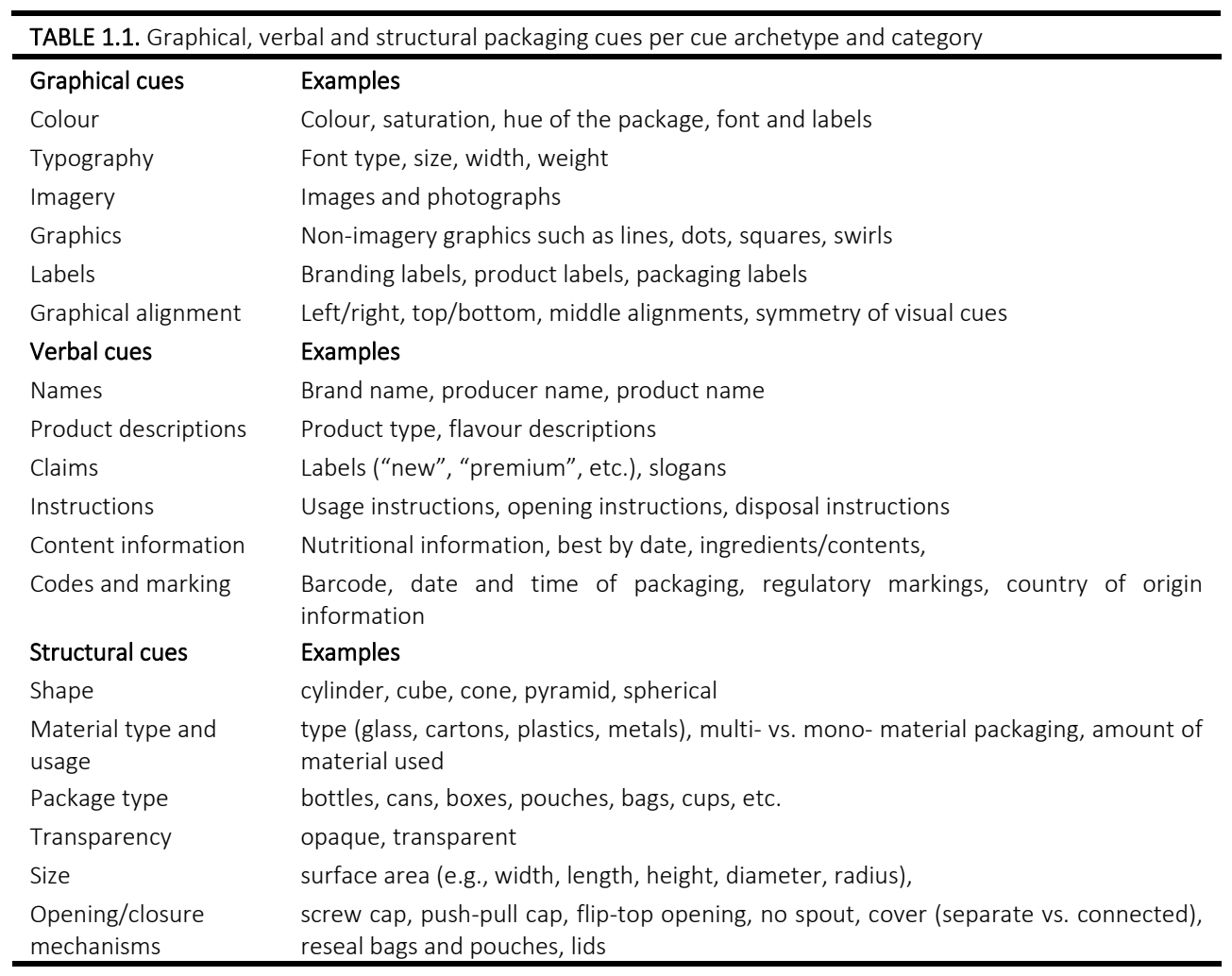

Verbal cues consist of textual information such as marketing claims, product descriptions, brand names and instructions. These largely contain explicit information upon which consumers can for example form informational sustainability beliefs (i.e., based on sustainability information), yet consumers may also make inferences about other (unobservable) benefits. Furthermore, some verbal cues such as (brand) names are implicit, and rely on mental schemata in consumer memory (e.g., 'this brand is of good quality'). Verbal cues contain the literal information, whereas the graphical forms (e.g., fonts, colors) in which such information is presented are considered to be graphical cues.

Table 1.1. presents an overview of cue categories (such as color and typography) relevant to packaging design. Note that this is a classification of the most prevalent 
cues (per category) and not necessarily an exhaustive list, as cues can be highly specific to the product and packaging.

All three cue archetypes can be incorporated into the more specific area of sustainable packaging design. The actual environmental friendliness of packaging is predominantly represented in structural cues (e.g., material compositions, sizing/weight, etc.) $)^{1}$. Graphical cues are used as a consumer signal for sustainability. Verbal cues encompass for example sustainability labels and promotional descriptions (either on the packaging itself or outside of it, for example in advertisements).

\subsubsection{Sustainable packaging design and production process}

The cues represented in the packaging's physical design are the outcomes of the packaging design and production processes. These processes specify the conversion of resource inputs into a physical packaging design (Golder et al., 2012), although not all specifications during these processes necessarily lead to packaging cues ascertainable by consumers. For example, using more efficient logistics or production can lessen the actual environmental burden, but does not necessarily lead to changes in the packaging's physical form. The production and design processes are informed by various goals and aims (Bloch, 1995), and the framework distinguishes between functional and aesthetical goals with regard to sustainable packaging design.

Functional design goals relate to the actual environmental footprint of packaging, as well as other functions of packaging such as product protection and preservation (Lindh, Williams, et al., 2016). Such goals can cause changes in structural cues, for example when improved sustainability is achieved by changing packaging material. Aesthetical design goals are centered around the use of packaging's form to generate brand and benefit impressions (Littel \& Orth, 2013; Orth \& Malkewitz, 2008), or to ensure that the packaging is visually distinctive at the point of purchase (Orth \& Crouch, 2014). These goals can initiate changes in both structural and

${ }^{1}$ It should also be noted that not necessarily every determinant of actual environmental impacts is directly ascertainable through physical packaging cues. These impacts can for example originate more indirectly from production and transportation processes, or positive contributions through preventing product losses. 
graphical packaging cue types (e.g., packaging shapes, materials, graphics and typefonts) in order to convey the desired message.

Successful sustainable packaging design is likely to depend on both functional (e.g., to achieve actual sustainability improvements) and aesthetical (e.g., to signal sustainability improvements to consumers) design goals. While these goals can be considered independently during design and production processes, they can affect the same packaging cues. For example, changes in packaging for functional environmental reasons may have unavoidable consequences for the appearance of that packaging, and vice versa. At the same time, other functional and aesthetical goals can be realized (mostly) independently. For example, a functional sustainability goal can be achieved by packaging lightweighting, which in turn can be almost imperceptible by consumers without additional explicit cues such as labels. Alternatively, aesthetical changes in packaging color or imagery can evoke sustainability perceptions in consumers despite having little to no actual impacts on the environment. Taken together, these considerations imply that it is important to consider both functional changes in sustainable packaging design (potentially independent of the design's physical cues) as well as the salient effects of cues resulting from aesthetical (sustainable) design goals.

Different conceptual sustainability strategies have been discussed in view of business and design strategies, particularly in consideration of designing for circular economies (e.g., biodegradability or recyclability) versus linear-economic lightweighting approaches (Bocken, De Pauw, Bakker, \& Van der Grinten, 2016; Bocken, Farracho, Bosworth, \& Kemp, 2014). These functionally different ways to (re)design for sustainability however have received little attention in consumer research. Hence, there is a lack of knowledge in how consumers respond to different functional redesigns.

Packaging aesthetics are also important for the consumer aspects of sustainable packaging design, even though its aesthetics may not directly affect the environmental impacts. Packaging appearance provides salient (implicit) cues upon which consumers make inferences, and consumers therein tend to naturally rely on what is suggested by this physical appearance, even if explicit verbal cues contradict what the appearance suggests (Hoegg \& Alba, 2011). On one hand, aesthetics are a powerful tool for sustainably packaged products. For example, superior aesthetic design can inspire confidence in a sustainable packaged product's performance, more so than it does for conventional packaged products (Luchs, Brower, \& Chitturi, 
2012). This implies that packaging aesthetics can be used to overcome perceived shortages resulting from the use of sustainability cues, even when the aesthetical elements do not directly pertain to signaling sustainability. On the other hand, aesthetical elements of packaging can also prove to be a risk if not managed carefully. For example, the use of typical sustainability (graphic) cues affects consumer inferences of product performance and can introduce category ambiguity when sustainability cues are incongruent with other packaging cues (Brough, Wilkie, Ma, Isaac, \& Gal, 2016; Pancer et al., 2017). In sum, the above research warrants further investigations in the use of aesthetic (sustainable) packaging design. Research as to how typical sustainability aesthetics are perceived in general, as well as how packaging appearance can be actively used to improve consumer response to sustainable designs, is scarce.

\subsubsection{Contextual factors}

The theoretical framework also considers various contextual and situational factors. First, the degree of sustainability of the product contained within the packaging may be an important contextual factor in determining consumer response to sustainable packaging alterations. Given that consumers purchase packaged products, the qualities of the product contents (even if they are signaled through packaging design) are important situational elements which can influence consumer response to sustainable packaging design (Magnier et al., 2016; Seo, Ahn, Jeong, \& Moon, 2016).

Second, firms' marketing communications can also influence consumer response (cf. Bloch, 1995). Firms can use various types of sustainability claims, often expressed in advertisement. Such claims generate expectations, which may or may not be matched in actual environmental performance (Kopalle, Fisher, Sud, \& Antia, 2017). When such mismatches occur, consumers could be more prone to make greenwashing inferences where they discount the firm's stated motives. Advertisements and claims can differ in the expectations that they set (Kopalle \& Assunção, 2000), therefore the type of claim could exacerbate or inhibit consumer greenwashing inferences.

Third, the purpose for which consumers intend to use the packaged product could affect their responses toward more sustainably packaged products (relative to conventional alternatives). This pertains more specifically to prior research that has investigated under which circumstances sustainability contributes to consumer preferences, and under which it detracts from it (Luchs et al., 2012; Luchs \& Kumar, 
2015; Luchs et al., 2010; Newman, Gorlin, \& Dhar, 2014; Pancer et al., 2017). For many product categories, the importance of various benefits depends on for what purpose consumers intend to use packaged products. As outlined in the model, consumers can use sustainability cues to infer about other (unobservable) benefits (i.e., the third type of inference making outlined in Figure 1.1), and these inferences do not always lead to positive effects on consumer outcomes (e.g., purchase intentions and choices). For example, sustainable products are perceived negatively in terms of strength benefits (Luchs et al., 2012; Luchs et al., 2010). This implies that in scenarios wherein consumers seek strength benefits, using overtly sustainable packaging designs might backfire. There has been limited research investigating the moderating effects of consumer usage scenario on consumer benefit evaluations, as well as how to counteract negative effects of sustainability in usage scenarios where sustainability cues would otherwise be a detriment.

\subsection{Thesis aims and outline}

The thesis aims to investigate the consumer processes outlined in the theoretical framework. Specifically, the thesis focusses on the different types of inferences consumers make on the basis of both functional sustainable packaging design as well as aesthetical form design elements, and tests their effects on consumer responses toward the packaged product.

Chapter 2 presents an initial empirical test of the consumer cue perception and inference-making processes by using a method of idiosyncratic attribute elicitation to analyze consumer response to packaging designs. These packaging designs vary in graphical and structural packaging cues, thus testing both influences of functional and aesthetical design. It provides a 'status quo' overview of consumer perceptions, inferences and attitudes based on common tomato soup packaging options. Consumer cue perceptions are elicited and consequently linked to benefit inferences. These inferences include both packaging sustainability inferences, as well as inferences relating to product sustainability and other product benefits (e.g., expected taste, healthiness). Additionally, Chapter 2 seeks to address the knowledge gap regarding the relationship between consumer packaging sustainability perceptions and expert assessment by combining consumer insights with data from life-cycle analysis.

Where Chapter 2 presents insights into the consumer processes using a series of 'status quo' packaging types with varying levels of sustainability, Chapter 3 seeks to 
develop insights regarding consumer response toward packaging that has been actively redesigned for improved sustainability. The chapter considers how different functional redesign strategies can affect consumer preferences and willingness-topay. Specifically, it distinguishes between biological and technical 'circular' strategies and 'linear' strategies of sustainable redesign. Two experiments consider the mediated effects of packaging redesign strategies on purchase intentions/willingness-to-pay through perceived sustainability, and inferences of naturalness, functional performance and financial- and behavioral costs. The chapter also investigates consumer response to the simultaneous incorporation of multiple redesign strategies into a (single) packaging's design in view of theories of (perceived) diminishing returns.

Chapter 4 focusses on contextual factors surrounding consumer response to sustainably packaged products. It considers the influence of packaging sustainability in conjunction with product sustainability and examines consumer response under different firm sustainability claims and advertisements. The chapter investigates the extent to which the usage of explicit sustainability claims is perceived as 'greenwashing' when the firm presents product-packaging combinations that are (not) unequivocally sustainable. It considers that consumers may feel ambivalent because they can hold positive attitudes towards the improved sustainability of packaged products (contributing to purchase intentions), yet at the same time can be averse to the potentially deceptive positioning and advertising of partially sustainable offerings (subtracting from purchase intentions). The chapter considers how the usage of puffy versus more 'subdued' claims or making no explicit sustainability statement whatsoever affects consumer response towards (partially) sustainable packaged products. Additionally, based on centrality theories, the chapter considers whether combining a sustainable packaging (a peripheral attribute) with non-sustainable product contents (a central attribute) leads to a different effect than the vice versa scenario.

Chapter 5 focusses on the aesthetic aspects of (sustainable) packaging form as a potential means to promote choice for sustainably packaged products, and also includes the role of consumer usage scenario. The chapter emphasizes inferences toward benefits other than sustainability, specifically perceptions of strength and gentleness benefits of the product contained within. Using variants of sustainable versus conventional laundry detergent packaging, the chapter shows how consumer choices differ depending on whether consumers' intended product usage scenario emphasizes strength benefits (e.g., having to remove stains or clean particularly dirty 
laundry) or gentleness benefits (e.g., having to protect delicate laundry). The chapter shows that the sustainable option is disadvantaged when consumers seek strength and conversely is preferred when they seek gentleness benefits. In order to overcome the perceived deficiencies of the sustainable alternative on strength benefits, the research introduces the concept of gendered packaging design. Particularly, it tests whether the usage of masculine (versus feminine) aesthetics in design (e.g., in terms of shapes, colors and typefonts) can improve the competitive position of sustainable packaged products where strength benefits play a role.

Chapter 6 lastly summarizes the findings of the thesis and discusses implications for theory and practice. 


\section{CHAPTER 2}

Consumer response to packaging design: The role of packaging materials and graphics in sustainability perceptions and product evaluations

This chapter is published as:

Steenis, N. D., Van Herpen, E., Van der Lans, I. A., Ligthart, T. N., \& Van Trijp, H. C. (2017). Consumer response to packaging design: The role of packaging materials and graphics in sustainability perceptions and product evaluations. Journal of Cleaner Production, 162, 286-298. 


\section{ABSTRACT}

Building on theories of cue utilization, this study investigates whether and how packaging sustainability influences consumer perceptions, inferences and attitudes towards packaged products. A framework is tested in an empirical study among 249 students using soup products varying in packaging material and graphics. The findings show that (packaging) sustainability is a highly salient association but is only moderately important for consumer attitudes. A comparison between consumer judgments and life-cycle assessment indicates that consumers rely on misleading, inaccurate lay beliefs to judge packaging sustainability and are therefore susceptible to making ineffective environmental decisions. The research also demonstrates the power of packaging in shaping perceptions of food products. Particularly, it shows that changes in actual environmental impacts (by altering packaging materials) affect not only sustainability perceptions but also several other benefits, such as perceived taste and quality. At the same time, consumers' sustainability assessments are also highly influenced by mere graphical packaging cues that have no obvious actual sustainability consequences. 


\subsection{Introduction}

Packaging is a pervasive element of modern consumption that provides a wide range of functionalities and consumer benefits. The role of packaging is perhaps of greatest importance in consumer packaged goods (CPG) markets, which often strongly rely on packaging elements to maintain product quality, prevent product losses, facilitate transportation and storage, and provide marketplace differentiation. In the current practice, packaging is designed to outlast its contents and, after usage, often becomes redundant. Given the high frequency of CPG purchase and disposal, this adds to an increasing environmental burden, which contributes to global warming, raw material depletion, acidification and energy consumption (Bovea, Serrano, Bruscas, \& Gallardo, 2006). Consequently, incessant packaging waste has received major attention from policy-makers, environmental lobbyists, consumers and the packaging industry alike.

Because the concept of sustainability seems to be increasingly important to consumers (Bemporad, Hebard, \& Bressler, 2012; UNEP, 2005), they could be important actors in the trend toward more-sustainable packaging. However, getting consumers to choose sustainably packaged products is challenging. First, although knowledge on the environmental impacts of packaging is well developed in the form of life-cycle assessments (LCAs), consumers have limited knowledge about packaging sustainability. They therefore rely on their own lay beliefs and may not spontaneously include sustainability in their purchase decisions (Lindh, Olsson, et al., 2016; Van Dam, 1996). Locating and understanding discrepancies between LCA outcomes and consumer beliefs is important, as these discrepancies may be a threat to sustainable development. Second, consumers' limited knowledge does not withhold them from forming opinions and making purchase decisions, which are often based on simple inferential cue utilization processes. In this sense, even consumers with sustainable motivations could be misled (by their own beliefs) and end up making (environmentally) ineffective decisions. Third, sustainability is only one of many aspects that consumers may integrate into their decision-making. Prior research attests to the power of packaging in shaping consumer product expectations, evaluations and experiences (Orth \& Malkewitz, 2008), but comparatively little of this research has been performed in light of sustainable packaging. This is important because sustainable packaging options may be perceived differently in other aspects (e.g., price or quality), which could hinder the product from being chosen. 
Sustainable packaging can be defined as packaging that has a comparatively low environmental impact as assessed by life-cycle assessment models (Glavič \& Lukman, 2007). From a consumer-perspective, sustainable packaging can be considered "a packaging design that evokes explicitly or implicitly the ecofriendliness of the packaging" (Magnier \& Crié, 2015). In this consumer view, packaging provides the relevant cues from which consumers infer sustainability using their stored subjective knowledge. Packaging design involves a combination of structural (e.g., materials), graphical and verbal (informational) elements. Packaging materials are the main contributor to direct (objective) environmental impacts, and they signal sustainability (Lindh, Williams, et al., 2016). Graphics and colors on packaging may also be used to signal sustainability, such as green coloring being implicitly associated with sustainability (Hoogland, de Boer, \& Boersema, 2007; Magnier \& Schoormans, 2015; Pancer et al., 2017). In addition, verbal features can be used to communicate sustainability explicitly, for instance, through labelling, which has been extensively studied in prior research (e.g., Magnier \& Schoormans, 2015, Pancer, McShane, \& Noseworthy, 2015).

This chapter examines the implicit influences of both the structural elements (materials) and graphical design of packaging on consumer perceptions of sustainability and their effects on product attitudes. This is done by elaborating a cue-utilization framework within the context of (sustainable) packaging that details the different steps in consumer perception and evaluation of a set of packaging designs. Additionally, consumers' sustainability perceptions are compared with lifecycle assessment outcomes.

\subsection{Literature review}

\subsubsection{Consumer response to sustainable packaging}

Prior research on consumer response to sustainable packaging can be classified into three areas of research: (1) general attitudinal models, (2) holistic approaches focusing on consumer perceptions and semiotics, and (3) analytical approaches testing the effects of specific packaging design cues. Research building on general attitude models (typically the Theory of Planned Behavior, TPB) explains consumers' choice for sustainable packaging from psychological factors such as environmental awareness, knowledge and concern, amongst other TPB factors, such as perceived behavioral control and subjective norms (Martinho, Pires, Portela, \& Fonseca, 2015; Prakash \& Pathak, 2017; Van Birgelen, Semeijn, \& Keicher, 2009). These studies focus 
on the general propensity of consumers to engage in the purchase (and disposal) of environmentally friendly packaging, but they often lack detailed information on how specific packaging design elements can affect behavior. Furthermore, because sustainability aspects are typically explicitly prompted from participants, these studies also fail to address the salience of packaging sustainability to consumers.

The second line of research includes studies following a holistic approach. These studies focus on the concept of packaging as a whole and generally do not provide or independently consider specific characteristics of the packaging (Lindh, Olsson, et al., 2016; Magnier \& Crié, 2015; Nordin \& Selke, 2010). For example, Orth and Malkewitz (2008) state that "the overall effect of the package comes not from any individual element but rather from the gestalt of all elements working together as a holistic design". These studies focus on how consumers construe and convey meaning to the concept of sustainable packaging and highlight that structural, graphical and verbal design cues of packaging may signal packaging sustainability in a variety of ways.

Findings suggest that consumers strongly rely on material/structural cues to form judgments on packaging sustainability (Lindh et al., 2016; Magnier \& Crié, 2015; Van Dam, 1996), but the studies do not explain how (specific) packaging materials can lead to different consumer responses. Understanding this is important, as consumers' packaging material choices are key in decreasing the actual environmental burden of packaging. This stream of sustainable packaging research also shows that consumers are not very knowledgeable about the concept of (packaging) sustainability and that their terminology and perceptions are often inconsistent (Lindh, Olsson, et al., 2016; Magnier \& Crié, 2015; Nordin \& Selke, 2010; Scott \& Vigar-Ellis, 2014). For example, survey studies attest that many consumers are unable to identify sustainable packaging and/or lack insight as to what it should entail (Lindh et al., 2016; Nordin \& Selke, 2010). Consequently, consumers appear to over-emphasize some environmental aspects (e.g., recyclability), whilst ignoring others (e.g., transport and production costs).

In the third line of research, there are numerous packaging studies following a more atomistic ('piecemeal') and analytical approach. These studies isolate specific packaging cues such as transparency (Deng \& Srinivasan, 2013), single vs. multiserve formats (llyuk \& Block, 2016), shape/volume (Folkes \& Matta, 2004) and graphical and verbal features such as colors and labels (Celhay \& Trinquecoste, 2015; Magnier \& Schoormans, 2015), and they estimate their effects on purchase criteria, 
choice and/or consumption. This is important because at the point-of-purchase, consumers are confronted with (and purchase) a packaged product. That is, consumers may purchase canned tomato soup, in which case the can is the packaging and tomato soup is the product contained within. The influence of packaging on product (benefit) evaluations is thus highly relevant to explaining actual purchase decisions. The role of packaging design is, for example, demonstrated in its effects on aesthetic appreciation (Celhay \& Trinquecoste, 2015), price and quality expectations (Orth et al., 2010), taste impressions (Becker et al., 2011; Van Rompay, Deterink, \& Fenko, 2016), naturalness (Binninger, 2015) and health perceptions (Van Rompay et al., 2016). Only a few studies in this line of research explicitly investigate the role of packaging sustainability. These studies suggest that the environmental aspects of packaging design play a significant role in consumers' choice behaviors (Rokka \& Uusitalo, 2008) and purchase intentions (Magnier \& Schoormans, 2015; Magnier et al., 2016; Pancer et al., 2017). Additionally, the results of these studies suggest that perceptions of sustainability are related to inferences on other benefits, such as the product's taste or price. These associations have garnered increasing attention in the sustainable marketing literature (Lin \& Chang, 2012; Luchs et al., 2010) and could be an important factor in understanding consumer preferences for more-sustainable alternatives. Generally, these analytical studies have focused on verbal and graphical cues signaling sustainability (Magnier \& Schoormans, 2015; Pancer et al., 2017; Spack, Board, Crighton, Kostka, \& Ivory, 2012); a more comprehensive understanding of material effects is still lacking.

Bringing the three lines of research together, it is likely that consumers' attitudes (and, by extent, purchase behaviors) depend strongly on both holistic and atomistic (analytical) processing of packaging designs (Bloch, 1995). Integrating these insights, the following contributions of the current research are highlighted. Since consumer attitudes rely on perceptually salient features, the first contribution is to examine whether sustainability is actually salient in consumers' perceptions of packaging designs relative to other perceptions. For this, the current study generates insight into consumers' intuitive spontaneous associations with packaging without prompting them. Second, prior literature has identified that a gap exists between consumers' subjective judgments of sustainability and the 'objective' environmental impact, but thus far, these discrepancies have hardly been specified. The current research assesses whether and where discrepancies occur between consumers' subjective judgments of sustainability and the 'objective' environmental impact assessed through LCA. Third, using varying packaging designs (and keeping the product constant), consumers' packaging-based perceptions are linked to specific 
benefits of the packaged product (e.g., taste, quality, price perceptions). In doing so, the importance of sustainability is investigated relative to other benefits.

\subsection{Conceptual framework}

\subsubsection{Benefits and consumer attitudes}

Many fundamental models of consumer behavior posit that consumers purchase products because they possess benefits that are connected to consumers' needs and desires (Grunert, 2005; Steenkamp, 1990; Zeithaml, 1988). Choice is considered as being derived from consumers' attitudes towards the product, which in turn are based on an evaluative integration of benefits ascribed to the product by consumers (Ajzen, 1991; Fazio, 2007). Although benefits can be highly diverse and dependent on the product category, research in the food domain suggests that quality, health, sensory appeal (e.g., taste), naturalness, price, and convenience, as well as social benefits such as sustainability, are generally important to consumers (Furst, Connors, Bisogni, Sobal, \& Winter Falk, 1996; Steptoe, Pollard, \& Warde, 1995). In terms of packaging, a large part of consumer response is a function of which benefits the packaging is perceived to provide, in which two possible effects are discernible. First, packaging may directly provide a benefit, for example, by providing convenience through portability. Second, packaging may more indirectly signal product benefits through consumer inferences. For example, glass may be associated with high quality, or the graphics may be designed to communicate luxury (Celhay \& Trinquecoste, 2015; Orth \& Malkewitz, 2008).

\subsubsection{Cue utilization process \& packaging}

Consumers often need to infer benefits they cannot reliably assess when making a purchase (e.g., taste) or that are difficult to assess even after consumption (e.g., sustainability). Since packaging is often designed to generate consumer impressions and, for example, consumers infer product taste from the packaging design (Becker et al., 2011), consumers rely on a wide range of beliefs and associations to form judgments. This process can be described as a cue utilization process (Olson \& Jacoby, 1972). In the classical view of cue utilization theory, consumers ascertain and evaluate multiple cues (e.g., packaging color) based on the cues' predictive and confidence values (Olson \& Jacoby, 1972). The predictive value of cues is the degree to which cues are perceived to be associated with specific benefits (e.g., sustainability or taste), while the confidence value is the degree to which consumers are confident 
in making accurate judgments based on these available cues. Before such an inferential process is possible, the packaging cues must first be acquired and interpreted. These subjective cue perceptions can be seen as a function of the objective features "as designed" and consumers' idiosyncratic perceptions and assessments thereof (Steenkamp, 1990).

In most purchase contexts, cues are plentiful and consumers' attention is limited (Higgins, 1996). Hence, not all cues are readily perceived, and only those cues that are sufficiently salient lead to benefit inferences. Cue salience is regarded as the propensity of the cues to be noticed or come to mind (Romaniuk \& Sharp, 2004). Since consumers rely on salient cue perceptions, they may be unable to (correctly) perceive certain features, may have varying and possibly conflicting perceptions of the same design, and may vary in which cues are salient to them in the first place. Although intrinsic (product) cues often have higher confidence values than extrinsic (packaging) cues, in purchase environments, these intrinsic cues may be difficult to assess. Consumers, then, place greater emphasis on (extrinsic) packaging cues (Richardson, 1994; Underwood, Klein, \& Burke, 2001; Zeithaml, 1988).

Packaging can be viewed as consisting of an array of structural, graphical and verbal design features that may serve as consumer cues (Magnier \& Crié, 2015; Rettie \& Brewer, 2000; Underwood, 2003). Structural features consist of the material type, shape, size, weight and texture, while graphic features include the colors, imagery, graphics and typewriting (Magnier \& Crié, 2015; Magnier \& Schoormans, 2015; Underwood, 2003). Verbal features consist of explicit textual information available on the package (Rettie \& Brewer, 2000; Van Rompay \& Veltkamp, 2014) and often relate to information about the product contained within (e.g., taste, nutritional contents, best by date, brand name). Packaging may play a large role in implicitly cueing sustainability, in particular because packaging material directly affects the environment (e.g., due to production and energy consumption), but also because the packaging provides graphical cues for sustainability inference through colors, labels, fonts, etc. (Magnier \& Schoormans, 2015; Pancer et al., 2015). Such cues may lead consumers to infer that the packaging itself is more sustainable, but these cues may also affect the perceptions of the product contained within. Furthermore, although graphical elements have no (or minimal) direct effects on the environmental burden in terms of LCA, consumers may still rely on these cues in their perception of sustainability. 


\subsubsection{Model integration}

Integrating the different concepts of the literature review, a framework is proposed (Figure 2.1) that contains three phases. Phase one considers the cue perception process of packaging wherein salient cues are acquired and interpreted by consumers as "cue perceptions". Phase two considers how these packaging-based cue perceptions lead to benefit inferences of the product, such as taste, quality and price perceptions. Phase three examines how these benefits contribute to product attitudes.

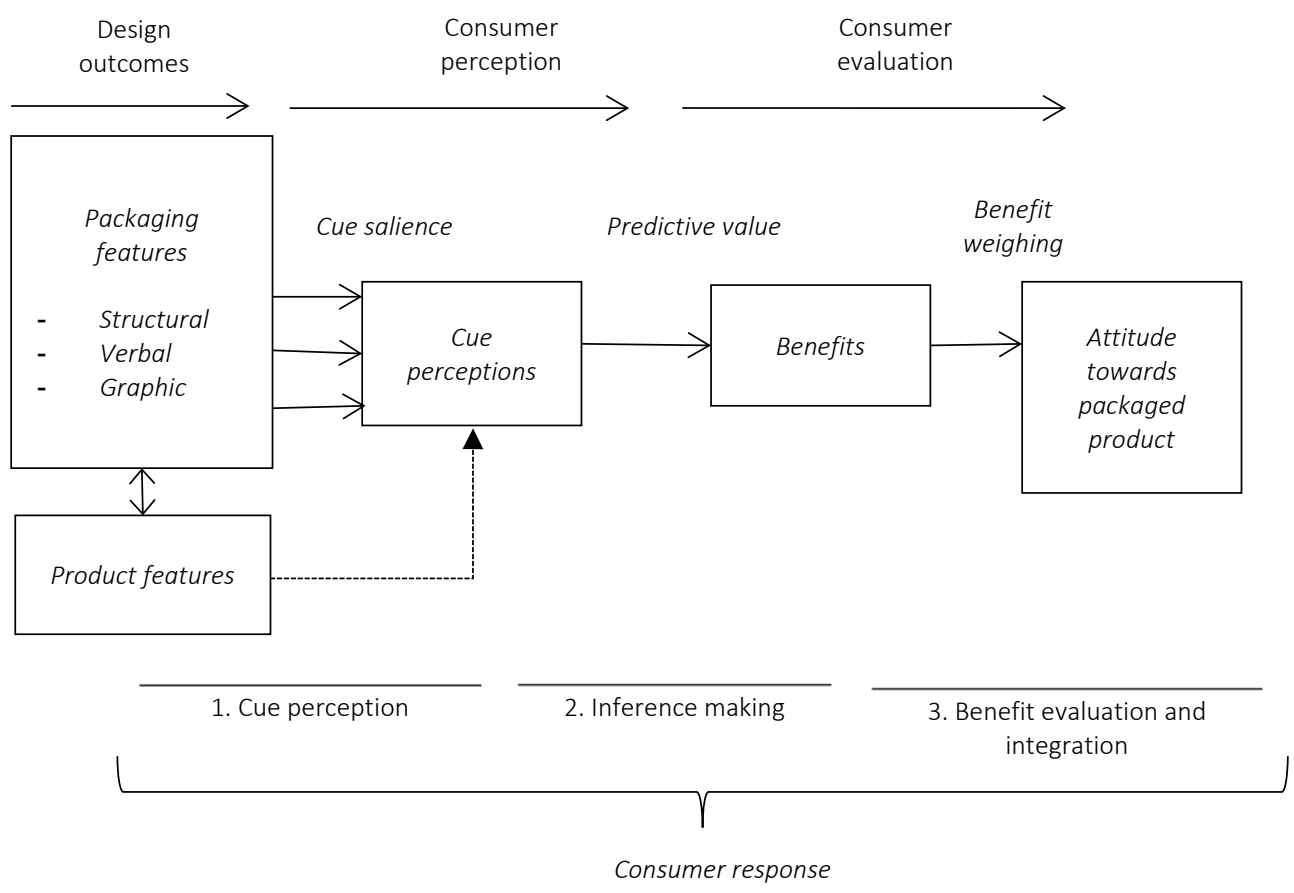

FIGURE 2.1. Conceptual framework 


\subsection{Method}

\subsubsection{Consumer perceptions, inferences and attitudes: empirical study}

An empirical study of cue perception elicitation was conducted based on the free choice profiling method (Steenkamp, Van Trijp, \& Ten Berge, 1994; Williams \& Langron, 1984). The elicitation methodology requires respondents to express, in their own words, perceived differences based on packaging designs, without being exposed to researcher items. This makes the method suitable for exploring consumer perceptions without imposing pre-defined constructs. The elicitation procedure was followed up by collecting consumer evaluations for each packaging.

\subsubsection{Respondents and stimuli}

Respondents were 249 Dutch university students ( $69 \%$ female, $\left.M_{\text {age }}=20.4\right)$. The stimuli consisted of 14 tomato soup products varying in packaging design (7 structural designs and 2 graphical schemes), presented as pictures (Appendix 2.1). The Unox brand was chosen as a familiar national soup brand that does not occupy specific market niches. Tomato soups were used because these are available in a wide range of packaging options with different environmental impacts. Common structural designs were chosen: glass jar, bioplastic pot, liquid carton, dry carton sachet, plastic pouch, mixed material pouch (plastic with carton wrapping) and a can. The two graphic schemes differed in colors, graphics, typography and imagery. One graphic scheme was designed to be "conventional-looking", the other as "sustainable-looking" (cf. Magnier and Schoormans, 2015), but this was not explicitly communicated to respondents. This was done to create a distinction between graphical designs often used for sustainable or "green" products and more-standard tomato soup options. By extent, this allows a test of whether consumers are affected by cues that are generally irrelevant for LCA (i.e., both graphical designs are equivalent in terms of LCA impacts). On-package verbal information (e.g., brand and product name/type) was kept constant across designs, with the exceptions of the bioplastic pot and dry carton, which were respectively labelled to indicate that the pot material was bioplastic and that the carton contained multiple packs within, since otherwise this would not be discernible.

\subsubsection{Procedure}

The study was carried out in a lab setting in a self-administrative manner (behind a computer) using Qualtrics software. Prior to the study, the procedure was tested 
on a small sample $(n=7)$ to check for clarity and errors. Minor textual changes were made, and image sizes were maximized. Respondents proceeded through three stages. The first stage was cue perception elicitation using triadic sorting Respondents were presented with seven randomly generated sets of three tomato soups (triads) selected from the total pool of 14 images. A selection of seven triads seemed reasonable based on elicitation research with similar (amounts of) stimuli (Ares \& Deliza, 2010; Gelici-Zeko, Luters, ten Klooster, \& Weijzen, 2012). Respondents were instructed to sort the packaged soups in such a way that two were similar and different from the third (cf. Bech-Larsen \& Nielsen, 1999; Kelly, 1955). They were asked: "In which way are two of these products alike and different from the third product? Think of the positive and negative characteristics upon which you would base your choice during purchase and provide a description of this".

For each triad, respondents wrote down two cue perceptions in a short phrase or word: first, how they perceived the two similar products to be alike, and second, how the third was different. This generated a series of dichotomous cue perceptions. Respondents first started with an unrelated warm-up triad before continuing.

In the second stage, respondents were presented with their own descriptions (i.e., cue perceptions) and were asked to indicate which of these described each of the 14 tomato soup products in a "check all that apply" (CATA) format (Coombs, 1964). The third stage asked respondents to score all tomato soup products on eight benefits based on the Food Choice Questionnaire (Steptoe et al., 1995). The benefit items

were (translated from Dutch): "This product is/has: convenient/healthy/natural/cheap/sustainable/sustainably packaged/good taste/excellent quality", using the anchors "disagree completely" and "agree completely". The order was randomized. Attitudes towards the packaged product were measured by asking "What is your overall evaluation of this product?", using "bad" and "good" as scale anchors. All items were measured using an unnumbered 0 to 100 slider scale.

\subsubsection{Life-cycle assessment (LCA) data}

Additionally, LCA data were obtained to facilitate a comparison with consumer judgments. The environmental impacts for cans, plastic pouches, liquid cartons and glass jars were based on measurements of the packaging composition, applicable for the Dutch context. For the bioplastics and dry sachet, estimates were made based on single measurements and the literature (Boukris, Van Gijlswijk, Ansems, \& Jongeneel, 2014; Kuraray, 2012; Ziem et al., 2013).The soup product itself and its 
preparation were excluded from LCA. The life cycle inventory data were obtained from the ecoinvent v3.01 database (ecoinvent, 2013). When inventory data for the packaging were missing, approximations were used. The ReCiPe endpoints method was used for analysis, as it is a commonly accepted LCA method (Goedkoop, Huijbregts, Schryver, De Struijs, \& Van Zelm, 2013). Further details on LCA specifications can be found in the supplementary materials (Appendix 2.2).

\subsection{Data analysis}

Analyses were carried out with the aim to examine each phase outlined in the conceptual framework. The first model phase contained multiple analyses. First, content analysis was conducted (1) to give an indication of the variety and frequency (i.e., salience) of the constructs respondents mentioned, (2) to facilitate the interpretation of the following cluster analysis, and (3) to facilitate grouping of cue perceptions for regression analysis. Coding followed an inductive procedure (using a single coder), with the aim to group conceptually similar cue perceptions into general content categories. Coding followed two iterations. First, individual cue perceptions were coded into 83 categories. Second, categories with a similar meaning were grouped once more (e.g., "environmentally friendly" and "degradable materials" would become part of the overlapping "sustainability" category) into 28 final content categories. Before proceeding further, data were cleaned by first removing cue perceptions that were not checked at all during the CATA-task, leaving 3224 (out of 3500 total) cue perceptions. Another 145 cue perceptions were scattered over a set of small uninformative content categories and/or were difficult to classify, and were thus excluded from further analysis.

Second, hierarchical cluster analysis (HCA) was conducted using the CATA data. To interpret the clusters, proportions were calculated to measure the extent to which the 14 packaged products were described by the clusters. Third, content categories and clusters were cross-tabulated in order to (a) interpret the clusters, (b) analyze how cue perceptions are associated with specific packaging designs (e.g., "sustainability" with "glass pot"), and (c) investigate the degree of consensus in terms of how cue perceptions are ascribed to packaging designs. Finally, the LCAconsumer comparison was conducted. For this, respondents' ratings of packaging sustainability per material type (averaged over the two graphical schemes) were reversed (i.e., higher outcome equals lower degree of sustainability) to equalize them with LCA. 
The second phase of the conceptual framework considers how the cue perceptions of the previous phase are related to tomato soup product benefits. To analyze this, content categories from phase one were used as predictors for each benefit in a series of multilevel regression analyses. Further, repeated measures ANOVAs were conducted to analyze whether consumer benefits are affected primarily by packaging materials, graphics, or both. The final phase of the framework encompasses the integration of benefits into an overall attitude assessment. To investigate this, multilevel regression analysis of attitudes on the benefit dimensions was conducted.

\subsection{Results}

\subsubsection{Packaging cue perception}

Spontaneous cue perceptions: what did respondents say?

To indicate the variety and salience of cue perceptions as indicated by the respondents, the content analysis categorized 3224 cue perceptions into 28 content categories, displayed in the rows of Table 2.1 (final column indicates content category sizes). Content categories were divided into abstract and concrete cue perceptions. Abstract cue perceptions were the perceived consequences of packaging features (e.g., 'tastiness', 'attractiveness'). Concrete cues were those that relate specifically to packaging features such as its materials, shapes, transparency, or packaging type. The results indicated that sustainability appeared highly salient (293 cue perceptions), second only to convenience (382 cue perceptions). Novelty/conventionalism (263 cue perceptions) and quality (189 cue perceptions) were the third and fourth most commonly mentioned. These results showed that respondents primarily mentioned convenience and sustainability aspects as a result of changes in packaging.

\subsubsection{Clusters of meaning: associating packaging-based cue perceptions with tomato soups}

To uncover how respondents' cue perceptions were linked to the fourteen tomato soups, cluster analysis was conducted. Cluster retention indices provided by the Rpackage NbClust (Charrad, Ghazzali, \& Boiteau, 2014) suggested a 21-cluster solution; hence, this solution was chosen. The Jaccard similarity index was used, which ensures that only the presence of CATA "checks" contribute to similarity (and that similarity in absent checks does not contribute to the clustering). Eight clusters 
of meaning (representing $90 \%$ of the data) were retained. Table 2.2 displays the most-common cue perceptions per cluster, and proportions display the extent to which the given packaging was described by a cluster. The results show that a consistent distinction can be made between the two graphic designs. The conventional-looking scheme was described as modern and familiar (cluster one), whereas the sustainable-looking scheme was described more as traditional (cluster four). Cluster two seemed to describe quality and, to a lesser extent, transparent, rounded and rigid packages, and it has considerable proportions on the bioplastic pots and cans. Cluster three was related to both pouches and dry cartons, and it described material flexibility, worse protective characteristics and lower package quality. Cluster five described cartons and rectangular shapes as related to convenience and (low-) sustainability aspects. Cluster six distinguished the bioplastic pots from other packages and contained a more concentrated amount of sustainability cue perceptions. Cluster seven described cans in relation to opacity and inconvenience as well as round shape and rigidness (similar to cluster two). Cluster eight included the transparent plastics. Overall, three important distinctions became apparent from clustering: (1) holistic impressions of modernity/familiarity vs. traditional design obtained from the graphics (e.g., Orth, 2008); (2) (protective) quality, where rigid packaging is mostly associated with higher protective quality, while flexible packaging is worse; and (3) sustainability, with bioplastic as the most sustainable and dry carton sachets as the least sustainable.

\subsubsection{Comparing content categories and clusters}

Table 2.1 shows the distributions of cue perceptions (in percentages) across the different clusters. Based on these distributions, the Herfindahl index (Simonson \& Winer, 1992; Tirole, 1989) was calculated to indicate consumer consensus among cue perceptions by measuring the degree of concentration of each of 28 content categories across the clusters. A Herfindahl index $(H)$ close to 1 indicates a highly concentrated distribution of cue perceptions over clusters, while lower scores indicate more dispersion (i.e., less consensus) among the cue perceptions' assignment to clusters.

Notably, the $H /$ for sustainability cue perceptions was low $(H I=.16)$, compared to the other salient cue perceptions: convenience $(H I=.22)$, novelty $(H I=.28)$ and quality $(H I=.24)$. This means that sustainability perceptions were relatively highly dispersed over multiple clusters. Furthermore, the Herfindahl index was significantly lower $(F(1,26)=16.18, p<.001)$ for the abstract cue perception categories $(M=.23)$ 
than for the concrete categories $(M=.54)$. This is likely due to the more subjective nature of the abstract categories. Overall, these results indicate that respondents used different sustainability criteria (e.g., recyclability vs. degradable materials) and/or viewed the same packaging designs differently in regard to how sustainable they are. Although a lower level of agreement is expected for more-abstract concepts, the low $\mathrm{H} /$ seems exacerbated for the sustainability cue perceptions. Conclusively, respondents on the whole appear to rely on different lay theories and heterogeneous perceptions and do not hold a singular, consistent idea of what sustainability means. 
CHAPTER 2

TABLE 2.1. Distribution of cue perception content categories among clusters.

\begin{tabular}{|c|c|c|c|c|c|c|c|c|c|c|c|}
\hline & $\mathrm{C} 1$ & $\mathrm{C} 2$ & C3 & $\mathrm{C} 4$ & $\mathrm{C} 5$ & $\mathrm{C} 6$ & $\mathrm{C7}$ & $\mathrm{C} 8$ & C9-21 & $H I$ & $n$ \\
\hline \multicolumn{11}{|l|}{ Abstract cue perceptions } & 1848 \\
\hline Convenient & $32 \%$ & $26 \%$ & $18 \%$ & $1 \%$ & $13 \%$ & $1 \%$ & $2 \%$ & $3 \%$ & $5 \%$ & 0.22 & 382 \\
\hline Sustainable & $23 \%$ & $23 \%$ & $11 \%$ & $6 \%$ & $7 \%$ & $18 \%$ & $1 \%$ & $2 \%$ & $10 \%$ & 0.16 & 293 \\
\hline Novel, modern & $32 \%$ & $6 \%$ & $6 \%$ & $41 \%$ & $1 \%$ & $4 \%$ & $1 \%$ & $1 \%$ & $9 \%$ & 0.28 & 263 \\
\hline High (packaging) quality & $21 \%$ & $40 \%$ & $17 \%$ & $4 \%$ & $2 \%$ & $2 \%$ & $3 \%$ & $3 \%$ & $10 \%$ & 0.24 & 189 \\
\hline Attractive & $36 \%$ & $7 \%$ & $6 \%$ & $26 \%$ & $1 \%$ & $2 \%$ & $1 \%$ & $6 \%$ & $15 \%$ & 0.21 & 130 \\
\hline Tasty & $32 \%$ & $14 \%$ & $3 \%$ & $11 \%$ & $7 \%$ & $3 \%$ & $2 \%$ & $11 \%$ & $15 \%$ & 0.16 & 124 \\
\hline Cheap & $24 \%$ & $13 \%$ & $15 \%$ & $15 \%$ & $6 \%$ & $6 \%$ & $4 \%$ & $6 \%$ & $13 \%$ & 0.13 & 108 \\
\hline Luxurious & $61 \%$ & $7 \%$ & $5 \%$ & $4 \%$ & $1 \%$ & $1 \%$ & $4 \%$ & $3 \%$ & $15 \%$ & 0.38 & 107 \\
\hline Familiar & $29 \%$ & $20 \%$ & $7 \%$ & $16 \%$ & $1 \%$ & $12 \%$ & $1 \%$ & $5 \%$ & $9 \%$ & 0.17 & 92 \\
\hline Healthy & $30 \%$ & $0 \%$ & $5 \%$ & $30 \%$ & $10 \%$ & $2 \%$ & $2 \%$ & $7 \%$ & $15 \%$ & 0.20 & 60 \\
\hline Preservable & $44 \%$ & $26 \%$ & $14 \%$ & $2 \%$ & $4 \%$ & $0 \%$ & $4 \%$ & $2 \%$ & $5 \%$ & 0.29 & 57 \\
\hline Natural, authentic & $42 \%$ & $7 \%$ & $2 \%$ & $23 \%$ & $12 \%$ & $5 \%$ & $2 \%$ & $2 \%$ & $5 \%$ & 0.25 & 43 \\
\hline \multicolumn{11}{|c|}{ Concrete cue perceptions: Materials \& structural features } & 985 \\
\hline Transparent & $41 \%$ & $41 \%$ & $1 \%$ & $1 \%$ & $1 \%$ & $2 \%$ & $2 \%$ & $6 \%$ & $6 \%$ & 0.33 & 264 \\
\hline Flexible & $0 \%$ & $39 \%$ & $44 \%$ & $0 \%$ & $1 \%$ & $1 \%$ & $6 \%$ & $1 \%$ & $7 \%$ & 0.35 & 142 \\
\hline Carton & $2 \%$ & $0 \%$ & $14 \%$ & $1 \%$ & $53 \%$ & $0 \%$ & $1 \%$ & $0 \%$ & $29 \%$ & 0.37 & 137 \\
\hline Pouch & $0 \%$ & $0 \%$ & $87 \%$ & $0 \%$ & $7 \%$ & $0 \%$ & $0 \%$ & $0 \%$ & $6 \%$ & 0.76 & 114 \\
\hline Canned & $1 \%$ & $7 \%$ & $0 \%$ & $0 \%$ & $0 \%$ & $0 \%$ & $91 \%$ & $0 \%$ & $0 \%$ & 0.84 & 81 \\
\hline Plastic & $0 \%$ & $1 \%$ & $46 \%$ & $0 \%$ & $0 \%$ & $29 \%$ & $0 \%$ & $19 \%$ & $4 \%$ & 0.33 & 72 \\
\hline Pot & $0 \%$ & $81 \%$ & $0 \%$ & $0 \%$ & $0 \%$ & $16 \%$ & $3 \%$ & $0 \%$ & $0 \%$ & 0.69 & 70 \\
\hline Glass & $0 \%$ & $88 \%$ & $0 \%$ & $0 \%$ & $0 \%$ & $0 \%$ & $0 \%$ & $0 \%$ & $12 \%$ & 0.78 & 58 \\
\hline Round & $11 \%$ & $70 \%$ & $0 \%$ & $0 \%$ & $0 \%$ & $0 \%$ & $11 \%$ & $4 \%$ & $4 \%$ & 0.52 & 27 \\
\hline Rectangular & $5 \%$ & $5 \%$ & $15 \%$ & $0 \%$ & $55 \%$ & $0 \%$ & $0 \%$ & $0 \%$ & $20 \%$ & 0.36 & 20 \\
\hline \multicolumn{11}{|c|}{ Concrete cue perceptions: Graphic features } & 186 \\
\hline Green graphic design & $48 \%$ & $1 \%$ & $0 \%$ & $45 \%$ & $0 \%$ & $0 \%$ & $1 \%$ & $0 \%$ & $6 \%$ & 0.43 & 107 \\
\hline Graphics, appearance & $45 \%$ & $2 \%$ & $2 \%$ & $23 \%$ & $6 \%$ & $2 \%$ & $4 \%$ & $2 \%$ & $13 \%$ & 0.26 & 47 \\
\hline Imagery & $56 \%$ & $0 \%$ & $0 \%$ & $38 \%$ & $3 \%$ & $0 \%$ & $0 \%$ & $0 \%$ & $3 \%$ & 0.46 & 32 \\
\hline \multicolumn{11}{|c|}{ Concrete cue perceptions: Product features } & 60 \\
\hline \multicolumn{2}{|c|}{ More contents per package $33 \%$} & $15 \%$ & $6 \%$ & $3 \%$ & $15 \%$ & $3 \%$ & $0 \%$ & $6 \%$ & $18 \%$ & 0.18 & 33 \\
\hline Liquid soup & $100 \%$ & $0 \%$ & $0 \%$ & $0 \%$ & $0 \%$ & $0 \%$ & $0 \%$ & $0 \%$ & $0 \%$ & 1.00 & 16 \\
\hline Dry powder soup & $0 \%$ & $0 \%$ & $0 \%$ & $0 \%$ & $100 \%$ & $0 \%$ & $0 \%$ & $0 \%$ & $0 \%$ & 1.00 & 11 \\
\hline Remaining cue perceptions & $29 \%$ & $10 \%$ & $17 \%$ & $8 \%$ & $13 \%$ & $1 \%$ & $1 \%$ & $8 \%$ & $13 \%$ & 0.16 & 145 \\
\hline
\end{tabular}

Note. Rows sum to $100 \% . n$ 1/4 number of elicited cue perception descriptions per category. HI. $1 / 4 \mathrm{Herfindahl}$ index, equalling the sums of squared row proportions. C9-21 are aggregated and displayed in a single column due to their small size. 


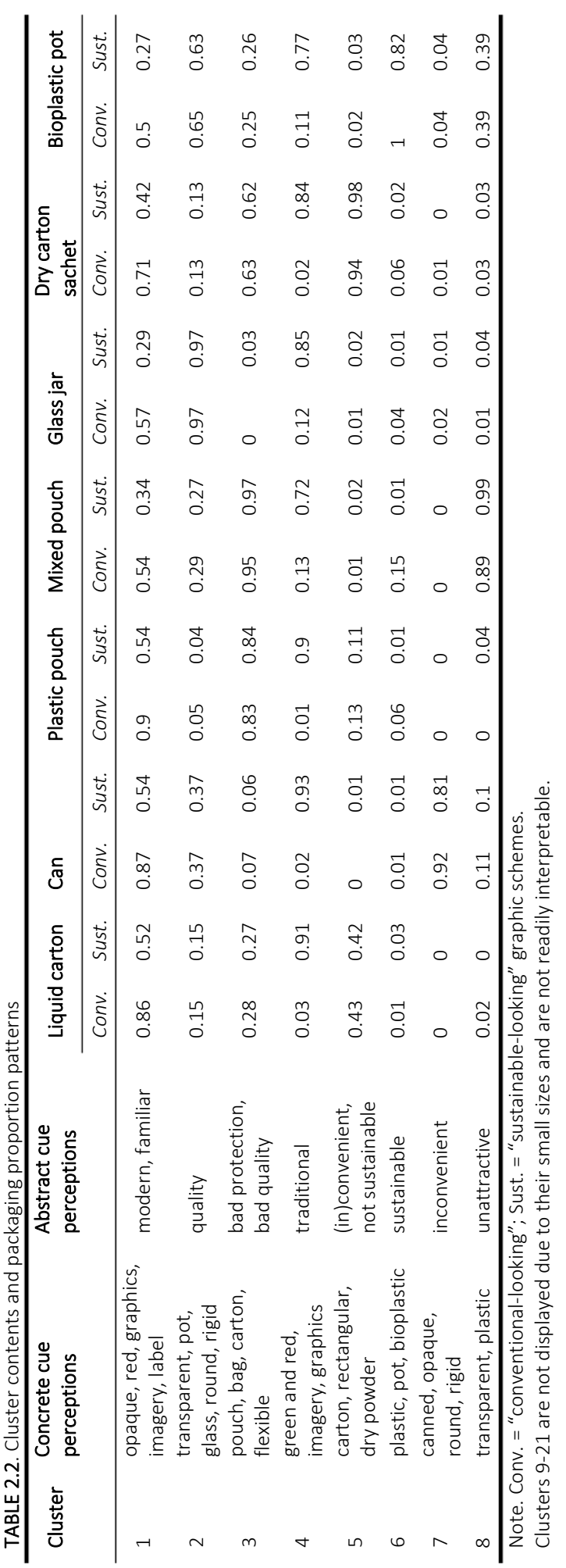




\subsubsection{Consumer and life cycle analysis (LCA) comparison}

Consumer judgments of packaging sustainability were compared with the outcomes of LCA (Table 2.3). Figure 2.2 shows a graphical display of this comparison. The results show several important incongruences between consumer judgments and LCA. Glass jars, which were perceived as very sustainable by consumers (ranked 2nd of 7), were actually least sustainable according to LCA. The bioplastic pot also caused a comparatively large environmental burden in LCA (ranked 5th of 7), while consumers ranked it first in terms of sustainability. Plastic and mixed material pouches, as well as dry carton sachets, were considered as not sustainable by consumers but were amongst the most sustainable options according to LCA endpoints. The differences in sustainability assessments are smallest for cans (consumer ranked 7th, LCA ranked 6th) and liquid cartons (both ranked 3rd). On the whole, the results show that consumer perceptions are severely misaligned with LCA outcomes.

\begin{tabular}{|c|c|c|c|c|}
\hline \multirow[t]{2}{*}{ Packaging type } & \multicolumn{2}{|l|}{ Consumer perceptions } & \multicolumn{2}{|l|}{ Life-cycle analysis } \\
\hline & $\begin{array}{l}\text { Sustainable packaging: ratings } \\
\text { (higher = more sustainable) }\end{array}$ & Ranking $^{\mathrm{a}}$ & $\begin{array}{l}\text { ReCiPe end points: outcomes } \\
\text { (higher = less sustainable) }\end{array}$ & Ranking $^{\mathrm{a}}$ \\
\hline Bioplastic pot & 60.615 & 1 & $2.85 \mathrm{E}-05$ & 5 \\
\hline Glass jar & 57.55 & 2 & 4.72E-05 & 7 \\
\hline Liquid carton & 54.27 & 3 & 1.10E-05 & 3 \\
\hline Plastic pouch & 46.33 & 4 & 1.20E-05 & 4 \\
\hline Mixed pouch & 45.755 & 5 & 8.40E-06 & 2 \\
\hline Dry carton sachet & 45.14 & 6 & $1.90 E-06$ & 1 \\
\hline Can & 43.22 & 7 & $3.17 \mathrm{E}-05$ & 6 \\
\hline
\end{tabular}

${ }^{a}$ Rankings: 1 = most sustainable, 7 = least sustainable 


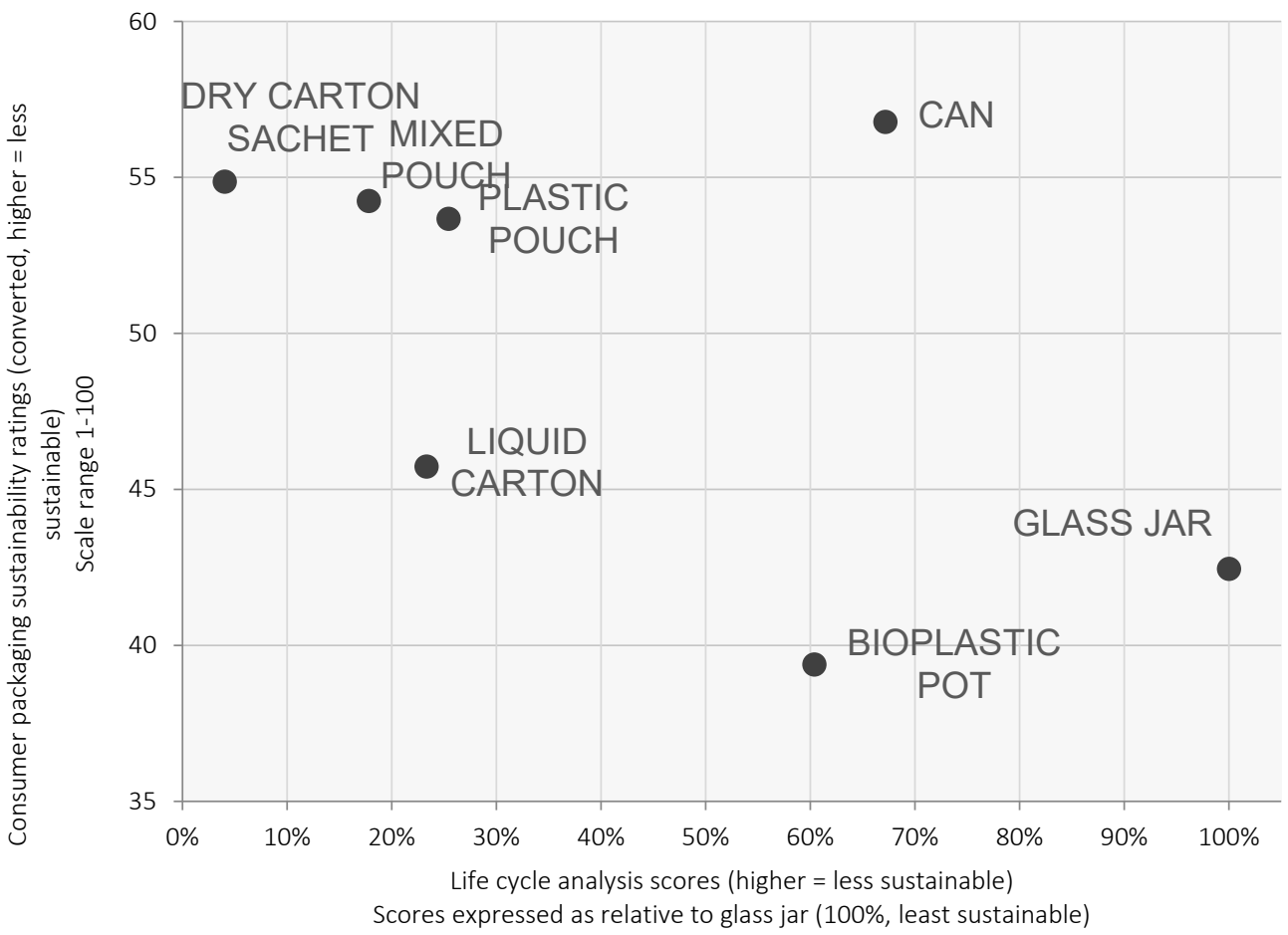

FIGURE 2.2. Consumer \& ReCiPe Endpoints LCA comparison

\subsubsection{Inferential benefit linkages}

Inferences between consumer packaging-related perceptions and product benefits

To understand how packaging-derived cue perceptions are predictive of packaged product benefits (Phase 2), the 28 content categories identified with content analysis were used as predictors for benefits using multilevel regression (Level 1 = product benefits, Level 2 = respondents) using maximum likelihood (ML) estimation to take into account the hierarchical nature of the data. Proportions were calculated to indicate the extent to which a product belonged to any of the 28 content categories. To account for possible differences in respondents' overall tendencies to "check" more or less frequently in the CATA task, these proportions were mean-centered per content category and per packaged product. Whenever a respondent did not have any cue perceptions in a content category, zeros were assigned instead. Random intercepts and slopes were included to best model 
between-subject differences, because cue perceptions were formed in idiosyncratic terms. To compare the fits of multilevel models, a Level- 1 pseudo- $R^{2}\left(\rho^{2}\right)$ was calculated (Hayes, 2006), which measures the proportion of variance explained by predictors that is not explained by between-respondent (Level 2) differences.

The results (Table 2.4) showed that all benefits that were obtained from prior research also showed up in respondents' spontaneous cue perceptions, and these cue perceptions were significantly related to their corresponding benefits (all $p$ 's $<.001)$. For example, the cue perception of "cheap" was significant in relation to the benefit of inexpensive pricing $(b=21.10, p<.001)$. The presence of a sizeable group of cue perceptions related to sustainability $(n=293)$ and the highly significant effects on sustainable $(b=17.25, p<.001)$ and sustainably packaged $(b=22.38, p<.001)$ benefits indicate that sustainability is spontaneously associated with packaging and that these perceptions are predictive of sustainability benefits. Sustainability cue perceptions also contributed to naturalness $(b=6.13, p<.001)$ and healthiness ( $b=$ $3.78, p<.001)$ benefits and, to a lesser degree, to taste $(b=1.63, p<.10)$ and quality $(b=2.32, p<.05)$, whilst detracting from inexpensive price perceptions $(b=-4.02, p$ $<.05)$. Overall, these results showed that spontaneous inferences based on mere packaging design cues were predictive of all included packaged product benefits. 


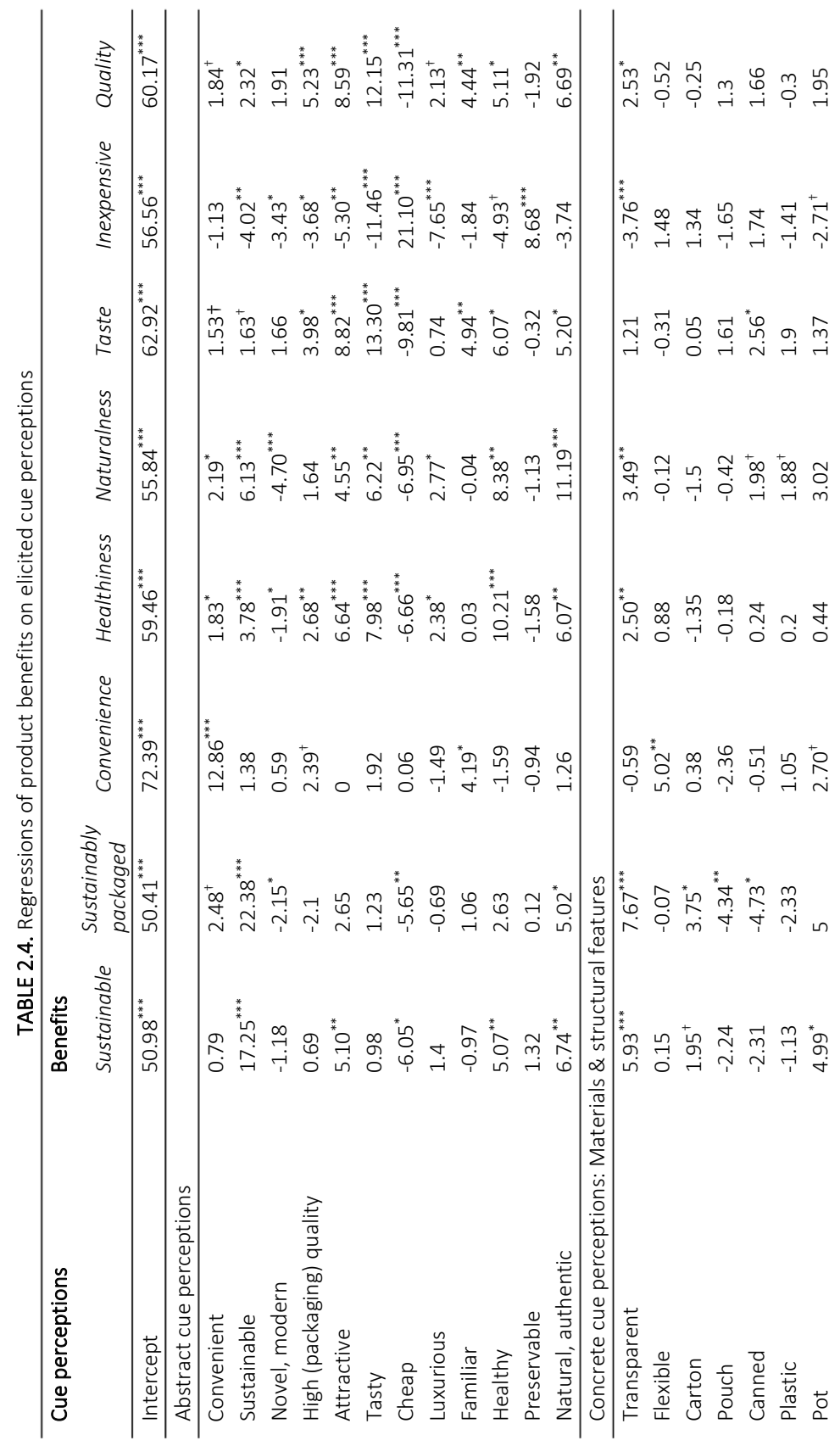




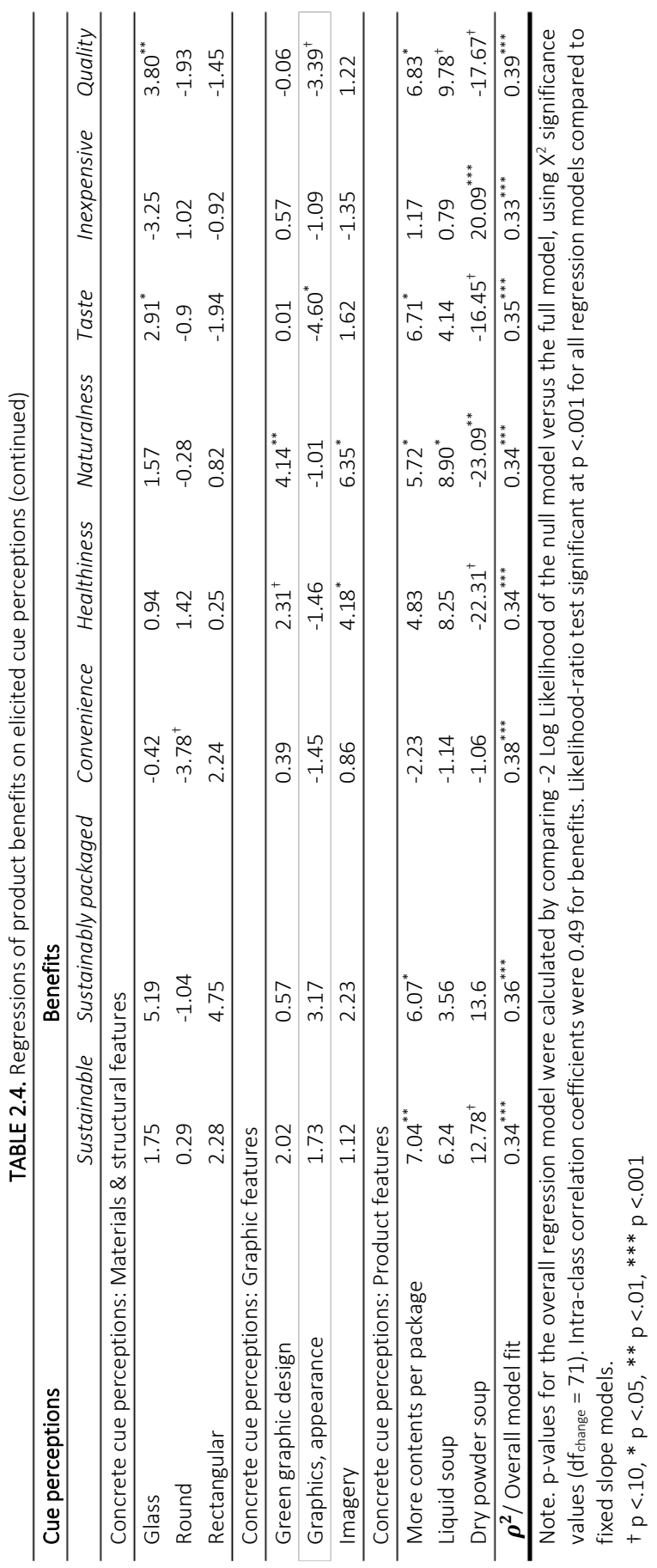




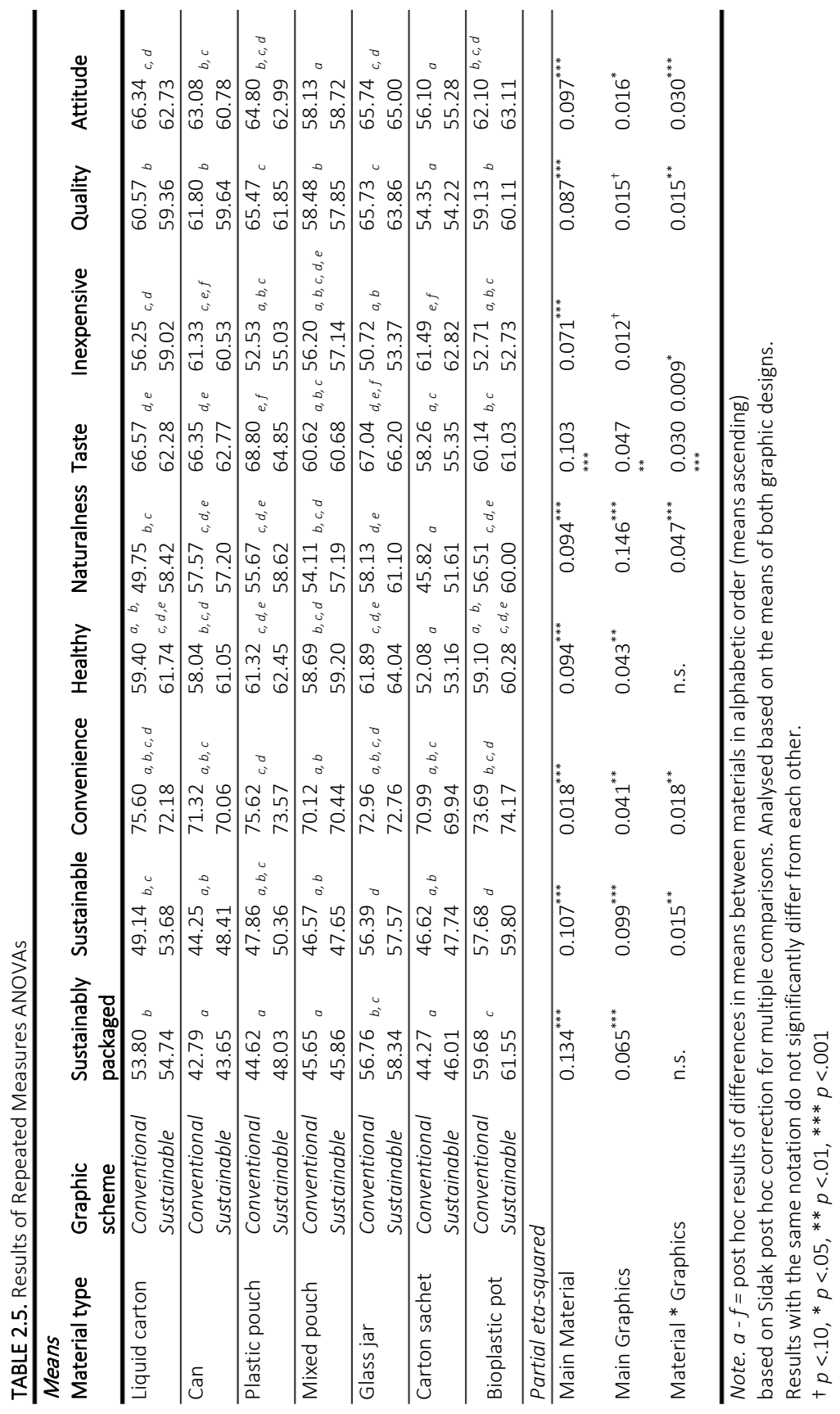




\section{Effects of graphic scheme and packaging materials on product benefit evaluations}

A series of repeated measures ANOVAs was conducted with packaging materials and graphics as independent variables and packaged product benefits (and attitudes) as the dependent variables. The results (Table 2.5) show that the main effects of both the manipulated material and graphic designs were significant for all benefits and attitudes. The largest effects were found for graphics on naturalness $\left(\eta_{p}^{2}=.146, p<.001\right)$ and for materials on sustainable packaging $\left(\eta_{p}^{2}=.134, p<.001\right)$. Notable medium-sized effects of packaging materials were found on (product) sustainability $\left(\eta_{p}^{2}=.099\right)$, attitude $\left(\eta_{p}^{2}=.097\right)$, taste $\left(\eta_{p}^{2}=.010\right)$, naturalness $\left(\eta_{\mathrm{p}}^{2}=\right.$ .094), healthiness $\left(\eta_{p}^{2}=.094\right)$, quality $\left(\eta_{p}^{2}=.087\right)$, and inexpensiveness $\left(\eta_{p}^{2}=.071\right)$, with all $p^{\prime} s<.001$. Graphic design had medium-sized effects on both sustainability measures. The remaining effects were small $\left(\eta_{p}^{2}<.06\right)$ and are not further discussed. Specifically with regard to the two graphic schemes, the pattern of results suggests that the sustainable-looking scheme was perceived primarily as more natural, and it was perceived as more sustainable and healthier than the conventional-looking schema. Looking at individual material means (averaged over graphic designs, scale $1-100)$, respondents indicated the bioplastic pot $(M=60.6)$ and glass jar $(M=57.6)$ as the most sustainable packaging. Cartons were rated as intermediately sustainable $(M=54.7)$ when a single packaging was used (i.e., liquid carton), but when multiple smaller packages were used (i.e., dry carton sachets), they were perceived as least sustainable $(M=45.1)$, together with plastic pouches $(M=46.3)$ and cans $(M=43.2)$; differences not significant. In terms of attitudes, tomato soups packaged in liquid cartons $(M=64.5)$, plastic pouches $(M=63.9)$, glass jars $(M=65.4)$ and bioplastics $(M=62.6)$ were evaluated best. Dry carton sachets $(M=55.7)$ and the mixed material (transparent) pouch $(M=58.4)$ were evaluated least positively.

\section{Benefit evaluation and attitude formation}

To analyze the effects of the benefits in determining consumer attitudes towards the tomato soup products, a random intercept multilevel regression model was used (Table 2.6). The results indicate that the benefits significantly predicted attitudes ( $p$ 's $<.001$, except inexpensive pricing, where $p=.10)$. Taste $(b=.34, p<.001)$ and quality ( $b=.21, p<.001)$ were the most important in influencing product attitudes. It is notable that the most-salient packaging perceptions, that is, convenience $(b=.01, p$ $<.001)$ and sustainability $(b=.12, p<.001$ for packaging sustainability and $b=.05$, $p<.001$ for product sustainability), were not the most important in determining overall attitude. Naturalness $(b=.08, p<.001)$ and healthiness $(b=.12, p<.001)$ 
were also intermediately important. Inexpensive pricing $(b=.02, p=.010)$ was deemed least important, but could likely play a larger role in actual purchase choices than in attitudes. Overall, these results support the final phase of the conceptual model, as all benefits contributed meaningfully to attitudes. The results also show that salience is not equal to importance; although packaging led to sustainability inferences, sustainability only modestly contributed to attitudes toward the tomato soups.

\begin{tabular}{|c|c|c|c|c|c|c|c|}
\hline \multirow[t]{2}{*}{ Benefit } & \multirow[t]{2}{*}{$b$} & \multirow[t]{2}{*}{ SE } & \multirow[t]{2}{*}{$d f$} & \multirow[t]{2}{*}{$t$} & \multirow[t]{2}{*}{$p$} & \multicolumn{2}{|c|}{ Confidence Interval $95 \%$} \\
\hline & & & & & & $\begin{array}{l}\text { Lower } \\
\text { Bound }\end{array}$ & $\begin{array}{l}\text { Upper } \\
\text { Bound }\end{array}$ \\
\hline (Intercept) & -0.66 & 1.13 & 2414.398 & -0.59 & .558 & -2.88 & 1.56 \\
\hline $\begin{array}{l}\text { Sustainably } \\
\text { packaged }\end{array}$ & 0.12 & .010 & 3364.868 & 12.56 & $<.001$ & 0.10 & 0.14 \\
\hline Sustainable & 0.05 & .012 & 3391.373 & 4.43 & $<.001$ & .003 & 0.08 \\
\hline Convenience & 0.01 & .009 & 3458.773 & 10.9 & $<.001$ & 0.08 & 0.11 \\
\hline Healthiness & 0.12 & .014 & 3485.897 & 8.27 & $<.001$ & 0.09 & 0.15 \\
\hline Naturalness & 0.08 & .012 & 3471.646 & 6.58 & $<.001$ & 0.06 & 0.10 \\
\hline Taste & 0.34 & .014 & 3454.565 & 23.97 & $<.001$ & 0.31 & 0.37 \\
\hline Inexpensive & 0.02 & .008 & 3372.097 & 2.57 & .010 & 0.01 & 0.04 \\
\hline Quality & 0.21 & .015 & 3485.114 & 14.13 & $<.001$ & 0.18 & 0.23 \\
\hline
\end{tabular}

Note. Intraclass correlation coefficient $=0.30$. Level-1 pseudo R-squared $\left(\boldsymbol{\rho}^{2}\right)=0.66$

\subsection{General discussion}

\subsubsection{Theoretical implications}

The present study aims to increase understanding of consumers' perceptions of packaging and the role of sustainability therein. First, the study investigates perceptions and associations that are salient amongst consumers in relation to packaging materials and graphics. The research demonstrates that packaging can readily give rise to thoughts about sustainability. This is in line with previous research, where consumers are found to relate packaging chiefly to considerations of both convenience and sustainability (Van Dam \& Van Trijp, 1994; Lindh, Olsson, \& Williams, 2016). Yet, there is a low consensus among consumers about how sustainable different packaging designs are. Two reasons can underlie this heterogeneity. Consumers differ as to which aspects of sustainability they recognize, for example, whether they consider recyclability, reusability or the apparent excessiveness of the packaging material used. Additionally, consumers may differ in their perceptions of how the packaging designs perform on these aspects of 
sustainability. The current results also suggest that impressions of novelty, quality, and attractiveness are salient on an abstract level.

Second, the study adds to the understanding of consumers' benefit inferences based on packaging. The abstract cue perceptions evoked by differences in packaging are very consistently linked to determinants of food product choice defined in prior research (Steptoe et al., 1995). Thus, impressions based on the packaging tend to "spill-over" to the packaged product as a whole. The results also support the notion that sustainability perceptions are closely related to other benefits such as naturalness and healthiness (Binninger, 2015; Magnier et al., 2016; Van Rompay et al., 2016), better taste (Becker et al., 2011), higher costs (Luchs, Brower, \& Chitturi, 2012) and an overall increased quality (Magnier et al., 2016). Material choice has a strong effect on perceived sustainability, but consumers are also affected (and could be misled) by graphical influences.

Third, this research contributes to the scarce literature that compares consumers' sustainability judgments and more-accurate assessments of sustainability of expert (LCA) models (Tobler, Visschers, \& Siegrist, 2011; Van Dam, 1996). The results show that consumers judge plastics and metals to be least sustainable, while they judge glass and bioplastics as most sustainable, followed by (single) cartons. These results are very similar to prior findings (using non-student samples) by, Lindh, Olsson, et al. (2016) in Sweden, Van Dam (1996) in The Netherlands and Allegra, Zarbà, and Muratore (2012) in Italy. Comparing the consumer scores to the outcomes of the lifecycle analyses of these seven packages reveals that the most-sustainable packaging options according to LCA (dry carton sachets and mixed material pouch) are deemed least sustainable by consumers. Similarly, the most-sustainable packages in consumer perceptions (bioplastic and glass) are ranked fifth (out of seven) and last in LCA. Consumer intuitions are thus very inaccurate, and in some cases are practically opposite to life-cycle assessments. Therefore, these findings stress the opposition between consumer beliefs and 'objective' environmental impacts as a threat to sustainable development.

Finally, the findings provide insight into how product attitudes are formed through packaging. The measured benefits are generally determinants of consumers' attitudes towards the tomato soup products. However, the most-salient packagingbased inferences about convenience and sustainability are only intermediately important in determining attitudes and are subordinate to inferences about quality and taste. This suggests that in their attitude formation, consumers stick closer to 
generally important benefits, even though these benefits are more distant from the actual distinguishable features they directly perceive.

\subsubsection{Managerial implications}

One of the key challenges for packaging managers, marketers and designers is to develop sustainable packaging designs that are acceptable to consumers. While developing packaging designs, it should be taken into account that different materials communicate different levels of sustainability to consumers, which may not be in line with LCA outcomes. Therefore, even though consumers generally hold positive attitudes toward sustainable packaging, it should not at all be assumed that consumers will readily make the right environmental choice. This presents a challenge in terms of persuading consumers to choose packaging alternatives that, based on their own knowledge, they would normally not believe to be environmentally friendly. At the same time, graphic aspects of packaging design also implicitly communicate sustainability, and these may often be more deliberately designed to signal sustainability (e.g., by the use of green and sustainable-looking graphics). This could mislead consumers (e.g., as in "greenwashing"), but it could also be used to promote packaging types that consumers would not intuitively perceive as sustainable.

Moreover, the study suggests that deliberate design changes aimed at reducing the environmental burden of packaging are likely to lead to implications for other perceived benefits. These design alterations could also signal unintended and undesirable trade-off consequences. For example, changing a product's packaging from a metal can to glass is likely to increase perceived sustainability, but such packaging will also be prone to lead to higher price perceptions. To increase marketplace success, more-sustainable packaging should be positioned to complement (rather than detract from) important product purchase benefits such as taste and quality.

\subsubsection{Limitations and future research}

Several limitations of the current study and avenues for future research can be distinguished. First, the study uses a student sample. Although there are no large differences in packaging sustainability judgments between student samples and research using more-representative samples, caution is still advised in terms of generalizing toward populations. 
Second, in real purchase scenarios, consumers may be less likely to (extensively) compare different packaging options of the same product compared to a lab setting. Soup products in the study carried the same brand name, and hence, attitudinal differences could only reflect consumer inferences based on packaging materials and graphics. Brand attitudes were not measured. Although there is no a priori reason to expect that brand attitudes influence the inferences consumers draw from packaging design, the roles of brand image and packaging could be investigated in future research. Moreover, it is worthwhile to venture beyond attitudinal measures toward more-realistic purchase scenarios in future research, as this would improve the external validity of the outcomes.

Third, some limitations of the study design should be noted. The stimuli consisted of images of common packaging options. For this reason, the bioplastic and dry carton sachet packaging had to be labelled to indicate their properties, as these were otherwise not discernible. Consumers may also perceive the dry soup in the carton sachet as different from the liquid soups, although the results showed this basis for distinction to be uncommon as few respondents mentioned this in the elicitation of cue perceptions. The sachet's LCA outcomes were favorable in part due to its low volume compared to liquid soup packaging. It should be noted that contexts and/or specific methodologies can affect the relative LCA performances of the packaging types, and this is inherent to the LCA methodology. It should also be noted that the study's design did not randomize stimuli presentation after the elicitation phase, hence possible order effects (in relation to ANOVAs) could not be excluded.

Fourth, this study did not focus on how the retail environment could affect the role of packaging sustainability in consumer perceptions. Because purchases are increasingly made online, often affecting the role of packaging (e.g., due to the presence of additional secondary packaging or a different interaction with the product's packaging), future research could look into whether the role of packaging and its environmental concerns vary due to such contextual factors.

Finally, while the current research quantifies the gap between consumer judgments and LCA's environmental impact assessments, future research could expand upon this by designing and testing interventions to reduce this gap. It may, for example, be fruitful to investigate whether consumers' confidence in using packaging cues affects their ability to change their beliefs. 


\subsection{Conclusions}

This study aims to advance the understanding of consumer response toward packaging sustainability by advancing and empirically testing perceptual, inferential and attitudinal aspects of consumer decision making that arise from packaging material and graphical differences. New insights show that (packaging) sustainability is salient but not highly important for determining attitudes. It is shown that packaging has consistently powerful effects on product-level expectations and, by extent, sustainable packaging is most likely to be accepted when it enhances perceptions of product quality and taste. The current study also contributes by showing that consumers' sustainability perceptions of packaging are highly diversified, possibly because they perceive different aspects of sustainability (e.g., recyclability vs. reusability) and vary in how they believe packaging performs on such aspects. It is shown that these consumer perceptions do not align with life-cycle assessment; rather, consumers rely on their own lay beliefs and can be easily misled by salient cues that may not be very relevant for objective environmental impacts. 
APPENDIX 2.1. Stimuli

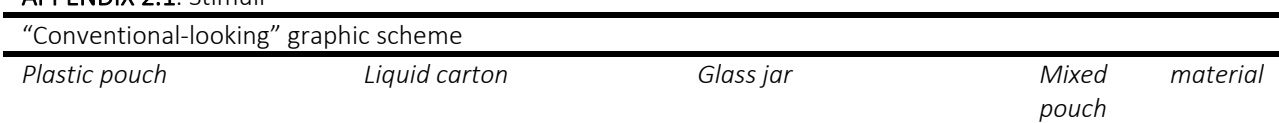

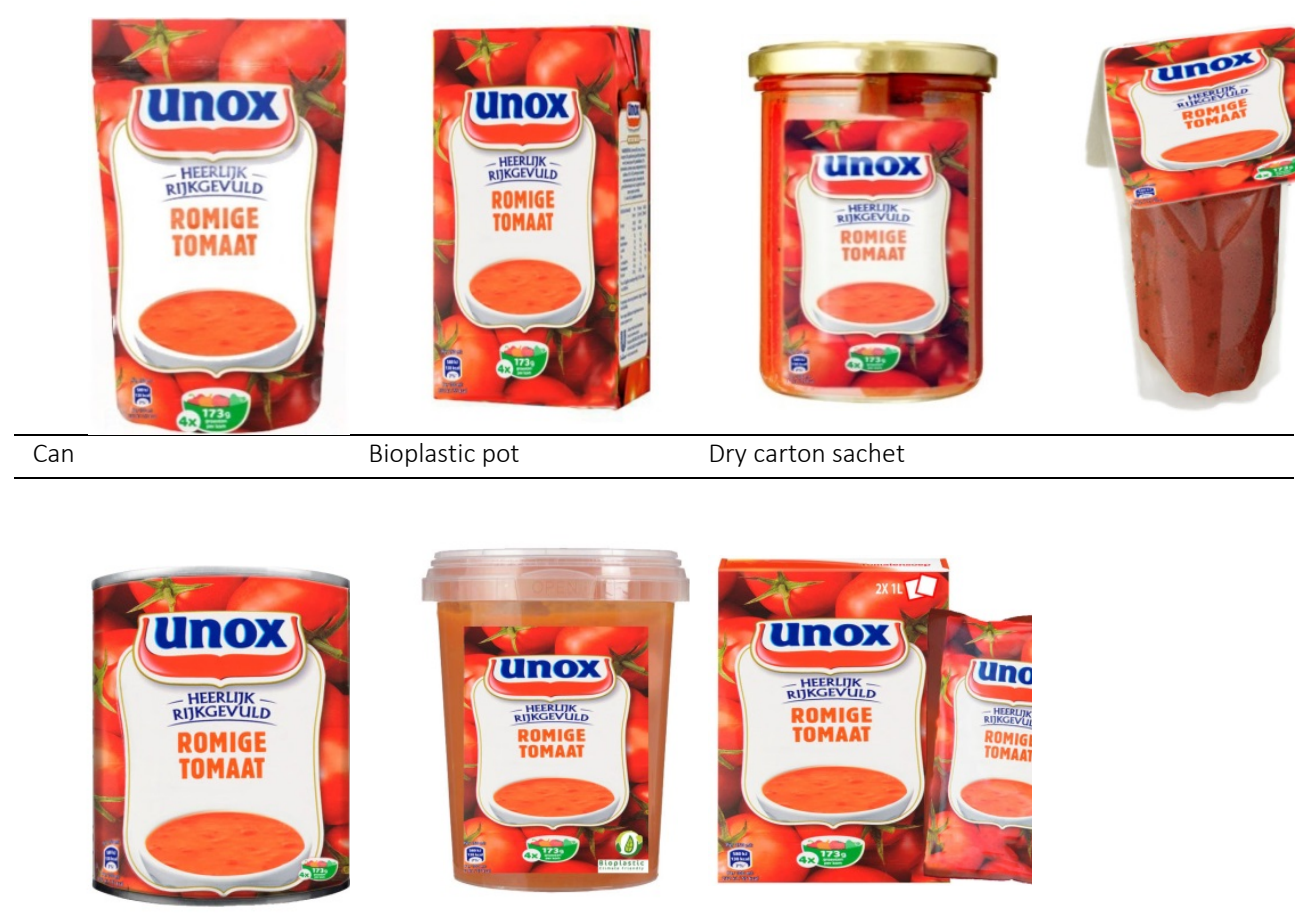


APPENDIX 2.1. Stimuli (continued)

"Sustainable-looking" graphic scheme

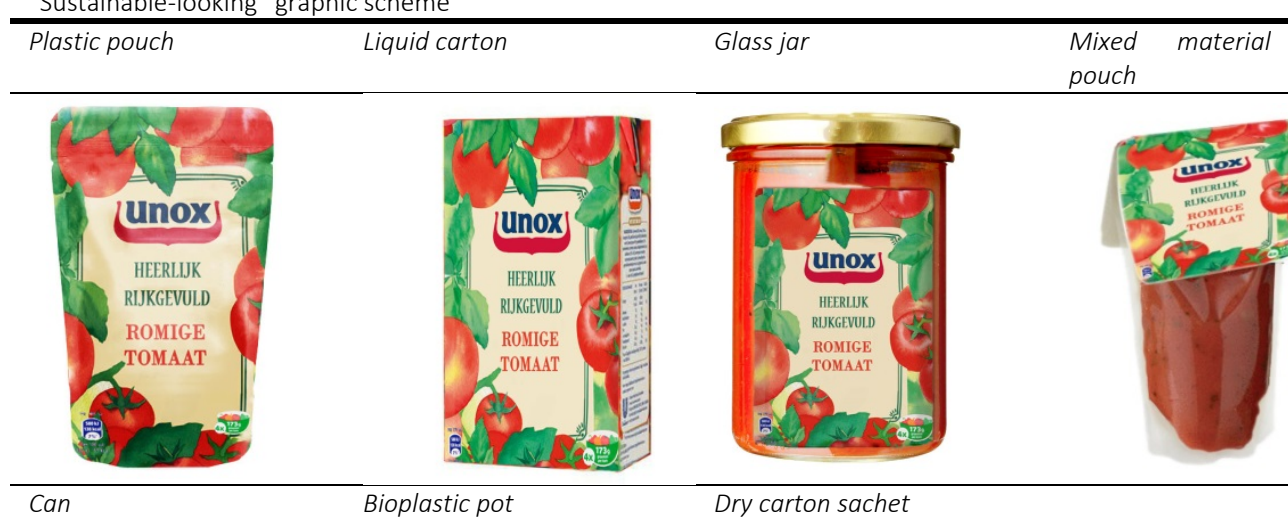
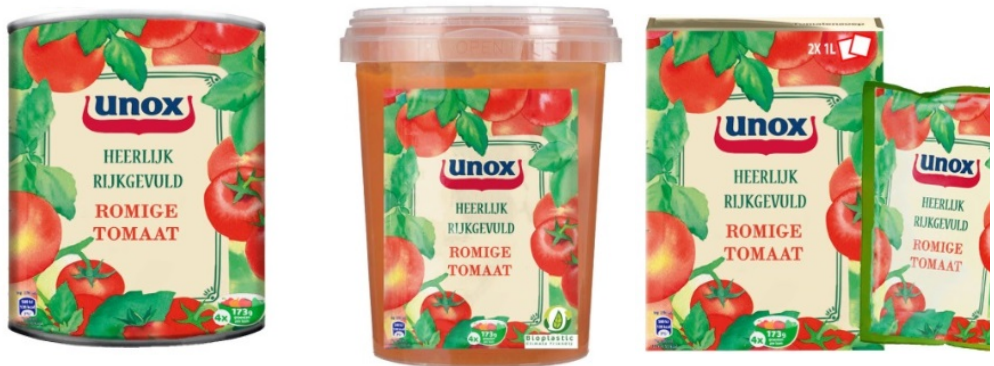

APPENDIX 2.2. Supplementary material 


\section{Life cycle assessment material compositions}

The material composition of the packaging per $800 \mathrm{ml}$ soup is given in Table 1.

The bioplastic pot was modelled as bio-HDPE, using ethanol, mainly from sugar cane and corn, from the global market as the raw material and assuming a 100\% yield. The production process of bio-HDPE further includes electricity and heat consumption plus energy needed for process cooling.

TABLE 1. Material composition and material mass for the $800 \mathrm{ml}$ soup packaging

\begin{tabular}{|c|c|c|}
\hline Packaging & Material & Mass [g] \\
\hline Bio-HDPE pot & Bio-HDPE/PP & 35.8 \\
\hline \multirow[t]{3}{*}{ Glass jar } & Glass & 449.1 \\
\hline & Steel, coated & 11.0 \\
\hline & Paper label & 0.6 \\
\hline \multirow[t]{4}{*}{ Liquid carton } & LPB & 16.2 \\
\hline & LDPE & 5.0 \\
\hline & $\mathrm{EVOH}$ & 0.4 \\
\hline & Alu & 0.90 \\
\hline \multirow[t]{5}{*}{ Plastic pouch (opaque) } & $\mathrm{PP}$ & 8.8 \\
\hline & $\mathrm{EVOH}$ & 0.74 \\
\hline & Nylon & 2.6 \\
\hline & PET & 4.5 \\
\hline & Alu & 1.96 \\
\hline \multirow[t]{3}{*}{ Mixed material pouch (translucent) } & $P E$ & 12.5 \\
\hline & $\mathrm{EVOH}$ & 0.9 \\
\hline & Cardboard label & 4.8 \\
\hline \multirow[t]{3}{*}{ Dry carton (sachet) } & Paper & 1.6 \\
\hline & Alu & 0.58 \\
\hline & PE & 2.2 \\
\hline \multirow[t]{2}{*}{ Can (steel) } & Steel, coated & 86 \\
\hline & Paper label & 3.5 \\
\hline
\end{tabular}

\section{Environmental impact calculations}

For the calculation of the environmental impact of the packaging a cradle to grave approach was used, meaning that not only the production of packaging materials and packaging, but also the waste treatment (incineration and/or recycling) was included. Transport of packaging (materials) and transport at the end-of-life 
were included. For the end-of-life packaging specific scenarios, including collection method and efficiencies for sorting, recycling and recovery, for the recent Dutch situation were applied (Ligthart et al, 2017). Waste treatments that yielded recovered energy or recycled materials were allocated $50 \%$ of the avoided environmental impact by these products. This is the so-called 50:50 approach, used in for instance the EU's Product Environmental Footprint (Manfredi et al., 2012). The opaque standing pouch and the dry soup satchel are not recycled, instead they are incinerated with energy recovery. The soup itself and its preparation have been excluded of the life cycle assessment.

The environmental impacts were assessed with four different methods:

3. Modified ReCiPe midpoint combined with shadow prices

4. ReCiPe endpoint

5. Cumulative Energy Demand (CED)

6. Circular Economy endpoints

Note that the paper reports results based on ReCiPe endpoints.

The methods reflect different perspectives on the environmental impact of a packaging chain. The ReCiPe midpoint method has a focus on the actual impact mechanisms, like global warming and eutrophication, that affect the environment. The endpoint method of ReCiPe focusses on the damage that is done to three endpoints: human health, ecosystems and natural resources (Goedkoop et al, 2013). The CED-method addresses the use of renewable and non-renewable energy resources. Lastly, the Circular Economy method includes the depletion of three natural resources: fossil fuels, metals and fresh water (Ligthart et al, 2017). All four methods express the environmental impact in a single score, each with their own unit; respectively euros, points, dollars and MJ (megajoule). 


\section{Environmental impacts of packaging}

The glass jar appeared in all but the ReCiPe shadow prices method to be the packaging with the highest impact (see Table 2). The biobased pot displayed the highest impact in case of the ReCiPe shadow prices method; the score is largely caused by the impact of land use. The steel can was the runner-up for the ReCiPe endpoints and Circular Economy methods, the pot made from bio-HDPE also showed a relative high impact for the CED method. The dry sachet always showed the lowest score. It must be noted that the packaging volume of this lightweight packaging is much lower as ready-to-eat soup contains over $90 \%$ water, while the moisture content of dry soup will be around $5 \%$.

TABLE 2. Environmental impacts of soup packaging for four assessment methods.

\begin{tabular}{|c|c|c|c|c|c|c|c|c|}
\hline Method & Unit & Bio-HDPE pot & $\begin{array}{l}\text { Soup } \\
\text { Can }\end{array}$ & $\begin{array}{l}\text { Soup } \\
\text { Carton }\end{array}$ & $\begin{array}{l}\text { Soup } \\
\text { Glass }\end{array}$ & $\begin{array}{l}\text { Soup } \\
\text { Pouch }\end{array}$ & $\begin{array}{l}\text { Translucent } \\
\text { pouch }\end{array}$ & $\begin{array}{l}\text { Dry } \\
\text { sachet }\end{array}$ \\
\hline $\begin{array}{l}\text { ReCiPe/ILCD } \\
\text { shadow prices }\end{array}$ & $E \cup R$ & $2.12 \mathrm{E}-01$ & $\begin{array}{l}9.60 \mathrm{E}- \\
02\end{array}$ & $\begin{array}{l}5.97 \mathrm{E}- \\
02\end{array}$ & $\begin{array}{l}1.71 \mathrm{E}- \\
01\end{array}$ & $\begin{array}{l}3.22 \mathrm{E}- \\
02\end{array}$ & $3.41 \mathrm{E}-02$ & $\begin{array}{l}5.26 \mathrm{E}- \\
03\end{array}$ \\
\hline $\begin{array}{l}\text { ReCiPe } \\
\text { endpoints }\end{array}$ & Pt & $2.85 \mathrm{E}-05$ & $\begin{array}{l}3.17 \mathrm{E}- \\
05\end{array}$ & $\begin{array}{l}1.10 \mathrm{E}- \\
05\end{array}$ & $\begin{array}{l}4.72 E- \\
05\end{array}$ & $\begin{array}{l}1.20 \mathrm{E}- \\
05\end{array}$ & $8.40 \mathrm{E}-06$ & $\begin{array}{l}1.90 E- \\
06\end{array}$ \\
\hline $\begin{array}{l}\text { Cumulative } \\
\text { Energy Demand }\end{array}$ & MJ & $7.09 E+00$ & $\begin{array}{l}3.31 \mathrm{E}+ \\
00\end{array}$ & $\begin{array}{l}2.19 E+0 \\
0\end{array}$ & $\begin{array}{l}7.60 E+0 \\
0\end{array}$ & $\begin{array}{l}2.31 E+0 \\
0\end{array}$ & $1.80 \mathrm{E}+00$ & $\begin{array}{l}3.92 \mathrm{E}- \\
01\end{array}$ \\
\hline $\begin{array}{l}\text { Circular } \\
\text { Economy }\end{array}$ & $\$$ & $1.05 \mathrm{E}-02$ & $\begin{array}{l}2.16 \mathrm{E}- \\
02\end{array}$ & $\begin{array}{l}3.72 \mathrm{E}- \\
03\end{array}$ & $\begin{array}{l}2.56 \mathrm{E}- \\
02\end{array}$ & $\begin{array}{l}7.10 \mathrm{E}- \\
03\end{array}$ & $6.28 \mathrm{E}-03$ & $\begin{array}{l}1.04 \mathrm{E}- \\
03\end{array}$ \\
\hline
\end{tabular}




\section{CHAPTER 3}

\section{Effects of sustainable design strategies on consumer preferences for redesigned packaging}

Steenis, N. D., Van der Lans, I. A., Van Herpen, E., \& Van Trijp, H. C. (2018). Effects of sustainable design strategies on consumer preferences for redesigned packaging. Journal of Cleaner Production, 205, 854-865. 


\section{ABSTRACT}

The environmental benefit from sustainable packaging is not only dependent on the characteristics of the packaging, but also on consumer willingness to purchase sustainably packaged products. Consumer response is likely influenced by the specific design strategies that are used to make packaging more sustainable. Based on the circular economy concept, this chapter distinguishes between circular and linear design strategies, and investigates consumer responses to packaging redesigned according to such strategies. Two experiments were conducted to assess to what extent (combinations of) sustainable design strategies affect consumers' purchase intentions. The results show that consumers are more positive toward redesigns following a circular design strategy (e.g., biodegradable materials) compared to linear redesigns (e.g., packaging lightweighting). Additionally, consumers are not more willing to buy packaging redesigns combining multiple sustainable design strategies, relative to those using only a single redesign strategy. Multi-strategy redesigns are perceived only as marginally more sustainable than single strategy redesigns. These diminishing returns can be attributed to a lack of increase in the moral satisfaction consumers achieve from buying product with multi- rather than single-strategy redesigned sustainable packaging. 


\subsection{Introduction}

Increasing attention from the public, industry and politics for environmental problems related to product packaging has gone hand in hand with an increasing number of corporate initiatives toward sustainable packaging design (Mintel, 2018). Many of these sustainability initiatives adhere to circular economy principles, a concept that has gained importance among both consumers and corporate decision makers (Geissdoerfer, Savaget, Bocken, \& Hultink, 2017). In essence, the circular economy concept is a sustainability paradigm that focuses on (economic) systems that are restorative and regenerative by design and that aims to keep products, components, and materials at their highest utility and value at all times (Ellen MacArthur Foundation, 2015). The circular economy is often proposed as an alternative for the "take, make, dispose" model of linear economy systems (Bocken et al., 2016).

The application of the circular versus linear economy paradigms relies to a large extent on business and design strategies (Bocken et al., 2016; Bocken et al., 2014; De Koeijer, Wever, \& Henseler, 2017). Based on the conceptualization of Bocken et al. (2016) sustainable packaging design solutions can be classified into circular design for technical cycles (e.g., recycling, reuse), circular design for biological cycles (e.g., renewability, biodegradability) and design through linear reduction strategies (e.g., reduce, lightweighting). Such designs are readily observable in packaging design innovations. For example, the Coca-Cola Company has been steadily introducing PlantBottle ${ }^{\mathrm{tm}}$ packaging, a fully recyclable plastic bottle partially made from plants, in order to promote the use of renewable materials (Anderson, 2015). Alternatively, Unilever has recently marketed compressed deodorants which are stated to use $25 \%$ less packaging material due to savings from compression (Unilever, 2015).

Important prerequisites for the success of sustainable packaging solutions are consumers' purchase likelihood and willingness-to-pay for such alternatives (Adeyeye, She, \& Baïri, 2017; Petersen \& Brockhaus, 2017). Actual environmental improvements are difficult to attain if sustainably packaged products are not preferred by consumers over conventional alternatives. Purchase intentions for sustainably packaged products might be affected by the way in which the packaging is made environmental friendlier (i.e., through which sustainable design strategy). Due to a lack of consumer insights related to various sustainable design strategies, many firms and their (packaging) designers have difficulty in effectively adopting 
and developing coherent strategies to spearhead sustainable design initiatives (Brockhaus, Petersen, \& Kersten, 2016; Murto, Person, \& Ahola, 2014).

The current research uses the circular economy concept to distinguish between different sustainable design strategies and investigates how these affect consumers' willingness to purchase. Three research questions are investigated. First, do consumers differ in their purchase intentions toward packaging that is redesigned in accordance with circular economy strategies, compared to linear sustainability strategies? Second, if so, which consumer perceptions and inferences drive this? Finally, are consumers' purchase intentions higher for packaging designs incorporating multiple sustainable design strategies than for designs with only a single strategy? A conceptual model and hypotheses about consumer response to different sustainable redesign strategies are developed and tested in two experiments.

\subsection{Literature review}

\subsubsection{Consumer response to sustainable packaging}

Perceived sustainability and purchase intention

A large stream of consumer research suggests that consumers have a positive attitude toward more sustainable packaging (Martinho et al., 2015; Prakash \& Pathak, 2017; Van Birgelen et al., 2009), that packaging sustainability is relevant and salient to consumers, and that it can contribute to consumers' purchase likelihoods and willingness-to-pay (Nordin \& Selke, 2010; Steenis, Van Herpen, Van der Lans, Ligthart, \& Van Trijp, 2017). On the whole, the research on consumer perceptions of packaging sustainability suggests that sustainability attributes in and of themselves are desirable and have positive effects on consumer response (Prakash \& Pathak, 2017; Steenis et al., 2017; Van Birgelen et al., 2009). Formally:

H1: Greater perceived sustainability of packaging contributes positively to consumer purchase intentions.

\subsubsection{Sustainable packaging design strategies and consumer-perceived sustainability}

Consumers are able to differentiate between ways to achieve greater sustainability in packaging design (Steenis et al., 2017). For example, they respond to whether the packaging is recyclable/recycled or re-useable, whether it is 
Effects of sustainable design strategies

(bio)degradable or uses renewable material sources, and whether material amounts are perceived as excessive (Lindh et al., 2016; Magnier \& Crié, 2015; Nordin \& Selke, 2010). Furthermore, consumers distinguish between pre- and post-consumer waste, such as using a recycled material package, or optimizing a (virgin material) packaging's recyclability (Cude, 1993). Given consumers' ability to distinguish between various sustainable packaging solutions, it seems plausible that consumers may also react differently on the basis of whether packaging redesigns are in line with (technical or biological) circular economy design principles or whether they follow a linear economy approach. Particularly, consumers may see linear changes as incremental, pragmatic solutions that are low in transformative power and that are involving only minor changes (cf. Dangelico \& Pujari, 2010; Klewitz \& Hansen, 2014). Hence, it is expected primarily that consumers will perceive circular designs to be more sustainable than linear packaging designs. Thus:

H2: Consumers perceive circular redesigns of packaging to be more sustainable than linear redesigns.

\subsubsection{Consumer inference-making}

Consumers rely on stored associations to make inferences about other qualities of packagings and/or products based on sustainability signals (Luchs et al., 2010; Petersen \& Brockhaus, 2017). Prior research indicates that consumers infer naturalness from packaging sustainability cues, which exerts positive effects on purchase intentions (Magnier et al., 2016) due to humans' innate attachments to ancestral natural environments (Rozin et al., 2004) and/or from a perceived material superiority of natural alternatives in terms of sensory elements such as taste (for foods), effectiveness, safety and purity (Li \& Chapman, 2012; Rozin et al., 2004). Beyond positive associations, there may be trade-offs between perceived sustainability and other factors contributing to consumer satisfaction. First, the concepts of sustainability and functionality are sometimes diametrically opposed in terms of consumer perception (Luchs et al., 2010). Specifically, sustainability may trigger perceptions of lower functionality. Consumers are often unwilling to sacrifice functional performance for social attributes such as sustainability (Auger, Devinney, Louviere, \& Burke, 2008). Therefore, it is expected that, generally, packaging redesigns aimed at increasing sustainability lead to inferences of lower functionality, in turn negatively affecting purchase likelihoods. Second, the perception that more sustainable offerings lead to higher production costs, and therefore command higher marketplace prices, is also likely to play a role (cf. Magnier \& Crié, 2015; Ozaki, 
2011; Vermeir \& Verbeke, 2006). Third, the amount of inferred behavioral costs could also prevent consumers from choosing more sustainable alternatives (McDonald \& Oates, 2006). Sustainable offerings are often associated negatively with convenience (Vermeir \& Verbeke, 2006); therefore, packaging alterations may be inferred by consumers to lead to greater behavioral costs and by extension, may lead to lower purchase likelihood. Formally, the following is hypothesized:

H3a: Perceived naturalness and functionality contribute positively to purchase intentions, while financial and behavioral costs detract from purchase intentions.

H3b: The effect of perceived sustainability on purchase intentions is mediated by consumer perceptions of (higher) naturalness, (lower) functionality and (higher) financial and behavioral costs.

\subsubsection{Multiple sustainable design strategies and diminishing returns}

Sustainable design strategies are often not mutually exclusive, and the best results may be achieved by combining approaches (Bocken, et al., 2016). For example, Ecover, a firm specializing in sustainable cleaning products, specifically highlights that their laundry detergents use recycled plastics and plant-based plastics as well as bio-based ingredients (amongst others) to cover both biological and technical cycles (Ecover, 2018).

Kahneman and Knetsch (1992) demonstrated an embedding effect, which states that sometimes items may be valued more highly when presented singularly than when they are combined. This effect implies diminishing returns from incorporating multiple sustainable design strategies in a packaging, leading to declining increases (or a lack of any increase) in willingness-to-pay premiums and purchase likelihoods, rather than additive effects (cf. sustainable car features, Irwin \& Spira, 1997). For example, the usage of both biodegradability and lightweighting improvements may not lead to the sum of consumer preferences for biodegradability and lightweighting whenever they are considered separately.

Existing theoretical perspectives offer two reasons for diminishing returns. First, consumers may purchase products with environmental attributes to buy moral satisfaction or "warm glow", to satisfice their moral goals and to signal their involvement with morally justified causes (Andreoni, 1990; Irwin \& Spira, 1997; Kahneman \& Knetsch, 1992). If this is the case, the application of any strategy providing a sustainability improvement might be enough to satisfy such a goal (Irwin 
\& Spira, 1997). For example, consumers who want to "do the right thing" may be morally satisfied in a similar way regardless of whether their purchase features one sustainability improvement or several.

Second, sustainability attributes are often inferred to require some degree of trade-off on personal benefits such as higher prices (Luchs et al., 2010; Torelli, Monga, \& Kaikati, 2012). A single sustainability feature may not considerably threaten these self-oriented motivations. However, when additional sustainable design strategies are incorporated into the design, consumers may infer more strongly about such perceived sacrifices. Particularly when sustainability becomes a central part of the design (Gershoff \& Frels, 2015), this may lead consumers to more strongly infer that the design has had to sacrifice elsewhere. Thus, the following hypothesis is considered:

H4: Multiple sustainable design strategies lead to diminishing returns such that, in general, each additional sustainable design strategy (beyond the first) leads to a diminishing increase in consumer purchase intentions and willingness to pay.

Second, it is hypothesized that these effects occur through the two distinct processes related to moral satisfaction and consumer inferences:

H5a: Multiple sustainable design strategies will lead to diminishing increases in terms of consumers' moral satisfaction.

H5b: Consumer moral satisfaction mediates the effect of design strategies on purchase intentions (through perceived sustainability).

H6: Multiple sustainable design strategies will lead to stronger inferences about trade-offs with functionality, behavioral and financial costs, compared to using single strategies. 


\subsection{Materials \& Methods}

\subsubsection{Conceptual model \& study overview}

Figure 3.1 displays the conceptual model which displays the hypotheses and relations between the proposed constructs. The hypotheses are tested in two experimental studies. The aim of Study I is to test $\mathrm{H} 1-\mathrm{H} 3$ by investigating whether consumers perceive a packaging as more or less sustainable depending on whether a circular (biological or technical) or linear approach is taken to redesign the package, (2) to consider whether this mediates effects on purchase intentions, and (3) to test the inference-making process. The second study expands upon Study I by investigating the effects of using multiple sustainable design strategies simultaneously, and by also measuring moral satisfaction (i.e., $\mathrm{H} 4-\mathrm{H} 6$ ). Additionally, Study II seeks to replicate results from Study I in a between-subjects setting, using a larger consumer sample, a different product and more explicitly measuring perceived trade-offs. 


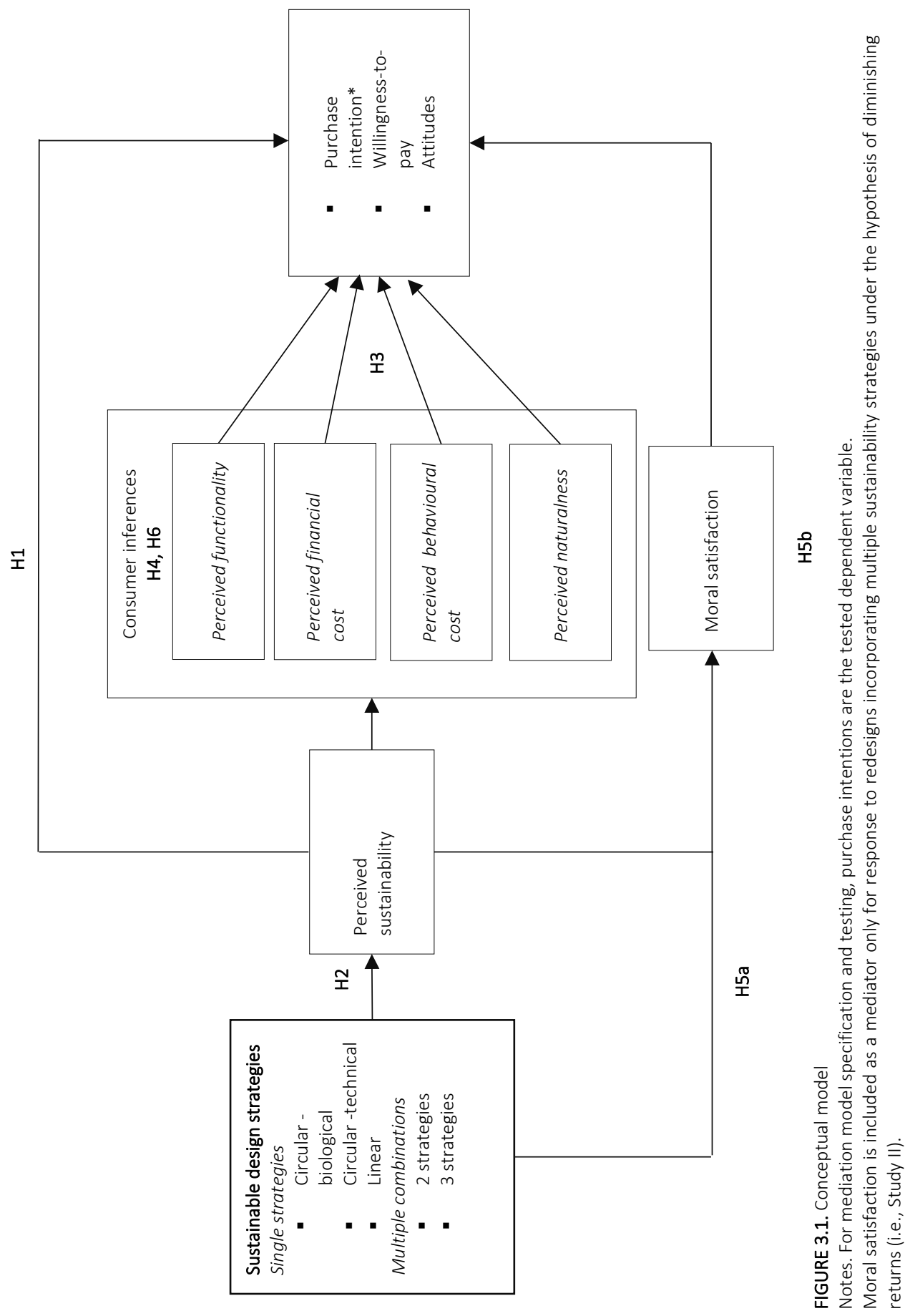




\subsubsection{Methodology}

\section{Study designs \& respondents}

Study I used a 3 (sustainable packaging design strategy: circular biological design, circular technical design, linear design) $\times 2$ (life phase impact: pre-consumer, postconsumer) within-subjects experimental design. Thus, each participant saw all six possible combinations of design strategy and life phase impact, randomized in order. Since the distinction between the pre- and post-consumer sustainability impacts and its interactions with sustainable design strategies did not lead to significant differences on any outcome and mediator variables, therefore results of this factor are not discussed further.

Study II aimed to test combinations of strategies, therefore it followed a 2 (linear design strategy: material reduction present/absent) $\times 2$ (circular technical design strategy: recyclability present/absent) x 2 (circular biological design strategy: biologically renewable sourcing present/absent) between-subjects design. Thus, each participant in Study II only saw one variant of the stimulus. Since the distinction between pre- and post-consumer sustainability impacts did not have any significant effects in Study I, this factor was not varied in Study II.

Participants consisted of convenience samples recruited from the Qualtrics research panel. Participants were recruited separately for each study through e-mail invitations, and received a small financial compensation for participating. Consumers aged 18 to 65 were eligible to participate, corresponding to the age range of the vast majority of the Dutch working populace. No other quota were enforced. For Study I, 90 Dutch consumers ( $M_{\text {age }}=34.54, \mathrm{SD}_{\text {age }}=12.55,66.7 \%$ male) participated. Their education levels varied as follows (based on the Dutch census classification): $10 \%$ had a low education level (primary education or a lower secondary/vocational education), $36.7 \%$ had a medium education level (vocational degree or advanced secondary education) and $53.3 \%$ had a high education level (bachelor's degree or higher). For Study II, 643 consumers were recruited (Mage $=35.7, \mathrm{SD}_{\text {age }}=13.11,59.7 \%$ male). Education levels varied as follows: $17.4 \%$ had a low education level, $44.7 \%$ had a medium education level, and $38 \%$ had a high education level. 


\subsubsection{Stimuli}

Sets of stimuli were created for Study I and Study II separately. For Study I, a communication message from a company was created in the form of a corporate web page article (for an example, see Figure 3.2a). The company stated to currently use predominantly conventional PET (polyethylene terephthalate) bottles. Plastic bottles were chosen as they are commonly used and may be realistically subjected to any of the redesign strategies under consideration. Factors were manipulated by providing descriptions of the redesigns combined with general descriptions pertaining to the circular/linear distinction and the pre- or post-consumer distinction (Appendix 3.1.). The linear-circular distinction was also highlighted by an icon. No visual imagery of packaging designs was given to avoid their potential effects. To avoid possible effects of company/brand name, participants were also told that, for purposes of the study, the company's name was censored. These communication messages were pretested among a convenience sample of 38 students who rated the stimuli on three semantic-differential items that described a circular vs. linear packaging design approach on each scale end (e.g., "this packaging is [not] part of a cycle of materials"). For the circular conditions, they also rated three items to distinguish between technical and biological cycles (e.g., "this packaging is based on an organic (artificial) stream of materials"). Results demonstrated that the communication messages were interpreted in line with the various redesign strategies and life phases, and that they were sufficiently distinctive.

For Study II, pictures that represented a web-shop page for a shower gel product were created to represent a more purchase-oriented scenario (Figure 3.2b). All pictures contained the same general information about the shower gel. A visual mock-up depiction of the shower gel was created by merging several images of realworld shower gels, and then pixelating them. This was done to control for potential effects of packaging appearance while maintaining a realistic stimulus appearance. Brand name and price were similarly blurred out, and participants were told this was done for the purpose of the research.

Manipulations included a different sentence (for each sustainability strategy): "Biologically renewable. This packaging is based on sugarcane extracts - a completely biologically renewable resource" (circular biological); "Optimally recyclable. This packaging will be $100 \%$ recycled. By doing so, it is transformed into new shower gel packaging" (circular technical); or "Reduced material usage. This packaging is produced using a reduced amount of plastic materials" (linear). For the 
conditions including two or all three strategies, multiple descriptions were displayed in sequence. The order of presentation of these descriptions was counterbalanced within each condition.

\section{Sustainable packaging}

Our aim

wants to package in a more sustainable way.

We want to make sure that our packaging has a lowered environmental burden after disposal, and during the waste management process.

How do we do it?

Our current PET plastic bottles will be replaced by plastic bottles designed for recyclability.

This means that new plastic bottles can be created from this material (after it has been recycled)

By effectively using the means at our disposal, we want to work toward a

closed loop of our packaging.

FIGURE 3.2a. Study I stimulus example of the post-consumer, technical circular (recycling) redesign. Company name is censored. 
Home > Bath \& Shower > Shower gels

\section{Shower gel fresh \& cleansing $(250 \mathrm{ml})$}

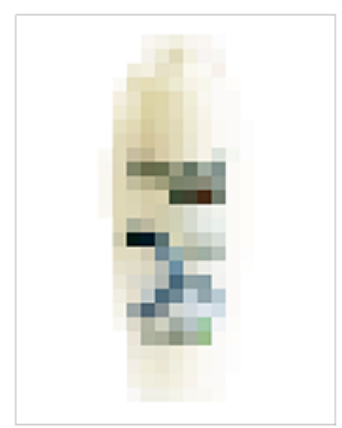

๑๑ $\odot$
Brand: | Size: $250 \mathrm{ml}$ | In stock

Features:

- Shower gel for daily use

- Pleasant and fresh scent - Hydrating effect

\section{New packaging!}

\section{BIOLOGICALLY RENEWABLE}

This packaging is based on sugarcane extracts - a completely biologically renewable resource

\section{OPTIMALLY RECYCLABLE}

This packaging will be $100 \%$ recycled. By doing so, it is transformed

into new shower gel packaging

REDUCED MATERIAL USAGE

This packaging is produced using a reduced amount of plastic materials

\section{Eren $\quad$ Add to cart +}

FIGURE 3.2b. Study II stimulus example including all three redesign strategies. Brand name, price as well as a depiction of the product were pixelated to prevent potential effects. Note. Translated versions are displayed here; original images were in Dutch.

\subsubsection{Procedure and measures}

In both studies participants were told that a company was considering to develop more sustainable packaging as a replacement for their current packaging, and that this company was interested in consumer opinions about its initiative. For Study I (beverages) PET bottles were stated to be the current packaging, while for Study II (shower gels) participants were told that it consisted of HDPE flasks based on crude oils. For Study II, it was stated that the current packaging was not biodegradable or highly recyclable and that they were incinerated after disposal. In the actual Dutch situation, end-of-life fates for PE non-beverage bottles are such that $56 \%$ are 
incinerated rather than recycled ${ }^{2}$ (Brouwer et al., 2018), thus the disposal descriptions provided were deemed relevant to the real-world situation. Study II also included a control condition where participants rated the baseline (current) packaging (i.e., no sustainability redesigns made).

In both studies, participants then viewed the communications message (Study I) or web-shop (Study II), and then answered the questions. Study I included scales for perceived sustainability, functionality, behavioral- and financial costs, naturalness, attitude towards the packaging and purchase intentions (Appendix 3.2.). Study II additionally included the measurement of moral satisfaction (Appendix 3.3.). In Study II, willingness-to-pay was also considered by asking participants their willingness to pay a premium for the new packaging ( $a € 2.79$ reference price for the conventional shower gel was provided). If they selected 'yes', they were instructed to denote the maximum price they were willing to pay for the packaged product.

\subsubsection{Data analysis}

\section{Study I}

Repeated-measures ANOVAs with post-hoc testing (Sidak-corrected values) were conducted to test the influence of the sustainable design strategies on perceived sustainability, attitudes and purchase intentions ( $\mathrm{H} 2)$. Furthermore, to test $\mathrm{H} 1 \& \mathrm{H} 3$, mediation analysis was conducted using the PROCESS macro in SPSS (Hayes \& Preacher, 2014) with 95\% confidence intervals based on 10000 bootstrap samples. Mediation analysis is a regression-based technique which statistically models a causal sequence in which independent (exogenous) variables affect the dependent variable indirectly through intervening mediator variables. Dummies were specified for the packaging designs as independent variables (biological circular design as the reference).

\section{Study //}

Analyses were first conducted to test $\mathrm{H} 1 \& \mathrm{H} 2$. Hypothesis 1 was tested by regressing purchase intentions on perceived sustainability. To test Hypothesis 2, ANOVAs were conducted for perceived sustainability (as well as attitudes and purchase intentions) using the three conditions that included only one strategy, i.e. either biological, technical or linear (equivalent to Study I).

\footnotetext{
${ }^{2}$ Landfilling of such plastics does not occur anymore in the Dutch situation.
} 
To test the hypothesized diminishing returns effects ( $\mathrm{H} 4$ to $\mathrm{H} 6$ ), two dummies were created: one for picking up the generic (i.e., regardless of the particular strategy) effect from 'none-to-one' strategy (assigning the value 0 to the control condition and the value 1 to all other conditions), and the second dummy for the generic linear increase from 'one-to-three' sustainable design strategies (assigning the value 0 to the control condition and the three conditions with only one strategy, the value 1 to the three conditions with two strategies, and the value 2 to the condition with three strategies). A series of nested regression models were conducted where the first model included only the 'none-to-one' dummy (which, while being alone in the model, picks up the difference between the control condition and all other conditions), where the second model also included the 'oneto-three' dummy for the generic linear effect when going from one to three strategies, the third model included additional dummy variables accommodating for the (possibly different) main effects of the biological circular, technical circular and linear strategies, and the fourth model included dummy variables for any further interaction effects of the three strategies. The third and fourth model were added to investigate whether, in addition to a generic increase from none-to-one strategy and a generic linear increase from one-to-three strategies, there was any additional generic (e.g., curvilinear) effect or any strategy-specific effect.

To further test effects of diminishing returns on willingness to pay a premium likelihood ('yes' or 'no') and willingness to pay amounts (for participants who answered 'yes' in the prior question), a binomial logistic regression and linear regression were respectively conducted, testing the differences between one, two and three integrated sustainable design strategies. Last, to test the hypothesized mediation model (H3, H5 \& H6), the PROCESS macro (Hayes, 2006) with 95\% confidence intervals based on 10000 bootstrap samples was utilized.

\subsection{Results}

\subsubsection{Results of Study I}

Main effects of sustainable design strategy on perceived sustainability, purchase intentions and attitudes

Results of ANOVAs (see Table 3.1) displayed significant main effects of the sustainable design strategy on perceived sustainability, attitude, and purchase intention. Circular design strategies were indeed perceived to be more sustainable than the linear design strategy $(\mathrm{H} 2)$. Results also indicated that biological solutions 
were perceived as more sustainable than their technical counterparts. Additionally, participants held the most positive attitudes about the circular designs and were less positive about the linear designs. The pattern for purchase intentions was similar although less pronounced, as the difference between the technical circular and linear designs was not significant.

TABLE 3.1. Study I Repeated-Measures ANOVAs of design strategy conditions

\begin{tabular}{|c|c|c|c|}
\hline & Dependent va & & \\
\hline & $\begin{array}{l}\text { Perceived } \\
\text { sustainability }\end{array}$ & Attitudes & $\begin{array}{l}\text { Purchase } \\
\text { intention }\end{array}$ \\
\hline \multicolumn{4}{|l|}{ Model statistics } \\
\hline df (Huyn-Feldt corrected) & $1.65,146.43$ & $1.72,153.67$ & $1.76,151$ \\
\hline$F$ & $20.44^{* * *}$ & $8.22^{* * *}$ & $4.89^{*}$ \\
\hline$\eta^{2} p$ & 0.19 & 0.09 & 0.05 \\
\hline \multicolumn{4}{|l|}{ Means } \\
\hline Biological circular design & $5.18^{\mathrm{a}}$ & $5.41^{\mathrm{a}}$ & $5.13^{\mathrm{a}}$ \\
\hline Technical circular design & $4.77^{\mathrm{b}}$ & $5.3^{\mathrm{a}}$ & $4.98^{\mathrm{a}, \mathrm{b}}$ \\
\hline Linear design & $4.42^{c}$ & $4.77^{\mathrm{b}}$ & $4.78^{b}$ \\
\hline
\end{tabular}

Notes. Superscripts $a, b$, denote statistically significant pairwise differences at the $\alpha=.05$ level, using post-hoc tests (Sidak-corrected)

$p<.05,{ }^{* * *} p<.001$

\section{Mediation through perceived sustainability}

Results of mediation analysis (Table 3.2) showed that there was a significant effect of perceived sustainability on purchase intention $(\beta=.56, p<.001)$, in support of $\mathrm{H} 1$. Moreover, indirect effects of the sustainable design strategies through perceived sustainability were significant $(\beta=.03, \mathrm{Cl} 95[.01, .05])$, and direct effects were not significant $(F(2,536)=.28, p>.05)$. Thus, the effect of the sustainable design strategies on purchase intentions was fully mediated by perceived sustainability.

\section{Mediation of the effect of perceived sustainability through perceived functionality, naturalness, financial and behavioral costs}

Next, it was tested whether the effects of perceived sustainability on purchase intention were mediated by inferences of perceived functionality, naturalness, financial costs and behavioral costs (H3). Regression coefficients are displayed in Figure 3.3. Bootstrap confidence intervals showed that indirect effects occurred through all proposed mediators: functionality $(\beta=.08, \mathrm{C} 195[.05, .12])$, naturalness ( $\beta$ $=.09, \mathrm{Cl} 95[.03, .16])$, financial costs $(\beta=-.03, \mathrm{Cl} 195[-.06,-.002])$ and behavioral costs $(\beta=.03, \mathrm{Cl95}[.01, .06])$. A significant direct effect of perceived sustainability $(\beta=.38$, 
Cl95[.29, .47]) was also found, indicating partial mediation. The model supports the expectations with two exceptions. First, sustainability contributed positively to perceived functionality, where a negative contribution was expected. Second, higher perceived sustainability led to higher perceived behavioral costs, but in contrast to predictions, it appears that these behavioral costs positively contributed to purchase intentions. Thus, $\mathrm{H} 3$ is partially supported.

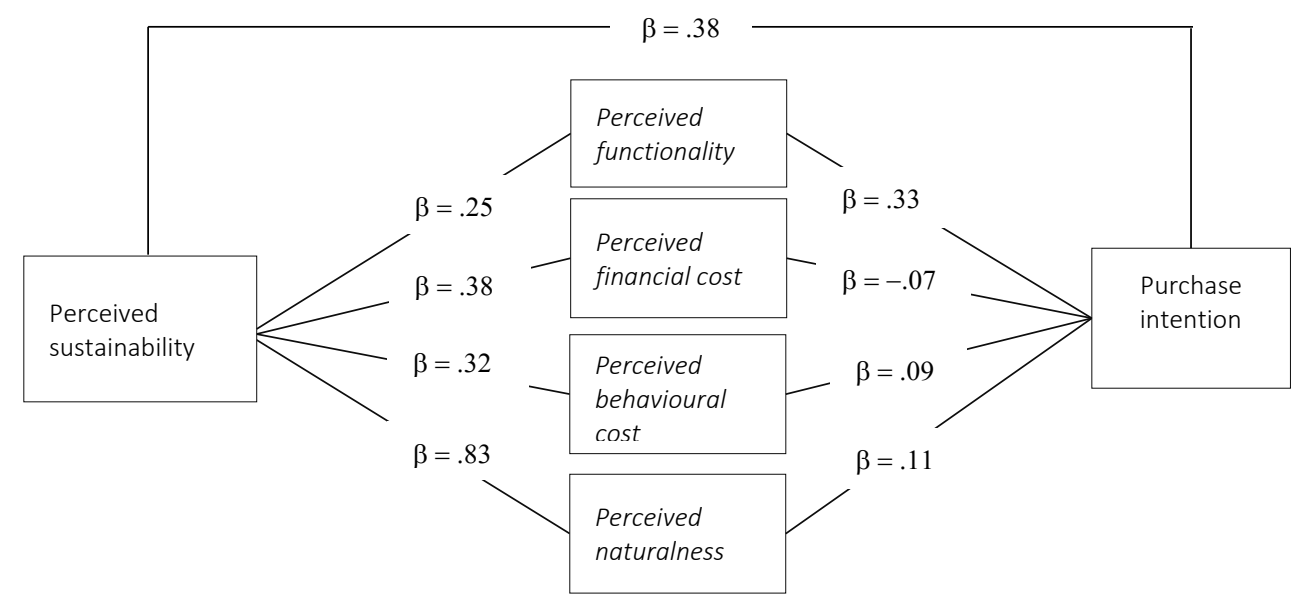

FIGURE 3.3. Study I regression analysis coefficients

Note. All coefficients significant at least at the .05 level 
CHAPTER 3

TABLE 3.2. Study I Mediation model on purchase intention through perceived sustainability

\begin{tabular}{|c|c|c|c|c|}
\hline \multirow[t]{2}{*}{ Outcome } & \multirow{2}{*}{$\begin{array}{l}\text { Perceived } \\
\text { Sustainability } \\
\text { Coefficient (SE) }\end{array}$} & \multicolumn{3}{|c|}{ Purchase Intention } \\
\hline & & $\begin{array}{l}\text { Total effects } \\
\text { Coefficient (SE) }\end{array}$ & $\begin{array}{l}\text { Direct effects } \\
\text { Coefficient (SE) }\end{array}$ & $\begin{array}{l}\text { Indirect effects Coefficient } \\
(S E)\end{array}$ \\
\hline Constant & $\begin{array}{l}4.79^{* * *} \\
(.06)\end{array}$ & $\begin{array}{l}.50^{* * *} \\
(.06)\end{array}$ & $\begin{array}{l}2.27^{* * *} \\
(.16)\end{array}$ & \\
\hline Linear design $\left(D_{1}\right)$ & $\begin{array}{l}-.37^{*} \\
(.08)\end{array}$ & $\begin{array}{l}-.19^{*} \\
(.08)\end{array}$ & $\begin{array}{l}-.03^{\text {n.s. }} \\
(.07)\end{array}$ & $\begin{array}{l}-.21^{*} \\
(.05)\end{array}$ \\
\hline $\begin{array}{l}\text { Technical circular design } \\
\left(D_{2}\right) \\
\text { Perceived Sustainability }\end{array}$ & $\begin{array}{l}-.02^{\text {n.s. }} \\
(.08)\end{array}$ & $\begin{array}{l}.02^{\text {n.s. }} \\
(.08)\end{array}$ & $\begin{array}{l}.02^{\text {n.s. }} \\
(.07) \\
.56^{* * *} \\
(.03)\end{array}$ & $\begin{array}{l}-.01^{\text {n.s. }} \\
(.05)\end{array}$ \\
\hline Overall model F & & $\begin{array}{l}F(2,537)= \\
3.40^{*}\end{array}$ & $\begin{array}{l}F(2,536)=.28 \\
\text { n.s. }\end{array}$ & $\begin{array}{l}.03^{*} \\
(.011)\end{array}$ \\
\hline
\end{tabular}

$D_{1} \& D_{2}$ relative to biological circular packaging design

${ }^{*} p<.05$

${ }^{* * *} p<.001$

TABLE 3.3. Study II ANOVAs of singular design strategy conditions

\begin{tabular}{llll}
\hline \multicolumn{3}{c}{ Dependent variable } & \\
\hline & $\begin{array}{l}\text { Perceived } \\
\text { sustainability }\end{array}$ & Attitudes & $\begin{array}{l}\text { Purchase } \\
\text { intention }\end{array}$ \\
\cline { 2 - 4 } Model statistics & $3.32^{*}$ & $3.58^{*}$ & $1.39^{\text {n.s. }}$ \\
$F(2,235)$ & 0.03 & 0.03 & - \\
$\eta^{2}$ & & & \\
Means & $68.97^{\mathrm{a}}$ & $5.36^{\mathrm{a}}$ & $4.34^{\mathrm{a}}$ \\
Biological circular design & $67.51^{\mathrm{a}, \mathrm{b}}$ & $5.02^{\mathrm{a}, \mathrm{b}}$ & $4.08^{\mathrm{a}}$ \\
Technical circular design & $61.14^{\mathrm{b}}$ & $4.77^{\mathrm{b}}$ & $4^{\mathrm{a}}$ \\
\hline Linear design & & & \\
\hline
\end{tabular}

Notes. Superscripts $a, b$, denote statistically significant pairwise

differences at the $\alpha=.05$ level using post-hoc tests (Tukey's b).

* $p<.05$. 


\subsubsection{Results of Study /I}

\section{Main effects of perceived sustainability and (combinations of) sustainable design strategies}

First, a linear regression of perceived sustainability on purchase intentions showed that perceived sustainability had a significant effect on purchase intentions ( $\beta=.03, p<.001, R^{2}=.18$ ), supporting $\mathrm{H} 1$. Results for $\mathrm{H} 2$ (Table 3.3) showed that the pattern for perceived sustainability was in line with the hypothesis. Particularly the biological circular design was consistently perceived as more sustainable than the linear redesign, while the technical circular design was positioned in the middle (and was not significantly different from either alternative). The analyses were also repeated for the other mediating constructs (perceived naturalness, functionality, financial and behavioral costs, and moral satisfaction), but no significant differences were found.

\section{Sustainable design strategies and consumer-perceived diminishing returns}

Next, H4 was tested which states that simultaneously applying multiple sustainable design strategies should lead to diminishing returns. Regression results showed significant differences between the control condition (i.e., no redesign) and conditions containing one redesign strategy $\left(p^{\prime} s<.05\right)$. The linear trend when going from one to three strategies was only significant for perceived sustainability $(p<$ $.05)$, and no other construct. Thus, the presence of any additional sustainable redesign strategy (in addition to the first) did not lead to significant linear gains, except for the packaging's perceived sustainability. A contrast test showed that gains in perceived sustainability resulting from the incorporation of multiple strategies were significantly lower than the initial gain from (any) first sustainable redesign strategy that was applied, relative to the packaging without any change $\left(\beta_{\text {none-to-one- }}\right.$ strategy $=23.74$ vs. $\left.\beta_{\text {one-to-three-strategies }}=3.07 ; p<.05\right)^{3}$.

Results from logistic regression on consumers' willingness to pay a premium (yes/no) likelihood (Table 3.4) showed that the model significantly improved when including the dummy variable from 'none-to-one' strategy, predicting that consumers would be willing to pay a premium for one or more strategies $(62.7 \%$ hitrate). The following addition of the generic linear effect (i.e., more than one strategy)

\footnotetext{
${ }^{3}$ These diminishing returns were not caused by level-effects, and the effects were similar regardless of specific combinations of multiple sustainable design strategies.
} 
again did not significantly improve the model, supporting $\mathrm{H} 4$. The participants who were ready to pay a premium, on average, wanted to pay a $€ 0.58$ extra ( $€ 2.79$ reference price). The linear regression results revealed once more that the generic linear effect did not have a significant effect on WTP amounts $\left(F_{\text {change }}(1,209)=0.03\right.$, $p=.85$ ). Thus, the premium amount did not significantly differ between packaging featuring one, two, or three sustainable design strategies, supporting $\mathrm{H} 4$.

TABLE 3.4. Results of binomial logistic regression on WTP Premium Likelihood

\begin{tabular}{llllll}
\hline & $\boldsymbol{\beta}$ & $\mathrm{SE}$ & Wald & $\boldsymbol{d}$ & $\boldsymbol{p}$ \\
\hline Increase from 'none-to-one' strategy (Step 0) & .52 & .09 & 35.82 & 1 & $<.001$ \\
Increase from 'one-or-more' strategies (Step 1) & -.052 & .13 & .19 & 1 & .67 \\
\hline
\end{tabular}

Note. Step 1 is the (additional) contribution of the 'one-or-more' strategies

inclusion when the 'none-to-one' strategy (Step 0) variable is also included.

The mediating process through perceived sustainability, consumer trade-off inferences and moral satisfaction.

The indirect effects of the dummy for the difference between 'none-to-one' strategy and the dummy for the linear trend from 'one-to-three' strategies were tested ${ }^{4}$. Both the effect arising from the difference between 'none-to-one' strategy and the linear effect from 'one-to-three' strategies on purchase intention were mediated by perceived sustainability (Table 3.5 , Model I). There were no significant direct effects $(p>.05)$, thus suggesting full mediation. Second, results (Table 3.5, Model II) showed that perceived naturalness and moral satisfaction increased by incorporating at least one sustainability strategy, but so did trade-off inferences of increased financial and behavioral costs and functionality. However, only the naturalness perceptions and moral satisfaction significantly affected purchase intentions, and both of these mediated the effect of using a sustainability strategy on purchase intentions. Third, bootstrapping results (Table 3.5, Model III) tests $\mathrm{H} 5$ and simultaneously provides a test for H3. Results showed significant indirect effects of perceived sustainability on purchase intentions only through moral satisfaction, providing support only for $\mathrm{H} 5$. A significant direct effect was also found $(\beta=.02, p$ $<.001)$. Last, to test the full individual paths according the theoretical model, serial mediation models were carried out, specifying the dummies as the independents and perceived sustainability as the initial mediator. The second mediator alternated

${ }^{4}$ Confidence intervals for both predictors were obtained by running PROCESS twice, interchangeably specifying one dummy variable as predictor and the other as a covariate. 
between perceived naturalness, functionality, financial costs, behavioral costs, and moral satisfaction. Bootstrapping for both the single strategy and multiple strategy outcomes results showed that indirect effects for the full pathway were significant only for moral satisfaction $(\mathrm{H} 5)\left(\beta_{\text {none-to-one }}=.17, S E=.56, \mathrm{Cl}\right.$. $5[.10, .29] ; \beta_{\text {one-to-three }}=$ $.02, S E=.01, \mathrm{Cl} 95[.01, .05])$ and not for any of the inferences $(\mathrm{H} 6)$. Thus, the effects of (multiple) sustainable design strategies on consumers' purchase intentions were mediated through sustainability perceptions, and this effect of sustainability perceptions on purchase intentions, in turn, was mediated by consumers' moral satisfaction $(\mathrm{H} 5)$ but not through stronger inferred trade-offs $(\mathrm{H} 6)$.

TABLE 3.5. Study II mediation models

\begin{tabular}{|c|c|c|c|c|c|}
\hline \multicolumn{2}{|l|}{ Effect of $X$ on $M$} & \multicolumn{3}{|c|}{ Effect of $M$ on $Y$} & \multirow{2}{*}{$\begin{array}{l}\text { Mediation testing } \\
\text { Indirect effects (SE) }\end{array}$} \\
\hline $\mathrm{X}$ & $\mathrm{M}$ & Coefficients (SE) & $\mathrm{Y}$ & Coefficients (SE) & \\
\hline \multicolumn{6}{|l|}{ Modell } \\
\hline $\begin{array}{l}\text { Zero-or-one strategy } \\
\text { (dummy) }\end{array}$ & $\begin{array}{l}\text { Perceived } \\
\text { sustainability }\end{array}$ & $23.74(2.62)^{* * *}$ & $\begin{array}{l}\text { Purchase } \\
\text { intention }\end{array}$ & $.03(.003)^{* * *}$ & $.64(.11)$ \\
\hline $\begin{array}{l}\text { One-or-more } \\
\text { strategies (dummy) }\end{array}$ & $\begin{array}{l}\text { Perceived } \\
\text { sustainability }\end{array}$ & $3.07(1.19)^{*}$ & & - & $.08(.03)$ \\
\hline \multicolumn{6}{|l|}{ Model II } \\
\hline \multirow[t]{5}{*}{$\begin{array}{l}\text { Zero-or-one strategy } \\
\text { (dummy) }\end{array}$} & $\begin{array}{l}\text { Perceived } \\
\text { naturalness }\end{array}$ & $1.70(.16)^{* * *}$ & $\begin{array}{l}\text { Purchase } \\
\text { intention }\end{array}$ & $.11(.04)^{*}$ & $.2(.09)$ \\
\hline & $\begin{array}{l}\text { Perceived } \\
\text { functionality }\end{array}$ & $.37(.13)^{*}$ & & n.s. & n.s. \\
\hline & $\begin{array}{l}\text { Perceived } \\
\text { financial cost }\end{array}$ & $.69(.17)^{* * *}$ & & n.s. & n.s. \\
\hline & $\begin{array}{l}\text { Perceived } \\
\text { behavioral } \\
\text { cost }\end{array}$ & $.31(.13)^{*}$ & & n.s. & n.s. \\
\hline & $\begin{array}{l}\text { Moral } \\
\text { satisfaction }\end{array}$ & $20.34(2.29)^{* * *}$ & & $.02(.003)^{* * *}$ & $.5(.1)$ \\
\hline \multicolumn{6}{|l|}{ Model III } \\
\hline \multirow[t]{5}{*}{$\begin{array}{l}\text { Perceived } \\
\text { sustainability }\end{array}$} & $\begin{array}{l}\text { Perceived } \\
\text { naturalness }\end{array}$ & $2.75(.16)^{* * *}$ & $\begin{array}{l}\text { Purchase } \\
\text { intention }\end{array}$ & n.s. & n.s. \\
\hline & $\begin{array}{l}\text { Perceived } \\
\text { functionality }\end{array}$ & n.s. & & n.s. & n.s. \\
\hline & $\begin{array}{l}\text { Perceived } \\
\text { financial cost }\end{array}$ & $.01(.003)^{* * *}$ & & n.s. & n.s. \\
\hline & $\begin{array}{l}\text { Perceived } \\
\text { behavioral } \\
\text { cost }\end{array}$ & n.s. & & n.s. & n.s. \\
\hline & $\begin{array}{l}\text { Moral } \\
\text { satisfaction }\end{array}$ & $.46(.03)^{* * *}$ & & $.02(.003)^{* * *}$ & $.01(.002)$ \\
\hline
\end{tabular}

Notes. Indirect effects significance based on bootstrapping results with $95 \%$ confidence intervals \& 10000 iterations. $* p<.05, * * * p<.001$ 


\subsection{Discussion}

\subsubsection{Theoretical implications}

The current research presents two studies to demonstrate how the usage of sustainable design strategies affects consumer response. In doing so, the findings advance the current understanding in several ways. First, in line with previous literature (e.g., Magnier et al., 2016; Prakash \& Pathak, 2017), findings show that increased perceived sustainability positively contributes to purchase intentions and attitudes and also show differences between design strategies. Particularly, the biological circular redesign is perceived as most sustainable, while the linear strategy is perceived least sustainable. Higher perceived sustainability, as a consequence of redesign, overall led to inferences of higher perceived naturalness which in turn mediates the effects on purchase intentions, in line with findings of Magnier et al. (2016). Potential negative inferences of lower perceived functionality and higher expected behavioral and financial costs were inconsistent. Packaging redesign for sustainability is thus most likely to elicit a positive consumer response.

Second, in line with the hypothesis of diminishing returns, whereas integrating any sustainable redesign strategy with packaging increases consumers' purchase intentions and their perception of sustainability (relative to the baseline packaging), at the same time additional sustainable design strategies beyond the first do not significantly improve consumers' purchase intentions or willingness-to-pay, corresponding with strong diminishing returns. For perceived sustainability, an effect of subadditivity occurs in which the integration of a second or third sustainability alteration still contributes positively, but to a reduced extent (cf. Kahneman \& Knetsch, 1992; Irwin \& Spira, 1997).

Third, perceived sustainability also contributed to consumers' moral satisfaction which is identified as another important mediator in determining consumer purchase likelihood. The current research shows that consumers may achieve a sufficient degree of moral satisfaction from any (single) sustainability strategy that has been applied to the design and that additional alterations do not make consumers feel (much) more morally satisfied. The "warm glow" (Andreoni, 1990) pathway is supported, suggesting that the relationship between consumers' purchase intention and redesigns using multiple sustainable design strategies is primarily driven by moral satisfaction perceptions rather than consumers making stronger trade-off inferences. 
Effects of sustainable design strategies

\subsubsection{Managerial implications}

The current research offers several important implications for decision-makers in the field of sustainable packaging and/or product marketing. Consumers may consider packaging redesigned through circular strategies (particularly within the biological cycle) as more sustainable than linear designs. However, any improvement is much preferred by consumers over the baseline packaging, and this initial step toward a more sustainable or circular design is more important than any further improvements. A prerequisite for this is that these redesigns for sustainability are explicitly communicated, since not all changes may be visible to consumers.

Furthermore, while more substantive redesigns (using multiple strategies) may improve the overall environmental footprint of packaging, consumers perceive these as only marginally more sustainable compared to single-strategy redesigns, implying that a more thorough redesign may not automatically lead to better consumer response. Thus, producers could initially focus on providing sustainable packaging for a wide range of products before providing packaging designs that offer more profound solutions (i.e., that combine multiple sustainable design strategies), and communicate the latter as a separate sustainable redesign. Additionally, to make the environmental impact of sustainable design strategies salient to consumers, environmental footprint indicators based on more objective environmental impact assessment (such as life-cycle assessment) could be developed to provide guidance at the point-of-purchase (Lupiáñez-Villanueva, Tornese, Veltri, \& Gaskell, 2018).

\subsubsection{Limitations and future research}

Finally, some limitations and caveats of the current research should be noted, also as a basis for future research. First, it should be noted that this chapter does not necessarily consider the effect of diminishing returns as a psychological anomaly (e.g., Kahneman \& Knetsch, 1992; Irwin \& Spira, 1997). For example, from an objective environmental impact perspective, a material reduction of a more sustainable biologically renewable material may indeed (by itself) lead to a smaller absolute environmental benefit than a similar reduction for a less sustainable material. It is thus not necessarily anomalous (or incorrect) that consumers infer a similar relationship based on their own lay-theories. Future research could test the validity of such consumer inferences for a variety of packaging redesign initiatives, relative to more objective measurements. 
Second, future research could investigate additional ways in which redesigns can contribute to environmental improvements. The current studies focused on biodegradability, recyclability and lightweighting of packaging, but these are not an exhaustive representation of the spectrum of potential redesign options. For example, packaging reusability can support environmental objectives for both linear and circular systems (Bocken et al., 2016), and in some cases packaging could potentially be eliminated altogether. Specific contexts could also elicit different responses, for example lightweighting could be considered more effective when the base packaging is excessively (vs. appropriately) packaged, following findings in prior research (Seo et al., 2016).

Last, while the samples consist of Dutch consumers of varying ages and educational backgrounds, the samples were not explicitly aimed to be representative of the Dutch population. The samples contained a relatively high proportion of young males skewed toward higher education levels, and did not include consumers aged $65+$. Caution should therefore be taken when generalizing the results towards Western populations. 


\subsection{Conclusions}

The current research explored consumer response toward three sustainable (packaging) design strategies, individually and when implemented in combination. The results show that compared to conventional (plastic) packaging consumers respond favorably to more sustainable packaging redesigns, but particularly to biological circular improvements and less so to linear ones. Such effects are shown to be mainly driven by a higher perceived sustainability, which in turn was associated with greater perceived naturalness and moral satisfaction. A final important conclusion is that the combinations of different sustainable design strategies in overall packaging design follow the principle of diminishing returns. Rather than adding up linearly, any additional design approach leads to minimal impact compared to the first strategy implemented. Consumers show largely insensitive to differences between redesigns with two or three sustainability strategies. The present study shows that this is due to the diminishing returns in consumers perceptive moral satisfaction after the first sustainable design implementation. A possible managerial implication of this that it is more effective to broaden individual sustainable design strategies across the whole of the product portfolio, rather than deepening it by combining sustainable designing into a limited range of the product portfolio. Compared to conventional packaging, any sustainable redesign increases purchase intentions. 


\section{CHAPTER 3}

APPENDIX 3.1. Study I - Stimulus descriptions

\begin{tabular}{|c|c|c|}
\hline General Circular description \& icon & \multicolumn{2}{|c|}{$\begin{array}{l}\text { By effectively using our resources, we want to work toward a closed loop of } \\
\text { packaging. }\end{array}$} \\
\hline \multirow[t]{3}{*}{ General Linear description \& icon } & \multirow{2}{*}{\multicolumn{2}{|c|}{$\begin{array}{l}\text { By efficiently using our resources we minimize the environmental burden of } \\
\text { our packaging. }\end{array}$}} \\
\hline & & \\
\hline & Pre-consumer & Post-consumer \\
\hline General sentence & $\begin{array}{l}\text { We want to make sure that our } \\
\text { packaging has a lowered } \\
\text { environmental burden at the } \\
\text { sourcing of raw materials and during } \\
\text { production }\end{array}$ & $\begin{array}{l}\text { We want to make sure that our } \\
\text { packaging has a lowered } \\
\text { environmental burden after disposal, } \\
\text { and during the waste management } \\
\text { process }\end{array}$ \\
\hline Circular - Biological & $\begin{array}{l}\text { Our current PET plastic bottles will be } \\
\text { replaced by plastic bottles based on } \\
\text { sugarcane. This means that they } \\
\text { consist of renewable material. }\end{array}$ & $\begin{array}{l}\text { Our current PET plastic bottles will be } \\
\text { replaced by plastic bottles based on } \\
\text { sugarcane. This means that they are } \\
\text { biologically degradable. }\end{array}$ \\
\hline Circular - Technical & $\begin{array}{l}\text { Our current PET plastic bottles will be } \\
\text { replaced by plastic bottles designed } \\
\text { for recyclability. This means that new } \\
\text { plastic bottles can be created from } \\
\text { this material (after it has been } \\
\text { recycled). }\end{array}$ & $\begin{array}{l}\text { Our current PET plastic bottles will be } \\
\text { replaced by plastic bottles made of } \\
\text { recycled materials. This means that } \\
\text { they are made of recycled plastic } \\
\text { waste. }\end{array}$ \\
\hline Linear & $\begin{array}{l}\text { Our current PET plastic bottles will be } \\
\text { replaced by plastic bottles that utilize } \\
\text { fewer materials. This means that the } \\
\text { required resources per bottle are } \\
\text { lower. }\end{array}$ & $\begin{array}{l}\text { Our current PET plastic bottles will be } \\
\text { replaced by plastic bottles that utilize } \\
\text { fewer materials. This means that less } \\
\text { plastic waste is generated. }\end{array}$ \\
\hline
\end{tabular}


APPENDIX 3.2. Study I-Scale measurements

\begin{tabular}{|c|c|c|c|c|}
\hline Construct & Response Scale & Item(s) & $\alpha^{\prime} s$ & Scale/item origins \\
\hline $\begin{array}{l}\text { Perceived } \\
\text { sustainability }\end{array}$ & $\begin{array}{l}\text { 7-point } \\
\text { (Completely } \\
\text { (dis)agree) }\end{array}$ & $\begin{array}{l}\text {...are environmentally friendly } \\
\text {...contribute a lot to improving the } \\
\text { environment } \\
\text {...deserve to be labeled as } \\
\text { environmentally friendly }\end{array}$ & $\begin{array}{l}.88 \\
-92\end{array}$ & $\begin{array}{l}\text { Haws, Winterich, and Naylor } \\
\text { (2014), Gershoff and Frels } \\
\text { (2015) }\end{array}$ \\
\hline $\begin{array}{l}\text { Perceived } \\
\text { functionality }\end{array}$ & $\begin{array}{l}\text { 7-point } \\
\text { (Completely } \\
\text { (dis)agree) }\end{array}$ & $\begin{array}{l}\text {...function well } \\
\text {...protect the product well }\end{array}$ & $\begin{array}{l}.83 \\
- \\
.91\end{array}$ & $\begin{array}{l}\text { Kukar-Kinney and Grewal } \\
\text { (2007) }\end{array}$ \\
\hline $\begin{array}{l}\text { Perceived } \\
\text { financial costs }\end{array}$ & $\begin{array}{l}\text { 7-point } \\
\text { (Completely } \\
\text { (dis)agree) }\end{array}$ & $\begin{array}{l}\text {... will be more expensive than the } \\
\text { current PET bottles }\end{array}$ & & \\
\hline $\begin{array}{l}\text { Perceived } \\
\text { behavioral } \\
\text { costs }\end{array}$ & $\begin{array}{l}\text { 7-point } \\
\text { (Completely } \\
\text { (dis)agree) }\end{array}$ & $\begin{array}{l}\text {... will require more efforts from my side } \\
\text {...demand adjustments in my daily } \\
\text { routine }\end{array}$ & $\begin{array}{l}.83 \\
- \\
.90\end{array}$ & \\
\hline $\begin{array}{l}\text { Perceived } \\
\text { naturalness }\end{array}$ & $\begin{array}{l}\text { 7-point } \\
\text { (Completely } \\
\text { (dis)agree) }\end{array}$ & ....are natural & & Zhu and Meyers-Levy (2009) \\
\hline $\begin{array}{l}\text { Purchase } \\
\text { intentions }\end{array}$ & $\begin{array}{l}\text { 7-point } \\
\text { (Very low } \\
\text { very high) }\end{array}$ & $\begin{array}{l}\text { My willingness to purchase a product in } \\
\text { this sustainable packaging is... }\end{array}$ & & $\begin{array}{l}\text { Dodds, Monroe and Grewal } \\
\text { (1991) }\end{array}$ \\
\hline $\begin{array}{l}\text { Attitude } \\
\text { (toward } \\
\text { packaging) }\end{array}$ & $\begin{array}{l}\text { 7-point } \\
\text { (negative - } \\
\text { positive) }\end{array}$ & $\begin{array}{l}\text { What is your general evaluation of } \\
\text { these new packages? }\end{array}$ & & $\begin{array}{l}\text { Crites, Fabrigar, and Petty } \\
\text { (1994) }\end{array}$ \\
\hline
\end{tabular}

Notes. Items up to purchase intentions were prefaced with "I expect that this new packaging..." Constructs were presented in the order listed.

For reliability analyses, Spearman-Brown coefficients (split-half reliability) are reported for two-item scales, as this method leads to the most adequate and least biased scores (Eisenga et al., 2012). Cronbach's alpha's is reported for the 3-item perceived sustainability scale. Ranges of alphas are presented (across all experimental conditions). Constructs are reported in the order in which they were measured. 
CHAPTER 3

APPENDIX 3.3. Study II - Scale measurements

\begin{tabular}{|c|c|c|c|c|}
\hline Construct & Scale & Item(s) & $\alpha$ & Scale/item origins \\
\hline $\begin{array}{l}\text { Purchase } \\
\text { intentions }\end{array}$ & $\begin{array}{l}\text { 7-point scale (very low } \\
\text { - very high) }\end{array}$ & $\begin{array}{l}\text { My willingness to purchase a shower gel in this } \\
\text { packaging is... } \\
\text { The chance I would buy shower gel in this } \\
\text { packaging, if it were available is... } \\
\text { The likelihood that I would actively search for a } \\
\text { shower gel in this packaging is... }\end{array}$ & .87 & $\begin{array}{l}\text { Dodds, Monroe, and } \\
\text { Grewal (1991) }\end{array}$ \\
\hline $\begin{array}{l}\text { Attitude } \\
\text { (toward } \\
\text { packaging) }\end{array}$ & $\begin{array}{l}\text { 7-point semantic } \\
\text { differential scale: } \\
\text { "what is your general } \\
\text { evaluation of these } \\
\text { new packages?" }\end{array}$ & $\begin{array}{l}\text {...positive/negative } \\
\text {...good/bad }\end{array}$ & .93 & Crites et al. (1994) \\
\hline $\begin{array}{l}\text { Perceived } \\
\text { sustainability }\end{array}$ & $\begin{array}{l}\text { 100-point slider scale: } \\
\text { "Please indicate how } \\
\text { sustainable } \quad \text { you } \\
\text { consider } \\
\text { [new/current] } \\
\text { packaging }\end{array}$ & $\begin{array}{l}\text {...extremely environmentally friendly/extremely } \\
\text { not environmentally friendly }\end{array}$ & & $\begin{array}{l}\text { Gershoff and Frels } \\
(2015)\end{array}$ \\
\hline $\begin{array}{l}\text { Perceived } \\
\text { functionality }\end{array}$ & $\begin{array}{l}\text { 7-point semantic } \\
\text { differential scale }\end{array}$ & $\begin{array}{l}\text {...functions better/functions worse } \\
\text {...will be fragile/more powerful } \\
\text {...performs worse/performs better } \\
\text {...is weaker/stronger }\end{array}$ & .82 & \\
\hline $\begin{array}{l}\text { Perceived } \\
\text { financial costs }\end{array}$ & $\begin{array}{l}\text { 7-point semantic } \\
\text { differential scale }\end{array}$ & $\begin{array}{l}\text {...is cheaper/more expensive } \\
\text {...will lead to a higher/lower price }\end{array}$ & .81 & $\begin{array}{l}\text { Kukar-Kinney and } \\
\text { Grewal (2007) }\end{array}$ \\
\hline $\begin{array}{l}\text { Perceived } \\
\text { behavioral }\end{array}$ & $\begin{array}{l}\text { 7-point semantic } \\
\text { differential scale }\end{array}$ & $\begin{array}{l}\text {...will require more/less effort in daily use } \\
\text {...will be more convenient/inconvenient }\end{array}$ & .67 & \\
\hline $\begin{array}{l}\text { Perceived } \\
\text { naturalness }\end{array}$ & $\begin{array}{l}\text { 7-point semantic } \\
\text { differential scale }\end{array}$ & $\begin{array}{l}\text {...is artificial/natural } \\
\ldots \text {... is less organic/more organic }\end{array}$ & .74 & $\begin{array}{l}\text { Zhu and Meyers- } \\
\text { Levy (2009) }\end{array}$ \\
\hline $\begin{array}{l}\text { Moral } \\
\text { satisfaction }\end{array}$ & $\begin{array}{l}\text { 100-point slider scale: } \\
\text { "Buying a shower gel in } \\
\text { this packaging, instead } \\
\text { of the current } \\
\text { packaging..." }\end{array}$ & $\begin{array}{l}\text {...would feel like doing the morally right thing } \\
\text {...would make me feel like a better person } \\
\text {...would feel like making a personal contribution to } \\
\text { something better } \\
\text {...would give me a good feeling, because I am } \\
\text { supporting an ethically responsible practice }\end{array}$ & .91 & $\begin{array}{l}\text { Bratanova et al. } \\
(2015)\end{array}$ \\
\hline
\end{tabular}




\section{CHAPTER 4}

Partially green, wholly deceptive? How consumers respond to (in)consistently sustainable packaged products in the presence of sustainability claims

This chapter is submitted as:

Steenis, N. D., van Herpen, E., van der Lans, I. A. \& van Trijp, H. C. M. (2019). Partially green, wholly deceptive? How consumers respond to (in)consistently sustainable packaged products in the presence of sustainability claims. 


\section{ABSTRACT}

Firms often emphasize 'green' benefits for products which are only partially made more sustainable (e.g., a more sustainable packaging without changing the product's ingredients). The current chapter posits that such strategies can lead to a claim-fact discrepancy (i.e., actual environmental performance does not fully match the claim) and investigates the degree to which consumers respond positively and/or negatively to cases wherein the packaged product is partially discrepant with the firm's claim. The chapter considers that potential misalignment between the implied and actual environmental performance can lead to consumers feeling deceived, detracting from attitudes and purchase intentions even though consumers can intrinsically value (partial) sustainability improvements. Additionally, given that marketing communication often relies on puffery, such as exaggerated language and (visual) hyperbole, the chapter also investigates how using puffy claims (vs. more subdued, or no claim) moderates this consumer process. Findings from an online experiment $(N=609)$ and a lab experiment $(N=409)$ unveil the effects of perceived greenwashing and deceptiveness for packaged products that are (partially) discrepant with the claim. Importantly, findings imply that usage of puffery has both pros and cons such that it increases positive responses (improved sustainability perception) as well as negative responses (higher perceived greenwashing). Furthermore, the results provide initial support for the idea that sustainability improvements in only peripheral attributes (packaging) are perceived as more deceptive than when only central attributes (product contents) are made sustainable. 
Partially green, wholly deceptive?

\subsection{Introduction}

Producers and brand owners of consumer packaged goods face ever increasing pressures to reduce the environmental impacts of their products. One way in which firms respond to such pressures is through the design and introduction of products that are 'greener' than their conventional counterparts, for example products that contain organic ingredients and/or are packaged more sustainably. While these products contain at least one sustainable component, this does not mean that the entirety of the offering is equally environmentally friendly (Gershoff \& Frels, 2015).

Consumers may respond to such inconsistencies which could explain why they sometimes seem apprehensive about purchasing more sustainable packaged products. For example, Pancer, McShane, \& Noseworthy (2017) considered how the use of isolated sustainability packaging design cues, such as an eco-label without any other sustainability cues, decreases purchase intentions because it triggers intuitively competing schemata of sustainability versus functionality, and causes consumers to penalize the product's efficacy. In another vein, Magnier et al. (2016) considered how combinations of (partially) sustainable packaging cues and intrinsic product cues contribute to consumers' perceptions of naturalness and quality.

While consumers are thus sensitive to inconsistencies from visual cues related to the packaged product in and of itself, the current chapter seeks to investigate a different side of the coin, namely, by considering the potential misalignment between firm's marketing claims and (only partially) sustainable packaging-product combinations. Thus, we consider that consumer response may not only be determined by inconsistencies between attributes (e.g., green packaging for a conventional product), but is also determined by how such partially sustainable packaged products might be discrepant with the firms' positioning. For example, producers of bottled water, a product widely criticized for its large impacts on the environment, may opt to package the water in bio-based bottles, and explicitly push such an improvement as 'sustainable'. Moreover, firms in their advertisement often use 'puffy' statements which exaggerate the actual (environmental) benefits and this could generate an even larger perceived discrepancy between the firm's claim and the packaged product itself. While consumers may hold positive attitudes toward the inclusion of sustainable attributes from either packaging or product contents in and of itself (Vermeir \& Verbeke, 2006), they may also infer deceitfulness from partial discrepancies with the firm's claim (i.e., it does not fully live up to expectations). These consumer judgments are relevant because sustainable marketing activities are 
viewed with a high degree of suspicion, and this may prevent consumer choices for more sustainable alternatives, even if these are not as sustainable as firms themselves imply. Indeed, the number of products claiming to be 'green' has increased rapidly, yet $95 \%$ of such products has been found to commit at least one "sin of greenwashing" (TerraChoice, 2010).

The current chapter has four objectives. First, we investigate the extent to which using a general environmental claim for a packaged product that is, in truth, only partially sustainable (i.e., as determined by an independent other organization) is perceived as deceptive by consumers (compared to packaged products that are wholly (un)sustainable). Second, we consider the underlying consumer process by examining how consumer inferences of greenwashing may counteract the improved environmental performance in contributing to consumers' purchase intentions and overall attitudes. Third, relating to theories of attribute centrality (Gershoff \& Frels, 2015; Sloman, Love, \& Ahn, 1998), we predict that consumers are more likely to feel deceived when firms introduce packaged products for which only a peripheral component (packaging) is made sustainable while a central component (product contents) is not, compared to the alternative where the central product contents are sustainable whereas its peripheral packaging is not. Last, we investigate the moderating role of claim puffery. In advertisement and product promotions, specific benefits are often emphasized, not uncommonly in a somewhat exaggerated fashion (Goldberg \& Hartwick, 1990). Yet, scarcely any research has looked into the influence of puffery in a sustainable marketing perspective where firms may make either highly puffy environmental claims or use a more 'down to earth' approach (or potentially no claim whatsoever). For example, Coca-Cola, in a recent newspaper ad on recyclable packaging stated that they are "aware that more work needs to be done" thus deliberately framing their actions as a work in progress. This may be less likely to induce feelings of deception, but at the same time could attenuate the effect of increased perceived sustainability. The current chapter presents two experiments to investigate these objectives. 
Partially green, wholly deceptive?

\subsection{Theoretical background}

\subsubsection{Greenwashing, deception and claim-fact discrepancies}

Sustainable marketing is particularly susceptible to negative consumer reactions because sustainability is a credence attribute which consumers are usually unable to verify (Ford, Smith, \& Swasy, 1990). Whereas consumers can verify an improved taste claim on a food product by buying and consuming it, they themselves cannot verify if a sustainable packaging is indeed more environmentally friendly. Perceived deception is the (perceived) discrepancy between the impression that the firm generates about the packaged product and the actual performance of the same packaged product (Darke \& Ritchie, 2007; Forehand \& Grier, 2002; Wagner, Lutz, \& Weitz, 2009). In the environmental marketing domain, deceptive intentions are often called 'greenwashing' which has been defined as a consumer-perceived gap between the 'green' rhetoric of the firm and consumer-perceived reality (De Vries et al., 2015; Vos, 2009).Thus, we consider the concept of perceived greenwashing to be a similar construct as perceived deception, but more specific to environmental marketing.

A key component of the current research is the presence of a claim-fact discrepancy (Gardner, 1975), which occurs when products do not live up to the expectation that the firm has generated (e.g., through its promotional activities). With regard to this discrepancy, Darke and Ritchie $(2007 ;$ p. 115) state that: "Consumers do not need to know exactly how they were misled by an advertising claim; they merely need to perceive a discrepancy between the impression that the advertisement generated and the performance of the product to know they have been fooled". This discrepancy may lead to inferences of deception, and thereby reduce preferences for the promoted products even if consumers appreciate the presence of environmental attributes in itself. The concept of a claim-fact discrepancy can be related to the misfit between two pieces of information (e.g., a firm's sustainability claims and its actual sustainability performance), which can contribute to consumer perceptions of corporate hypocrisy (Wagner et al., 2009), suspicion towards the company's inferred motives (Ellen, Webb, \& Mohr, 2006), scepticism (Forehand \& Grier, 2002) and low advertising credibility (Atkinson \& Rosenthal, 2014; Jain \& Posavac, 2001). This discrepancy increases the likelihood that consumers infer ulterior motives because consumers are more likely to engage in cognitive processing in order to reconcile the discrepant information (Ellen et al., 2006; Meyers-Levy \& Tybout, 1989). Consequently, the likelihood that consumers may infer an ulterior motive (e.g., making profits by misleading consumers) increases 
and consumers are prone to place greater value on the now-salient ulterior motive (Forehand \& Grier, 2002; Kelley, 1973).

We consider that when firms make sustainability claims that are not, or only partially supported by the packaged product offerings' actual environmental performance, the firm generates a claim-fact discrepancy which leads to consumer inferences of deception, and more specifically greenwashing. This discrepancy is expected to be largest when neither packaging nor product contents are factually green (full discrepancy), and relatively smaller when the firm provides a packaged product that is at least partially green (partial discrepancy). Alternatively, when both packaging and product contents are sustainable (i.e., they are consistent with the claim), deception should be lowest. Formally:

H1: In the presence of a sustainability claim, providing a packaged product whose actual environmental performance is fully or partially discrepant with what the claim implies leads to higher perceived greenwashing/deception than providing a packaged product whose actual environmental performance is consistent with the claim. Additionally, a partial discrepancy is perceived as less deceitful than a full discrepancy.

Following from the above reasoning, when consumers feel deceived, we expect that they are less likely to buy the packaged product and have less positive attitudes towards it:

H2: Perceived greenwashing/deception inferences negatively affect purchase intentions and consumer attitudes toward the packaged product.

Furthermore, we hypothesize that these inferences mediate the outcomes on purchase intentions:

H3a: Relative to fully discrepant packaged product offerings, partially discrepant and claim-consistent offerings exert a relatively less negative indirect effect on purchase intention through perceived greenwashing/deception.

When firms make sustainability claims that they only partially fulfil (or do not fulfil at all), we thus expect that consumers feel deceived. However, for partially discrepant and claim-consistent packaged product combinations, there may still be a positive contribution towards purchase intentions resulting simply from the increased degree of perceived sustainability, even when the firm's promise is not fully fulfilled. Thus, we also expect that: 
Partially green, wholly deceptive?

H3b: Relative to fully discrepant packaged product offerings, partially discrepant and claim-consistent offerings exert a relative positive indirect effect on purchase intention through perceived sustainability.

\subsubsection{Packaging versus product contents sustainability \& conceptual centrality}

Prior research in the domain of attribute centrality (Hadjichristidis, Sloman, Stevenson, \& Over, 2004; Sloman et al., 1998) has investigated whether specific attributes of objects are more central or peripheral to the concept of that object. In this view, centrality of attributes relates closely to how defining these attributes are for objects by considering how transformable ("mutable") they are, whilst retaining the same concept of that object (Sloman et al., 1998). Central attributes are least mutable and contribute most to a concept's coherence; they are integral to the mental representation of an object (Sloman et al., 1998). Central attributes are also more diagnostic to categorizing the object than are peripheral attributes (Gershoff $\&$ Frels, 2015) because if a highly central attribute were transformed, it would require a different categorization of the object as a whole. Peripheral attributes, on the other hand, can be mutated more easily without changing the core of the object.

Criteria to indicate the degree of centrality have been proposed by Sloman et al. (1998). Particularly, the conceptual centrality criterion would consider, for example, how easy it would be to consider a product without its (sales)packaging. Such a concept can be construed quite easily, for example by considering a soda beverage in a drinking glass or even as being spilled, thus the packaging type is not crucially defining for the beverage product. Conversely, it would be impossible to consider a beverage that does not contain liquid ingredients but that is gaseous or solid in nature. Thus, packaging is more likely to be conceptually peripheral whereas 'internal' attributes related to product contents and ingredients are central.

Recent research in marketing has demonstrated that the centrality of green attributes affects consumer response towards products (Gershoff \& Frels, 2015). In the research at hand, we consider that for partial discrepancies, packaging and product contents may have different effects because their centrality differs. As alterations of peripheral attributes have a much lower impact on transforming the mental representation of the packaged product, such a change may be more likely perceived as superficial. This adjustment could signal that a company could have done a more thorough change, but has foregone it in favor of a less transformative 
alteration. Therefore, consumers should feel more deceived when packaging is sustainable while the product content itself is not than vice versa:

H4: Partial discrepancies wherein only a peripheral attribute (packaging) is sustainable but where a central attribute (product contents) is not, induce greater perceived greenwashing/deception than do partial discrepancies wherein only a central attribute is sustainable, but a peripheral attribute is not.

Importantly, since the notion of centrality pertains to what defines an object, it does not presume that the consequences of the sustainability alterations are the result of differences in the peripheral attribute versus central attribute's perceived environmental impacts. In other words, we propose that making only packaging sustainable is perceived as more deceptive because packaging is more peripheral in the mental representation of the packaged products, and not necessarily because packaging sustainability is perceived as having a lesser environmental impact (versus product contents' sustainability).

\subsubsection{The role of claim puffery in advertisements}

Thus far, we have considered the firm's sustainability claim in broad, general terms. Realistically, however, firms might use various types of claims which can vary in the degree to which consumers attribute deception to them (Nyilasy et al., 2014). Particularly, advertisements and promotional activities often involve forms of puffery, defined as sales claims that involve exaggerations, superlatives or hyperbole which can potentially be deceptive for consumers, but that are generally legally permissible (Richards, 1990). Thus, puffery relates to the generation of expectations (e.g., through ads or promotional stimuli) which can reasonably be expected to exceed the product's actual performance (McQuarrie \& Mick, 1996; Toncar \& Fetscherin, 2012).

Puffery constitutes both verbal and visual elements. Verbal components often refer to the aforementioned use of exaggeration and superlatives, for example by using terms as "Everyone loves a Coca-Cola" and "Feel the power of the world's best shave" (Callister \& Stern, 2012). Similarly, visuals can also contribute to puffery for example through emphasizing specific color palettes, lighting, and the selection of objects included in advertisements which can signal boldness vs. understatement (Toncar \& Fetscherin, 2012). Visual hype and hyperbole may also be used (McQuarrie \& Mick, 1996; Toncar \& Fetscherin, 2012). For example 7UP used a (controversial) advertisement depicting a 7UP soda can hanging off the branch of a tree, a form of 
Partially green, wholly deceptive?

visual hyperbole. The ad was further combined with a predominantly green color palette throughout the ad which visually highlights the can, and using the headline "now $100 \%$ natural".

\subsubsection{Positive and negative effects of puffery}

The negative effects of puffery have mainly been emphasized because puffery involves distortions of truth that can increase the perceived claim-fact discrepancy, as puffery naturally causes an over-appraisal of the offering (Callister \& Stern, 2012; Darke \& Ritchie, 2007; McQuarrie \& Mick, 1996; Obermiller, Spangenberg, \& MacLachlan, 2005; Richards, 1990). For example, more extreme ad claims, such as "the very best product", tend to be seen as less credible and to negatively impact product evaluations compared to less extreme ad claims, such as "better than most products" (Goldberg \& Hartwick, 1990). Similarly, research regarding environmental advertisement shows that consumers tend to experience higher levels of discomfort from ads with particularly strong claims, and consider these ads less believable compared to less pronounced claims (Chang, 2005). Research on advertising shows that if the advertisement does not match actual performance, consumers can become skeptical and discount the ad's claims (Friestad \& Wright, 1994; Wagner et al., 2009) ultimately leading to consumer dissatisfaction (Kopalle \& Lehmann, 2015; Nyilasy et al., 2014). Extrapolating from these findings, we expect that when firms' sustainability claims are discrepant with the actual offering, making puffy claims is especially likely to backfire because such claims are prone to increase perceived deception. Conversely, providing more subdued claims or even making no sustainability claim whatsoever may reduce this because it attenuates the claim's environmental performance suggestions. Thus:

H5a: Claim puffiness moderates the indirect effects of the claim-fact discrepancy such that puffy claims generate a stronger (negative) indirect effect on purchase intentions and attitudes through perceived greenwashing/deception

Although the above discussion has focused on the cons of puffery, research also attests that puffery can lead to various firm-beneficial effects. Indeed, it has been argued that puffery would not exist if it did not work in some way (Haan \& Berkey, 2002; Toncar \& Fetscherin, 2012). Various explanations have been offered for the potential positive effects of puffery. One line of research focusses on the persuasiveness of puffy advertisement and indicates that consumers are prone to believe puffy claims to a relatively large extent, and that consumers consequently make inferences (e.g., quality judgments) based on these implied facts (Haan \& 
Berkey, 2002; Kamins \& Marks, 1987; Lee, 2014). At the same time, credibility does not seem a prerequisite for puffy claims to exert effects on consumer beliefs because consumer beliefs have been shown to change post-exposure even when the claims were perceived as relatively incredible (Cowley, 2006). Thus, another explanation suggests that consumers initially accept (puffy) claims as true, and discount these claims only after processing them fully. If consumers do not expend sufficient mental effort to discount the claim they are more likely to believe it, leading to positive effects. However, even if the advertisement itself is rejected it seems that consumers do not fully re-adjust associated beliefs stored in memory. As a consequence, the ad loses its credibility, but its targeted effects (e.g., on brand liking, or in this case, perceived sustainability) linger, whilst the initial exaggeration is forgotten (Cowley, 2006). Based on the above literature, we thus also predict that there is an indirect positive effect of puffery due to improved perceptions of sustainability.

H5b:Claim puffiness moderates the indirect effects of the claim-fact discrepancy such that puffy claims generate a stronger (positive) indirect effect of on purchase intentions and attitudes through perceived sustainability.

\subsection{Research overview}

We present two experiments using packaged beverage product scenarios to test the hypotheses. Experiment 1 tests $\mathrm{H} 1$ to $\mathrm{H} 4$. It creates a claim-fact discrepancy by providing a general sustainability claim (kept constant) paired with independent assessments of the true environmental impacts of packaging and product contents, separately. The experiment varies both extreme and intermediate discrepancy, and also considers a full discrepancy with the claim (i.e. both attributes not sustainable). Experiment 2 provides additional tests for $\mathrm{H} 1$ to $\mathrm{H} 4$, and also tests $\mathrm{H} 5$ by manipulating the firm's claim through the use of advertisements containing either a puffy, a subdued, or no description of the sustainability of the packaged product. In each experiment, we test the mediating effects of both perceived sustainability and greenwashing inferences on consumer attitudes/purchase intentions. Following from the theoretical section, deceptiveness was operationalized using two constructs: perceived deception and perceived greenwashing (as a more specific form of deception). 
Partially green, wholly deceptive?

\subsection{Experiment 1}

\subsubsection{Participants and design}

A total of 609 Dutch consumers $\left(M_{\text {age }}=41.64, S D_{\text {age }}=13.75\right.$, range $_{\text {age }}=18-65$; $50 \%$ male) were recruited from an online panel to participate in the study. Participants were recruited through e-mail invitations and received a small financial compensation for participating. Education levels varied as follows: $19.4 \%$ had a low education level (primary education or a lower secondary/vocational education), $45.5 \%$ had a medium education level (vocational degree or advanced secondary education) and $35.2 \%$ had a high education level (bachelor's degree or higher). The experiment consisted of a 3 (packaging sustainability: high, average, low) $\times 3$ (product contents sustainability: high, average, low) between-subjects design. Thus, the experiment contained one claim-consistent condition (both packaging and contents sustainability high), one condition that is fully discrepant (both packaging and contents sustainability low) and seven conditions which are to various extents partially discrepant with the claim (e.g., packaging high, product contents low).

\subsubsection{Stimuli and procedure}

Participants were instructed to evaluate an upcoming beverage product from a major company in the packaged beverages industry. Company and brand name were blurred out to avoid possible effects of brand recognition and preference. Participants were told that this was done in the interest of the study's purpose. Participants first read a short text stating that the company wanted to introduce a new sustainable non-carbonated beverage product, which had been rated on its environmental impacts. The environmental assessment was stated to be carried out by a (fictitious) independent organization named Ecojudge, which rates the sustainability of various products and publishes these results online. Ecojudge was stated to be well-known abroad, but relatively unfamiliar in the country of the study to account for participants not recognizing the fictitious name. It was also stated to be a non-profit organization that was renowned for its reliable rating, and that the producing firm claimed the beverage product to be sustainable.

Next, participants were shown an image of a web-page with Ecojudge's ratings of the environmental friendliness of the packaging and product (Appendix 4.1.). The web-page's design was based on real-world initiatives that rank brand/product sustainability such as Rank a Brand (www.rankabrand.org) and the Greenwashing Index (www.greenwashingindex.com), GoodGuide (www.goodguide.com). Package 
and beverage sustainability were displayed graphically with ratings including "bad", "average" or "excellent", depending on condition.

After viewing the web-page, participants filled in questions measuring purchase intentions (measured on a slider scale ranging from 1-100), attitudes (using 7-pt semantic differential scales), and the proposed mediators perceived sustainability and perceived deception/greenwashing (using 7-pt Likert scales). Finally, background characteristics were asked. See Appendix 4.2. for the complete set of items.

\subsubsection{Results Experiment 1}

\section{Purchase intentions and attitudes}

ANOVAs were conducted with packaging and product contents' sustainability levels as independent variables, and purchase intentions and attitude towards the packaged product as the dependent variables. Although attitude towards the firm was also investigated, its results were similar to attitude towards the packaged product, hence we report results of the latter. Results showed significant main effects of packaging sustainability on purchase intentions $\left(F(2,609)=6.031, p=.003, \eta_{p}^{2}=\right.$ $.02)$ and attitude toward the packaged product $\left(F(2,609)=13.34, p<.001, \eta_{p}{ }^{2}=.04\right)$. Similarly, there were significant main effects of product contents sustainability on purchase intentions $\left(F(2,609)=28.25, p<.001, \eta_{p}^{2}=.09\right)$ and attitude toward the packaged product $\left(F(2,609)=72.16, p<.001, \eta_{p}{ }^{2}=.19\right)$. There were no significant interaction effects.

Mean comparisons (Table 4.1) revealed that when both packaging and product contents were rated as sustainable, purchase intentions were significantly higher than when packaging was highly sustainable but product content sustainability was rated as average ( $M=63.69$ vs. $52.79, p<.05)$ or bad ( $M=63.69$ vs. $43.67, p<.05$ ). Purchase intentions were lower when product contents were rated as highly sustainable while the packaging was not sustainable, compared to when both were sustainable ( $M=63.69$ vs. $52.93 ; p<.05)$. Patterns of results were similar for attitudes. 
Partially green, wholly deceptive?

\section{Perceived sustainability, deception \& greenwashing}

Next, ANOVAs were conducted with the proposed mediators as the dependent variables. Results showed significant main effects of packaging sustainability on perceived sustainability $\left(F(2,609)=39.92, p<.001, \eta_{p}^{2}=.12\right)$, deception $(F(2,609)=$ $\left.12.45, p<.001, \eta_{p}^{2}=.04\right)$ and greenwashing $\left(F(2,609)=5.54, p<.01, \eta_{p}^{2}=.02\right)$. For product contents sustainability there were also significant main effects on perceived sustainability $\left(F(2,609)=44.29, p<.001, \eta_{p}^{2}=.13\right)$, deception $(F(2,609)=44.59, p$ $\left.<.001, \eta_{p}^{2}=.13\right)$ and greenwashing $\left(f(2,609)=19.78, p<.001, \eta_{p}{ }^{2}=.06\right)$. Again, there were no significant interaction effects. The pattern of means for both packaging and product contents sustainability (Table 4.1) was in line with expectations such that a higher packaging/product contents sustainability level led to lower perceived deception and greenwashing (and higher perceived sustainability). The main effects on perceived deception showed that for packaging sustainability, pairwise comparisons were significant ( $p$ 's $<05$ ) although the comparison between average and high sustainability was marginally significant $(p=.09)$. For product contents sustainability all pairwise comparisons were significant $\left(p^{\prime} s<.01\right)$. The main effects for perceived greenwashing were similar with the exceptions that the difference between average and high sustainability was not significant for neither packaging ( $p$ $=.24)$ nor product contents sustainability $(p=.15)$. Overall, the results were in line with $\mathrm{H} 1$ : in the presence of a sustainability claim, perceived greenwashing and deception increased when the level of actual packaging/product sustainability decreased (i.e., the claim-fact discrepancy increased). These effects however were more pronounced for product contents sustainability, suggesting a possible effect of attribute centrality. 
TABLE 4.1. Experiment 1: ANOVAs - Comparison of means

\begin{tabular}{|c|c|c|c|c|c|c|c|c|c|c|c|}
\hline \multicolumn{2}{|c|}{ Sustainability level } & \multicolumn{10}{|l|}{ DV } \\
\hline \multirow[b]{2}{*}{ Packaging } & \multirow[b]{2}{*}{ Product } & \multicolumn{2}{|c|}{ Deception } & \multicolumn{2}{|c|}{ Greenwashing } & \multicolumn{2}{|c|}{$\begin{array}{l}\text { Perceived } \\
\text { sustainability }\end{array}$} & \multicolumn{2}{|l|}{$\begin{array}{l}\text { Purchase } \\
\text { intention }\end{array}$} & \multicolumn{2}{|l|}{ Attitude } \\
\hline & & M & $S E$ & M & SE & M & SE & M & $S E$ & M & SE \\
\hline \multirow[t]{3}{*}{ High } & High & $3.35^{x, a}$ & .13 & $3.78^{x, a}$ & .16 & $5.19^{x, a}$ & .18 & $63.69^{x, a}$ & 2.74 & $5.38^{x, a}$ & .16 \\
\hline & Mid & $3.63^{x, a}$ & .13 & $3.88^{x, a}$ & .16 & $4.67^{x, a}$ & .18 & $52.79^{x, b}$ & 2.74 & $4.96^{x, a}$ & .16 \\
\hline & Low & $4.28^{x, b}$ & .13 & $4.59^{x, b}$ & .16 & $3.86^{x, b}$ & .18 & $43.67^{x, b}$ & 2.74 & $3.92^{x, b}$ & .16 \\
\hline \multirow[t]{3}{*}{ Mid } & High & $3.37^{x, a}$ & .13 & $3.86^{x, y, a}$ & .16 & $4.72^{\mathrm{y}, \mathrm{a}}$ & .18 & $57.29^{x, y, a}$ & 2.74 & $5.38^{x, a}$ & .16 \\
\hline & Mid & $3.78^{x, a}$ & .13 & $4.11^{x, y a}$ & .16 & $4.22^{y, a}$ & .18 & $49.73^{x, y, a, b}$ & 2.80 & $4.64^{x, b}$ & .17 \\
\hline & Low & $4.67^{x, b}$ & .13 & $4.73^{x, y, b}$ & .16 & $2.97^{y, b}$ & .18 & $40.38^{x, y, b}$ & 2.74 & $3.55^{x, c}$ & .16 \\
\hline \multirow[t]{3}{*}{ Low } & High & $3.89^{y, a}$ & .13 & $4.22^{y, a}$ & .16 & $3.76^{z, a}$ & .18 & $52.93^{y, a}$ & 2.74 & $4.80^{y, a}$ & .16 \\
\hline & Mid & $4.29^{y, a, b}$ & .13 & $4.43^{y, a, b}$ & .16 & $3.31^{z, a, b}$ & .18 & $44.53^{y, a, b}$ & 2.74 & $4.01^{y, b}$ & .16 \\
\hline & Low & $4.67^{y, b}$ & .13 & $4.87^{y, b}$ & .16 & $2.82^{2, b}$ & .18 & $39.42^{y, b}$ & 2.74 & $3.37^{y, c}$ & .16 \\
\hline
\end{tabular}

Notes. Superscripts $a, b, c$ denote statistically significant pairwise differences in product sustainability for each level of packaging sustainability, while $x, y, z$ denote differences between the levels of packaging sustainability $(\alpha=.05$; Tukey HSD corrected). Means with the same superscript are not significantly different.

\section{Mediation analysis}

In order to test whether the effects of packaging and product contents sustainability on purchase intention were mediated by perceived greenwashing and perceived sustainability (H3), we used the SPSS PROCESS macro (Hayes \& Preacher, 2014). Two mediation analyses were conducted. The first analysis included indicatorcoded dummies for packaging sustainability as the independent variable and product contents sustainability dummies as covariates. The second analysis swapped these such that dummies for product contents sustainability were the independents and dummies for packaging sustainability were the covariates. Perceived sustainability and perceived greenwashing were entered as parallel mediators (analyses with the perceived deception variable were also ran and outcomes were comparable, hence we report only results of perceived greenwashing), and purchase intention as the dependent variable. Significance was based on 10.000 bootstrap samples and $95 \%$ confidence intervals.

Results from the first analysis showed significant indirect effects of the packaging sustainability dummies on purchase intentions via perceived sustainability (low vs. average: $b=3.69, S E=0.92, C / 95[1.97,5.62]$, low vs. high: $b=7.05, S E=1.14$, C195[4.80, 9.42]) and via perceived greenwashing (low vs. average: $b=.78, S E=.44$, C195[0.02, 1.75], low vs. high: $b=1.21, S E=.52, C 1950.35,2.40])$. The contrast 
Partially green, wholly deceptive?

between the average and high packaging sustainability levels was significant for perceived sustainability (average vs. high: $b=3.36, S E=.86, C 195[1.79,5.16]$ ), although not significant for perceived greenwashing (average vs. high: $b=.43, S E=$ .39 , C195 $[-0.25,1.29])$. There was no significant remaining direct effect $(p=.89)$, indicating full mediation.

The results from the second analysis with product contents sustainability showed similarly significant effects through perceived sustainability (low vs. average: $b=$ 4.70, $S E=.96, C 195[2.91,6.69]$, low vs. high: $b=7.34, S E=1.24, C / 95[5.04,9.88])$ and perceived greenwashing (low vs. average. $b=1.68$, SE $=.57$, C195[0.69, 2.92], low vs. high: $b=2.21, S E=.70, C 195(.99,3.74])$. The contrast between the average and high product contents sustainability levels was significant for perceived sustainability (average vs. high. $b=2.64, S E=.85, C 195[1.08,4.42]$ but not greenwashing (average vs. high: $b=.53, S E=0.40, C 195-.13,1.44])$. The omnibus test also showed a significant direct effect $(p<.01)$, indicating partial mediation.

In summary, results from both these models showed that mediation occurred in line with expectations $(\mathrm{H} 3)$. That is, the indirect effects on purchase intention through perceived sustainability and greenwashing were more positive/less negative as the level of sustainability of either packaging or product contents increased compared to the low sustainability conditions. The pattern was similar when comparing the average to high sustainability conditions, however the differences were only significant in terms of perceived sustainability.

\section{Centrality effects}

A test for the asymmetry in the effects of packaging and product contents sustainability $(\mathrm{H} 4)$ was conducted by first specifying a contrast for the ANOVAs with perceived greenwashing/deception as the dependent variable. The overall contrast tested the difference between $l$ ) the three conditions where product contents sustainability exceeded packaging sustainability, versus ii) the three conditions where packaging was more sustainable than product contents. Results showed a marginally significant difference for perceived greenwashing $\left(M_{\text {contents }}\right.$ packaging $=3.17$ vs. $\left.M_{\text {packaging }>\text { contents }}=4.40 ; F(1,406)=2.91, p=.09\right)$ and a significant difference for perceived deception ( $M_{\text {contents }>\text { packaging }}=3.85$ vs. $M_{\text {packaging }>\text { contents }}=4.19 ; F(1,406)=$ $8.60, p<.05)$. Thus, when product contents sustainability exceeded the packaging's sustainability, deceptiveness was lower. Additionally, as a check, the contrast revealed no significant difference in perceived sustainability $\left(M_{\text {contents }}\right.$ packaging $=3.93$ vs. $\left.M_{\text {packaging }>\text { contents }}=3.84 ; p=.60\right)$, ruling out that this centrality effect on deception 
was caused by the difference in perceived environmental impacts of packaging and product contents. Overall, results were supportive of $\mathrm{H} 4$ : partial discrepancies wherein only a peripheral attribute (packaging) is sustainable but where a central attribute (product contents) is not, led to higher perceived greenwashing/deception than vice versa. Additionally, we showed that the effect of centrality was independent of perceived sustainability.

\section{Discussion Experiment 1}

Experiment 1 indicates that when discrepancies between the firm's claimed sustainability and its actual sustainability arise, consumers make inferences about deception/greenwashing. Specifically, the experiment showed that packaged products which were partially discrepant with the claim (i.e., partially sustainable) were perceived as less deceptive than those that were fully discrepant with the claim, but more deceptive than fully sustainable packaged products. Outcomes for both the perceived deception and greenwashing (as a more specific form of deception) variables were similar, although participants tended to respond somewhat more strongly for general deception.

Mediation analyses support the expectations by showing that the effects of the claim-fact discrepancy on purchase intention are mediated through perceived greenwashing and sustainability. Moreover, the outcomes support the hypothesis of asymmetry through centrality such that the perceived discrepancy from partially sustainable product-packaging combinations depends on whether a central or peripheral attribute is made sustainable in line with $\mathrm{H} 4$. This effect of centrality is not the mere consequence of different effects of packaging versus product contents sustainability manipulations on perceived sustainability.

\subsection{Experiment 2}

Experiment 2 seeks to provide further evidence for the effects in Experiment 1 in a controlled lab setting. It also tests effects of the claim-fact discrepancy as a function of different claims (puffy, subdued, no claim) in addition to the (partial) actual sustainability of the product-packaging combination. 
Partially green, wholly deceptive?

\subsubsection{Participants and design}

A total of 409 eligible responses were collected from a Dutch university student sample excluding 13 participants who failed an attention check $\left(M_{\text {age }}=20.75, S D_{\text {age }}\right.$ $=2.10 ; 75 \%$ female). The experiment consisted of a 3 (claim puffiness: puffy, subdued, claim-absent) $\times 3$ (actual sustainability rating: packaging and product contents (both) sustainable, packaging sustainable, product contents sustainable) between-subjects design. Thus, the latter factor essentially combined the two factors of Experiment I, wherein either only a peripheral attribute (packaging), only a central attribute (product contents), or both attributes were made sustainable. The experiment thus compared between two types of partial discrepancies and one wholly sustainable (claim-consistent) condition.

\subsubsection{Stimuli and procedure}

The stimuli and procedure were similar to those in the first experiment. However where in the first experiment it was merely stated that the company claimed that the product was sustainable, participants now were assigned to one of three claim conditions. Participants in the claim-absent condition were not shown an ad, and the other two conditions were shown either a puffy or subdued advertisement. The manipulation of actual sustainability was similar to Experiment 1 . Therefore, the degree of claim-fact discrepancy was determined by both the actual sustainability ratings and claim manipulation (where in Experiment I, the latter was kept constant). Instructions also stated that for the beverage category, on average, $50 \%$ of environmental impacts are caused by packaging and the other $50 \%$ by the product's contents. This was added to rule out perceived environmental impact as an alternative explanation for the effects of centrality and was based on the results from Experiment I.

Ads (Appendix 4.3.) were created based on a review of real-world campaigns and prior operationalizations (Darke \& Ritchie, 2007; Kopalle et al., 2017). Given that puffery can be constituted from various verbal and visual impressions, it was operationalized through both verbal and visual differences between the puffy and subdued ad versions. This was done to provide a general view of ad puffery (rather than specific forms of puffery), and to ensure that the manipulation was sufficiently strong. Verbal elements (1) contained superlative adjectives in the puffy ads (e.g., 'the most sustainable drink') versus comparative adjectives in the subdued ads (e.g., 'a more sustainable drink'), (2) differed in order such that they first mentioned 
sustainability information in the puffy ad versus (first) flavor information in the subdued ad, and (3) contained a statement that the firm was 'looking back on an amazing environmental result' for the puffy ad versus a statement that 'the firm realizes more work is to be done, and that it is continually working on environmentally friendlier options' for the subdued ad (based on recent ads by CocaCola and Bar-le-Duc). Visual elements included: (1) a green, 'craft-paper' background color for the puffy ad versus a plain blue background for the subdued ad, and (2) a bold green font to emphasize environmental claims for the puffy ad versus a regular white for the subdued ad. Based on prior research, we expected these visual elements in the puffy condition to strongly cue an environmental schema (Magnier \& Schoormans, 2015; Orth \& Malkewitz, 2008; Pancer et al., 2017; Steenis et al., 2017).

The degree of puffiness of the ads was pretested among a sample of students ( $N$ $=56, M_{a g e}=23.3 ; 79 \%$ female) following a two-group within-subjects design. We measured puffiness through six items on a 7-point semantic differential scale (exaggerated/humble, ostentatious/moderate, puffy/low-key, pretentious/sincere, bold/cautious, excessive/reserved) to examine whether the manipulations had the intended effects. Although to our knowledge no validated scale to measure puffiness exists, items were intended to capture the degree to which the ad generated (exaggerated) expectations about the offering's performance based on similar items in prior research (e.g., Callister \& Stern, 2012), and in line with the used definition of puffiness. The scale was sufficiently reliable with Cronbach's $\alpha$ 's of .91 and .93 for the puffy and subdued conditions, respectively. Repeated measures ANOVA showed that indeed the puffy ad scored higher on the scale than the subdued ad ( $M_{\text {puffy }}=5.21 \mathrm{vs}$. $\left.M_{\text {subdued }}=3.41 ; F(1,55)=108.78, p<.001, \eta_{p}^{2}=.66\right)$. Additionally, the ads should (on average) not significantly differ in the extent to which they emphasize either the packaging or product contents (7-point Likert scale items: "this ad gives me the impression that the packaging [product contents] are sustainable", with anchors fully (dis)agree). As expected, participants on average considered the ads to equally emphasize packaging and product content sustainability ( $M_{\text {packaging }}=4.80 \mathrm{vs.} M_{\text {product }}$ $=5.04 ; F(1,55)=1.97, p=.17)$. 
Partially green, wholly deceptive?

\subsubsection{Results Experiment 2}

\section{Manipulation checks}

To check whether puffiness was successfully manipulated, an ANOVA was carried out. It showed a significant effect of the ad claim manipulations on perceived puffiness $\left(F(1,286)=52.43, p<.001, \eta_{p}^{2}=.16\right)$. The puffy claim was, on average, perceived as more puffy than the subdued claim $\left(M_{\text {puffy }}=5.00\right.$ vs. $\left.M_{\text {subdued }}=4.19\right)$.

\section{Effects on purchase intentions \& attitudes}

Two-way ANOVAs were conducted to test the effects of claim puffiness and actual sustainability on purchase intentions and attitudes toward the packaged product (attitude towards the firm was also investigated, and again its results were similar to attitude towards the packaged product, hence we only report results of the latter).

Overall statistics showed medium to large significant main effects of actual sustainability on each of these dependent measures (Table 4.2). The condition wherein both packaging and product contents were sustainable ('both sustainable') led to significantly more positive outcomes than the conditions wherein only either packaging ('packaging-only) or product contents ('contents-only') were sustainable (Figure 4.1), and the pattern was similar for both dependent constructs. For claim puffiness, there only was a small and marginally significant main effect on purchase intention (Table 4.2), indicating that purchase intentions were higher in the claimabsent condition than in the puffy and subdued claim conditions (Figure 4.1).

TABLE 4.2. ANOVAs - main effects and interactions on (a) dependent variables and (b) mediators

\begin{tabular}{|c|c|c|c|c|c|c|c|c|c|}
\hline (a) Dependent variables & \multicolumn{3}{|c|}{ Purchase intention } & \multicolumn{3}{|c|}{ Attitude } & & & \\
\hline & $F$ & $p$ & $\eta_{p}^{2}$ & $F$ & $p$ & $\eta^{2} p$ & & & \\
\hline Actual sustainability rating & 41.93 & $<.001$ & .17 & 113.23 & $<.001$ & .36 & & & \\
\hline Claim puffiness & 2.69 & .07 & .01 & .66 & .52 & .00 & & & \\
\hline Interaction & .69 & .60 & .01 & 4.52 & $<.01$ & .04 & & & \\
\hline$R^{2}$ & & .19 & & & .38 & & & & \\
\hline (b) Proposed mediators & \multicolumn{3}{|c|}{ Deception } & \multicolumn{3}{|c|}{ Greenwashing } & \multicolumn{3}{|c|}{ Perceived sustainability } \\
\hline & $F$ & $p$ & $\eta_{p}^{2}$ & $F$ & $p$ & $\eta^{2} p$ & $F$ & $p$ & $\eta^{2} p$ \\
\hline Actual sustainability rating & 68.57 & $<.001$ & .26 & 53.58 & $<.001$ & .21 & 131.05 & $<.001$ & .40 \\
\hline Claim puffiness & 4.92 & $<.01$ & .02 & 12.50 & $<.001$ & .06 & 17.05 & $<.001$ & .08 \\
\hline Interaction & 0.87 & .48 & .00 & 3.75 & .01 & .04 & 1.92 & .11 & .02 \\
\hline$R^{2}$ & & .27 & & & .27 & & & .43 & \\
\hline
\end{tabular}

Note. $F(2,400)$ for main effects, $F(4,400)$ for two-way interactions. 
Small and significant interaction effects between actual sustainability and claim type were found for attitudes towards the packaged product (Table 4.2), supporting the idea that the effect of actual sustainability is moderated by claim puffiness. To explore these effects further, we first considered the effects of actual sustainability within each claim condition. Results (Figure 4.2a) showed that, within the puffy claim condition, the difference between the packaging-and contents-only conditions was significant in favor of the latter $\left(M_{\text {packaging-only }}=3.88, M_{\text {contents-only }}=4.51, p<.01\right)$ while in the other two claim conditions the difference was not significant (subdued: $M_{\text {packaging-only }}=3.92, M_{\text {contents-only }}=4.25, p=.15$; claim-absent: $M_{\text {packaging-only }}=3.81$ vs. $M_{\text {contents-only }}=3.67 ; p=.56$ ). The differences between either partially sustainable condition and the both sustainable condition were significant in all claim conditions such that the latter unequivocally led to the highest attitudes. Second, we considered the differences in the effects of actual sustainability (contents-only vs. both sustainable and packaging-only vs. both sustainable) across claim type conditions. Contrasts showed that the difference between the contents-only and both sustainable conditions was significantly smaller in the puffy claim condition ( $M_{\text {diff. }}=$ -.96) than in the subdued $\left(M_{\text {diff. }}=-1.52\right)$ and absent claim $\left(M_{\text {diff. }}=-2.35\right)$ conditions $(p ' s<.05)$. The difference in the subdued claim condition was in turn also significantly smaller than in the claim absent condition $(p<.05)$. For packaging-only vs. both sustainable, the differences were of equal size under either the puffy $\left(M_{\text {diff. }}=-1.59\right)$ or subdued claim ( $\left.M_{\text {diff. }}=-1.85\right)$ conditions $(p=.44)$, but were still significantly smaller than the difference in the absent claim $\left(M_{\text {diff. }}=-2.21\right)$ condition $\left(p^{\prime} s<.05\right)$. Taken together, the results for attitudes showed that the differences between the partially sustainable conditions and the fully sustainable condition were actually smaller (rather than larger) under puffy claims compared to absent claims, which implied that puffy claims might be used to increase (rather than decrease) overall attitudes.

\section{Effects on perceived deception, greenwashing and sustainability}

Similarly, ANOVAs were conducted to test the effects of claim puffiness and actual sustainability on perceived deception, greenwashing and sustainability. Results (Table 4.2) showed medium to large significant effects of actual sustainability, as well as small to medium significant effects of claim type, on each construct. The patterns of means for actual sustainability were such that the both sustainable condition led to lower perceived deception and greenwashing (as well as higher perceived sustainability) compared to either partially sustainable condition, in line with $\mathrm{H} 1$. The main effect of claim type indicated that perceived greenwashing and 
deception were equally high under both the puffy and subdued claims, and lower when no claim was used. Conversely, perceived sustainability was lower when no claim was used relative to either claim.

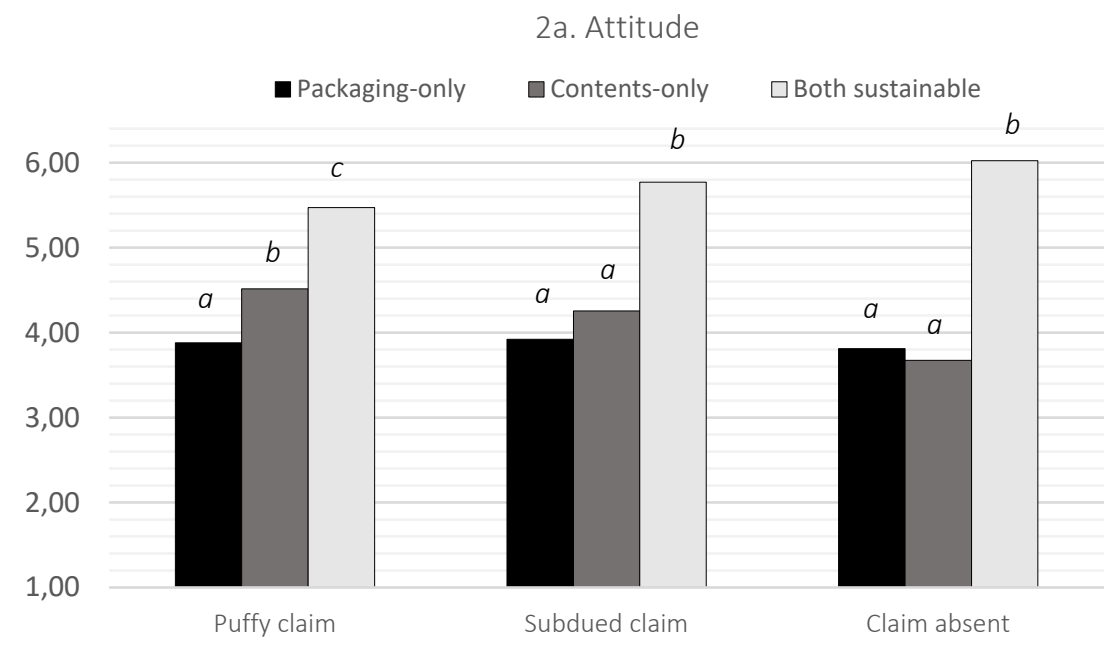

2b. Perceived greenwashing

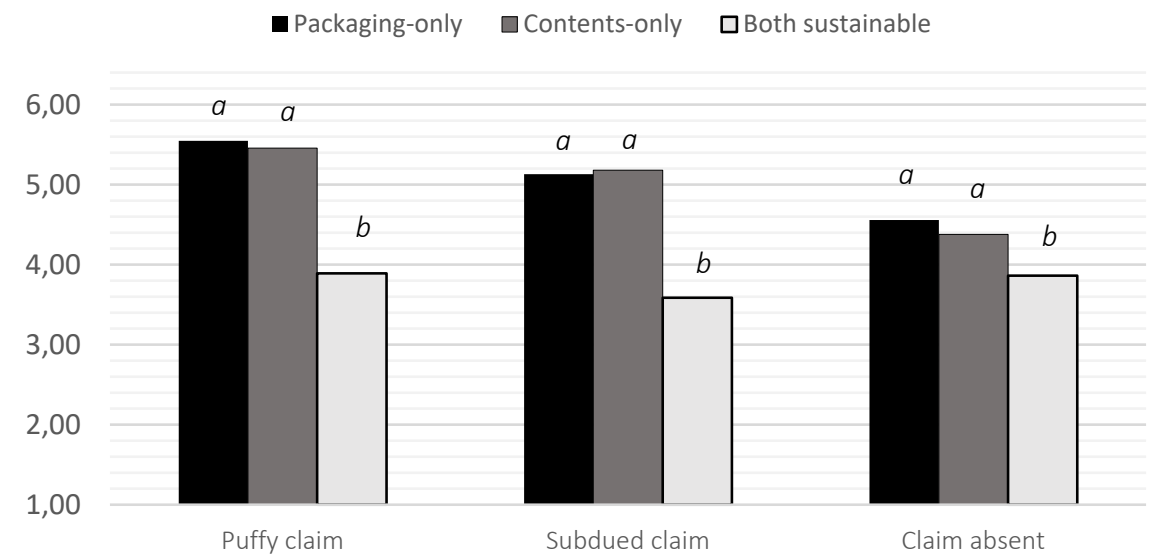

FIGURE 4.1. Interaction graphs for attitudes \& greenwashing per actual sustainability \& claim puffness conditions.

Note. Superscripts a-c denote statistically significant differences between actual sustainability means per claim at the $\alpha=.05$ level. Means that share the same superscript character are not significantly different from one another. 
The centrality hypothesis $(\mathrm{H} 4)$ was tested with a contrast between the packagingonly and contents-only conditions on perceived deception and greenwashing, under presence of (either) claim. Results showed no differences (perceived deception: $M_{\text {packaging-only }}=4.79$ vs. $M_{\text {contents-only }}=4.68, p=.47$, perceived greenwashing: $M_{\text {packaging- }}$ only $=5.34$ vs. $M_{\text {contents-only }}=5.32, p=.90$ ), suggesting that there was no centrality effect.

A significant interaction between actual sustainability and claim type was found for perceived greenwashing (Table 4.2). First, we consider the differences in actual sustainability for each claim (Figure 4.1b), which showed that the both sustainable condition scored significantly lower on perceived greenwashing than either partially sustainable condition (which were not significantly different from each other in any claim condition). Second, we consider the differences in effects of actual sustainability (contents-only vs. both sustainable and packaging-only vs. both sustainable) across claim type conditions. Contrasts showed that the difference between the contents-only and both sustainable conditions was significantly smaller in the claim-absent condition than in the subdued and puffy claim conditions $(p<$ .05). The difference between the subdued and puffy claim was not significant ( $p=$ .93). The difference between the packaging-only and the both sustainable condition was also significantly smaller in the claim-absent condition than under the subdued and puffy claims $(p<.05)$, and the difference of the subdued and puffy claim differences was not significant $(p=.75)$. Interestingly, these results on greenwashing are contrary to those of attitudes, that is, puffy claims tended to increase the gap between the fully sustainable offering compared to the partially sustainable alternatives.

\section{Indirect effects (moderated mediation) analysis}

In order to test for the proposed moderated mediation $(\mathrm{H} 3 / \mathrm{H} 5)$, we first investigated the effects of the mediators (perceived greenwashing ${ }^{5}$ and sustainability) on the dependent variables. Linear regression analyses with the two mediators as predictors showed significant negative effects of perceived greenwashing on attitude toward the packaged product $(b=-.23, p<.001)$ and purchase intentions $(b=-3.68, p<.001)$. Conversely, perceived sustainability had

\footnotetext{
${ }^{5} \mathrm{Although}$ the total effects interaction was not significant for perceived deception (the more general construct), its pattern of results in terms of moderated mediation was similar to perceived greenwashing.
} 
Partially green, wholly deceptive?

significant positive effects on attitude toward the product $(b=.52, p<.001)$ and purchase intentions $(b=3.59, p<.01)$. These results supported $\mathrm{H} 2$.

Subsequently, we used the SPSS PROCESS macro (Hayes \& Preacher, 2014) with 10,000 bootstrap samples. Actual sustainability was entered as the independent variable (based on two dummies to estimate the difference between contents/packaging-only vs. both sustainable, the latter as the reference category), and claim puffiness as (categorical) moderator. Perceived greenwashing and perceived sustainability were entered as parallel mediators and analyses were run for each dependent variable separately. This model thus tests whether mediated (indirect) effects occurred and simultaneously tests whether these indirect effects are moderated. To provide an omnibus test, results for the pathway through perceived sustainability showed significant indices of mediated moderation on attitude toward the product through the first dummy comparing contents-only vs. both sustainable (Index contents vs. both $=0.20, S E=0.08, C 195[0.05,0.36])$. The result for the second dummy (packaging-only vs. both sustainable) was marginally significant (Index packaging vs. both $=.12, S E=0.07, C 1900.004,0.24])$. For purchase intention, the moderated mediation through perceived sustainability was marginally significant for the first dummy (Index contents vs. both $=.77, S E=.54, C 1990.06,1.81])$, but not significant for the second (Index contents vs. both $=0.46, S E=0.40, C 199-0.03,1.32]$ ). Pathways through perceived greenwashing showed significant mediated moderation for attitude (Index $x_{\text {contents vs. both }}=-.09, S E=0.03, C 195[-0.15,-0.03]$, Index packaging vs. both $=-$ $.08, S E=0.03, \mathrm{Cl} 95[-0.15,-0.02])$ as well as purchase intention (Index contents vs. both $=-^{-}$ 1.36, $S E=0.62, C 195[-2.74,-.33]$, Index packaging vs. both $=-1.25, S E=0.60, C / 951-2.61$, $0.25])$. Significant direct effects of actual sustainability were found for attitude toward the packaged product $\left(F(2,404)=15.91, \Delta R^{2}=.04, p<.001\right)$ and purchase intention $\left(F(2,404)=15.93, \Delta R^{2}=.05, p<.001\right)$, indicating partial (moderated) mediation.

Table 4.3 shows all estimated indirect effects and provides significance testing of each contrast. In line with $\mathrm{H} 5 \mathrm{a}$, the patterns of these pathways showed that as claim puffery increased, the indirect effects through perceived greenwashing increased (i.e., led to a more negative response). All contrasts were significant such that the indirect contribution of perceived greenwashing was lowest for the claim-absent condition, highest for the puffy claim and intermediate for the subdued claim. At the same time, in line with $\mathrm{H} 5 \mathrm{~b}$, the indirect effect of perceived sustainability was highest for puffy claims, relatively lower for subdued claims, and lowest in the claim-absent condition. These effects however were less pronounced than the differences in perceived greenwashing, particularly as the contrasts between claims were not 
significant for the packaging-only versus both sustainable dummy for the effects on purchase intention. This implies that, for purchase intentions, (puffy) claims can exert a positive effect through (higher) perceived sustainability, but only when product contents are sustainable and not when only packaging is sustainable.

TABLE 4.3. Indirect effects of actual sustainability rating on attitudes and purchase intentions

\begin{tabular}{lllll}
\hline Dummy & \multicolumn{2}{c}{ Attitude - product } & \multicolumn{2}{l}{ Purchase intention } \\
\hline Perceived sustainability & $\underline{\text { Effect }}$ & $\underline{S E}$ & $\underline{\text { Effect }}$ & $\underline{S E}$ \\
Contents vs. both - Claim absent & $-1.03^{\mathrm{a}}$ & .16 & $-4.08^{\mathrm{a}}$ & 2.29 \\
Contents vs. both - Subdued claim & $-.84^{\mathrm{b}}$ & .11 & $-3.31^{\mathrm{b}}$ & 1.83 \\
Contents vs. both - Puffy claim & $-.64^{\mathrm{c}}$ & .11 & $-2.54^{\mathrm{c}}$ & 1.43 \\
& & & & \\
Packaging vs. both - Claim absent & $-.96^{\mathrm{a}}$ & .15 & $-3.80^{\mathrm{a}}$ & 2.14 \\
Packaging vs. both - Subdued claim & $-.85^{\mathrm{b}}$ & .11 & $-3.34^{\mathrm{a}}$ & 1.86 \\
Packaging vs. both - Puffy claim & $-.73^{\mathrm{c}}$ & .11 & $-2.89^{\mathrm{a}}$ & 1.63 \\
Perceived greenwashing & $\underline{E f f e c t}$ & $\underline{S E}$ & $\underline{E f f e c t}$ & $\underline{S E}$ \\
Contents vs. both - Claim absent & $-.12^{\mathrm{a}}$ & .05 & $-1.82^{\mathrm{a}}$ & .88 \\
Contents vs. both - Subdued claim & $-.20^{\mathrm{b}}$ & .05 & $-3.18^{\mathrm{b}}$ & 1.12 \\
Contents vs. both - Puffy claim & $-.29^{\mathrm{c}}$ & .07 & $-4.54^{\mathrm{c}}$ & 1.59 \\
& & & & \\
Packaging vs. both - Claim absent & $-.13^{\mathrm{a}}$ & .09 & $-2.12^{\mathrm{a}}$ & .96 \\
Packaging vs. both - Subdued claim & $-.21^{\mathrm{b}}$ & .09 & $-3.36^{\mathrm{b}}$ & 1.17 \\
Packaging vs. both - Puffy claim & $-.29^{\mathrm{c}}$ & .09 & $-4.61^{\mathrm{c}}$ & 1.59 \\
\hline
\end{tabular}


Partially green, wholly deceptive?

\subsubsection{Discussion Experiment 2}

Experiment 2 shows that, in line with Experiment I, when firms make explicit sustainability claims, partial discrepancies lead to worse attitudes and lower purchase intentions compared to fully sustainable product-packaging combinations. Moreover, in line with expectations, claim type moderates the (indirect) effects on attitudes and purchase intentions through perceived greenwashing and perceived sustainability. Specifically, using either type of sustainability claim increases perceived greenwashing (relative to the firm not making any sustainability claim) and this increase is strongest for puffy claims. At the same time, the effect of (puffy) claims is not wholly negative as they also tend to increase perceived sustainability of the packaged product which leads to an increase in the positive indirect effects on attitude and purchase intention. This suggests that for partially sustainable productpackaging combinations, consumers may positively value the increase in environment-friendliness yet at the same time also react negatively to potentially deceptive firm practices because these are seen as a form of greenwashing.

Contrary to Experiment I, the current study did not provide direct evidence for the centrality effect. However, the results from indirect effects on purchase intention did show that (puffy) claims exerted a positive effect through (higher) perceived sustainability for the contents-only sustainable condition, but not for the packagingonly condition. Thus, it appears that peripheral attributes in that sense are penalized more strongly as there is no relative increase in positive effects through perceived sustainability. Additionally, another interesting result is that the sum of indirect effects through perceived sustainability was several times larger than the sum of indirect effects through perceived greenwashing for attitudes, but not for purchase intentions (where sums are roughly equal), which implies that more weight is given to firms' potential greenwashing attempts in the decision whether to purchase than in mere product evaluation. 


\subsection{General discussion}

\subsubsection{Theoretical implications}

The current research offers several contributions to the literature. First, the chapter investigates how consumers respond to partially sustainable offerings when they are presented with explicit environmental claims provided by the producer, relative to wholly (not) sustainable packaging-product combinations. Specifically, we show that consumers are more likely to infer deceptive firm intentions when firms provide environmental claims for packaged products for which only either packaging or product contents are truly sustainable, compared to when both are sustainable. From a theoretical perspective, this means that consumers make attributions of deceptive (firm) intentions when such an inference becomes more salient due to a claim-fact discrepancy. That is, the firm implies 'full' sustainability but the actual offering is only partially sustainable. For such products, consumers make both positive and negative inferences such that they positively value the improved environmental impacts, yet at the same time negatively value the deceitful actions of the firm. Thus, even though the inclusion of a green attribute can itself exert a positive effect, perceptions of greenwashing and related feelings of deception cause consumers to penalize both the packaged product and firm simply because of how the offering is positioned. This negative impact dampens the positive impacts of sustainability attributes.

Second, building on this claim-fact discrepancy and following recent work in the marketing domain (Gershoff \& Frels, 2015), findings suggest that the impacts of claim-fact discrepancies between firm's claimed and actual environmental performance depend on the centrality of the attributes that are (or are not) sustainable. Making a peripheral attribute sustainable, and leaving a central attribute decisively less sustainable, tends to be perceived as a greater transgression. This centrality effect was found in the first experiment, however only an indirect effect of centrality could be inferred from the second experiment. While prior research has chiefly considered claim-fact discrepancies from a CSR (Wagner et al., 2009) and a marketing-communications perspective (Darke \& Ritchie, 2007), the current work implies that the nature of these discrepancies is more complex when considering them in light of a product attribute perspective because these attributes can inherently differ in their centrality, even when perceived environmental impacts are the same.

Third, the current work investigates the influence of claim puffiness as a moderator for the effects of the claim-fact discrepancy. Previous research has shown 
that the presence and specificity (general advertisement vs. green advertisement or no advertisement) affects consumer response in presence of objective sustainability performance ratings such that consumer reactions become more negative when the ad becomes more specific (Nyilasy et al., 2014; Parguel, Benoit-Moreau, \& Larceneux, 2011). Our findings complement this prior research by showing that claim puffery also affects consumer response. Specifically, the claims influenced perceived greenwashing and sustainability such that using puffy environmental claims leads to relatively more positive indirect effects through perceived sustainability, yet simultaneously also increases the relatively more negative effects through perceived greenwashing. Thus, the findings suggest there are both pros and cons to puffery, and while using subdued (rather than puffy) claims or avoiding the use of claims reduces the cons (lowers the negative effect through perceived greenwashing), it also reduces the pros (lowers the positive effect through perceived sustainability). Although for consumer attitudes these pros seem to outweigh the cons, for purchase intentions the indirect effects are comparable in sizes. While previous research has also indicated similar positive effects through perceived sustainability (Magnier et al., 2016), these findings thus highlight that (puffy) claims can make consumers feel ambivalent especially for partially sustainable offerings. Hence, the additional inclusion of potential perceived firm deceptiveness (and more specifically, greenwashing) provides a better explanation of consumer responses as the consideration of only a positive effect of using (puffy) claims on perceived sustainability can be considered as myopic. 


\subsubsection{Practical implications}

Firms that market and actively promote products with environmental attributes can best do so when the product's environmental performance matches that claim. Specifically, when making general sustainability claims consumers respond most positively to offerings that are wholly sustainable. Various sustainability-oriented firms make sustainability claims explicitly and seek to match this with products that include sustainability in all (or as many as possible) product attributes. For example in a recent campaign Arla, a European dairy producer, promotes its more environment-friendly packaging by introducing it for its organic dairy products and explicitly stating that "organic dairy deserves a more sustainable package". On the other hand, promoting products that possess sustainability attributes but also possess other attributes which are less (or decisively not) as sustainable can lead to a backlash because consumers may think that the firm is attempting to deceive them, despite consumers also valuing the increased environment friendliness in itself. This may be particularly troublesome for products which have some degree of improved environment friendliness in one component, but for which further improvements in other components could still be made.

While indeed making such products consistently 'green' might be the best option, such solutions may not always be feasible in practice. In such cases, the findings suggest that firms should be careful in setting expectations. Particularly, not providing explicit promotional sustainability claims (or using more subdued claims, rather than puffy ones) decreases the likelihood of consumers perceiving that the firm is actively trying to greenwash. However, without clear claims consumers may also not readily recognize the environmental benefits as strongly. Thus, using puffy claims (vs. subdued claims, or no claims) has clear pros and cons which should be weighted when making decisions on how to position (partially) sustainable packaged products.

\subsubsection{Limitations \& future research}

The current research provided participants with ratings of the 'true' environmental impacts of packaging and product contents. While similar real-world initiatives exist (e.g., Rank a Brand (www.rankabrand.org), Greenwashing Index (www.greenwashingindex.com) and GoodGuide (www.goodguide.com)), assessing the environmental impacts of such products is often complex and this information may not be readily available, especially not in a consumer-understandable format. 
Partially green, wholly deceptive?

In practice, consumers may rely on lay-theories (e.g., 'plastics are bad for the environment') rather than detailed information, to consider whether the producer is attempting to greenwash. Additionally, although research has used similar paradigms (Kopalle et al., 2017; Nyilasy et al., 2014; Parguel et al., 2011), the presentation of explicit sustainability scores in combination with the firm's claim also highlights the discrepancy in a way that is not necessarily common in real-world purchase contexts, and which could give rise to demand biases.

The experiments were also limited to investigating the beverages category with a specific focus on packaging versus product contents. While beverages and drinks are often the target of environmental improvement and related promotional campaigns (both in terms of ingredients and packaging), future research could consider the different (perceived) environmental impacts of various categories. Some categories may be more closely associated with environmental damage than others and consumers may be more skeptical towards inconsistent product offerings for categories associated with a high environmental burden (e.g., washing detergents, chemical household cleaners). Additionally, while we included only two attributes (packaging and contents) future research could consider using a larger set of more central/peripheral attributes which can be made more sustainable to provide further evidence for the centrality hypothesis in tandem with environmental product marketing. With regard to the (mixed) centrality findings we should also note that Experiment II contained an explicit reference stating that the environmental impacts of packaging/product contents are equal (based on the distribution found in Experiment I). Potentially, this explicit mention may have cued consumers to also consider its believability, which could have affected the results with regard to the centrality distinction.

In terms of methodology, we opted to operationalize the concept of ad puffery by utilizing multiple concurrent elements aligning with the concept of puffery (e.g., verbal elements such as superlatives as well as graphical elements such as colors and visual emphasis). The reasons for this were to provide a more general view of ad puffery and to improve the realism of the stimuli. A limitation of this approach is that it does not allow for the disentanglement of the separate effects of each manipulated element. Although we did not seek to investigate the relationships between each of these specific elements, future research might consider an investigation of specific means to convey puffy advertisement. This could be supported by the development of a validated scale to measure (various forms of) puffery as to our knowledge no validated scales exist. 


\subsection{Conclusion}

The current study contributes to the literature on sustainable consumer behavior by investigating how consumers respond when firms make sustainability claims that they only partially match in their actual packaging product combinations. The chapter shows that this information is processed through contrasting pathways of deceptiveness ('greenwashing') and (perceived) sustainability such that even though consumers value the (partial) improvements in the packaged product's sustainability, the effect of deception simultaneously exerts a negative effect on consumers' attitudes and purchase intentions, which hampers the generation of positive consumer outcomes. The way in which firms make sustainability claims also affects this process as using highly puffy claims increases both the positive effect of perceived sustainability as well as the negative effect through perceived greenwashing relative to using subdued claims or not making a claim at all. Thus, firms need to carefully weigh the pros and cons of making such claims. 
Partially green, wholly deceptive?

APPENDIX 4.1. Example stimulus for Experiment 1

\section{ECOJUDGE}

\begin{tabular}{|c|c|c|c|c|}
\hline FOOD \& BEVERAGES & ENERGY & ELECTRONICS & PERSONAL CARE & HOUSE \& GARDEN \\
\hline
\end{tabular}

SUSTAINABILITY SCORES

Category: Beverages \& juices Brand:
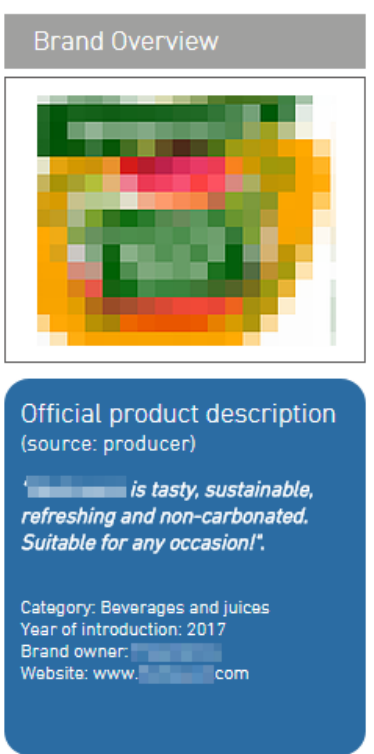

The sustainability of beverages is reflected in the packaging. such as the use of environmentally friendly (bio) materials and the improvement of recyclability. The use of sustainable ingredients in the beverage itself, and the energy and water consumption are also part of our criteria.

\section{How sustainable is an?}

We assess the sustainability of this product on the basis of both the packaging and the content (the beverage itself).

\section{PACKAGING}

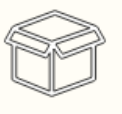

\section{VERDICT: EXCELLENT}

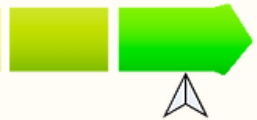

This package receives an EXCELLENT score on sustainability. The packaging thus belongs to the most sustainable packaging within this category.

- Technical details assessment (packaging)

PRODUCT CONTENTS
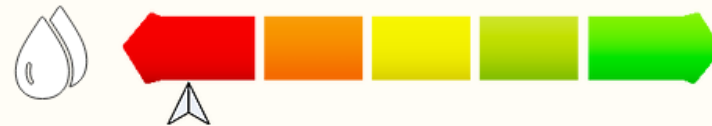

VERDICT: BAD

The contents of this product receive a BAD score on sustainability The content and ingredients thus belong to the least sustainable within this category.

- Technical details assessment (product contents)

Note. This is a translated version. Original stimuli were displayed in Dutch. 


\section{CHAPTER 4}

APPENDIX 4.2. Items and scales for Experiment 1 \& 2

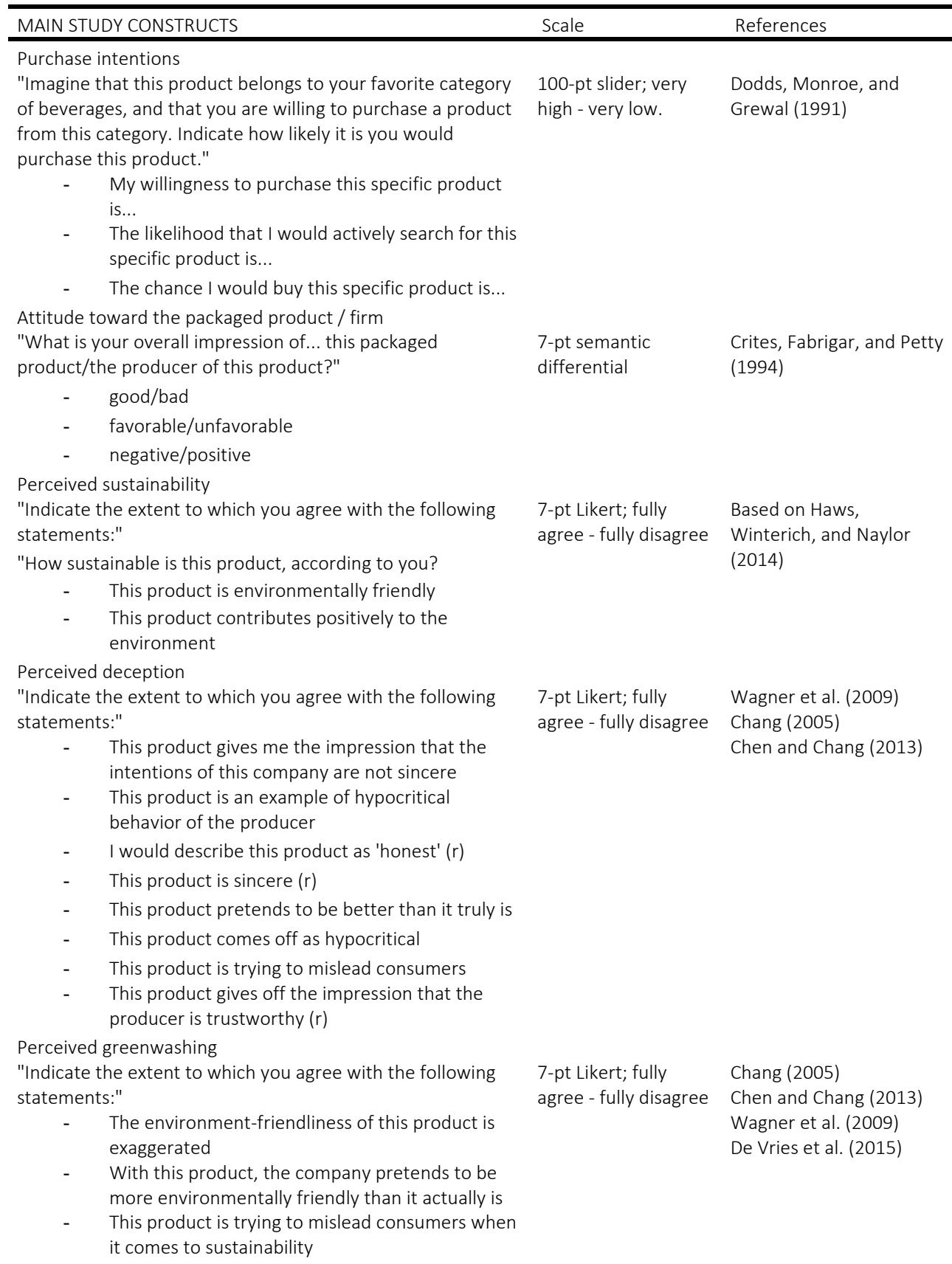


Partially green, wholly deceptive?

APPENDIX 4.2. Items and scales for Experiment 1 \& 2 (continued)

\section{ADDITIONAL MEASURES}

Packaging-Product Congruence (Degree of fit)

"Indicate the extent to which you agree with the following statements:"

- $\quad$ The packaging and product fit well together

- $\quad$ The packaging is compatible with this product

- $\quad$ The beverage drink itself and the packaging are very appropriate

Category inference

"Indicate the extent to which you agree with the following statements:"

- $\quad$ This product can easily be labelled as

'sustainable'

- $\quad$ I would clearly label this product as 'sustainable'

Elaboration/novelty

"Indicate the extent to which you agree with the following statements:"

- $\quad$ This product is surprising

- $\quad$ This product makes me think

Environmental concern

"Indicate the extent to which you agree with the following statements:"

- $\quad$ Humans are severely abusing the environment

- $\quad$ The balance of nature is strong enough to cope with the impacts of modern industrial nations

- The so-called "ecological crisis" facing humankind has been greatly exaggerated

- If things continue on their present course, we will soon experience a major ecological

catastrophe

- When humans interfere with nature it often produces disastrous consequences

Notes. $(r)$ indicates a reverse-coded item. Constructs were presented in the same order as they are listed. The additional measures were presented after measuring all constructs relevant to the theoretical model to prevent them from influencing prior measures. 7-pt Likert; fully agree -

fully disagree

7-pt Likert; fully agree -

fully disagree

7-pt Likert; fully agree -

fully disagree

7-pt Likert; fully agree - Hawcroft and Milfont fully disagree (2010) 
APPENDIX 4.3. Advertisement stimuli for Experiment 2 (translated).

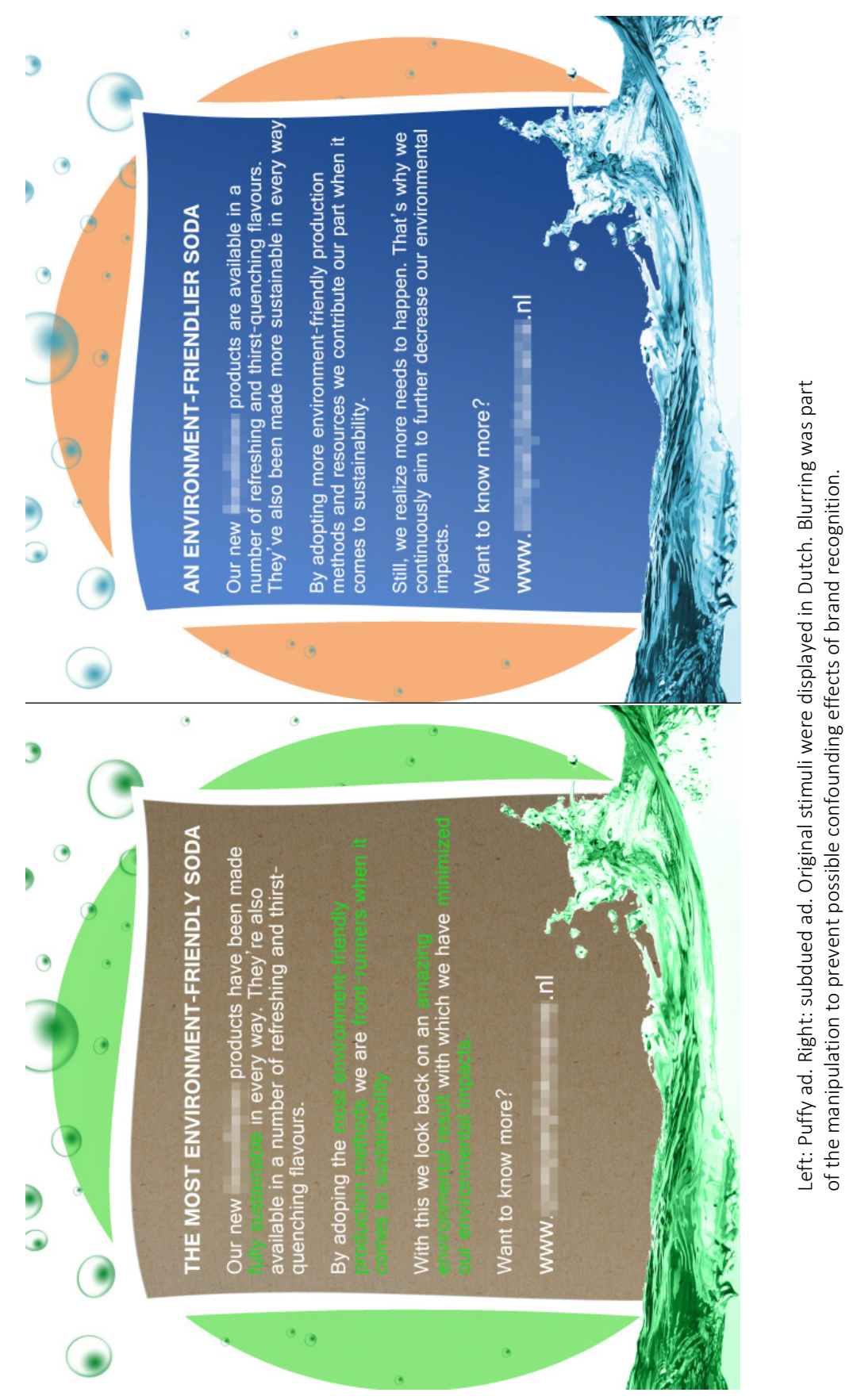




\section{CHAPTER 5}

Making it macho: Using 'gendered' packaging designs to increase consumer preferences for sustainably packaged products

This chapter is submitted as:

Steenis, N. D., van der Lans, I. A., van Herpen, E., \& van Trijp, H. C. M. (2019). Making it macho: using 'gendered' packaging designs to increase consumer preferences for sustainable packaged products. 


\section{ABSTRACT}

This chapter investigates how 'gendered' packaging designs affect consumer decision-making with regard to packaged products where the packaging overtly signals sustainability. Firms can use such packaging to draw consumers' attention and cue the environmental benefits in order to gain a competitive advantage. However, prior research attests that the use of sustainability signals can lead to both advantages in disadvantages in terms of consumer perception. For example, prior research shows that offerings with sustainability benefits are favorably perceived in terms of gentleness benefits, yet are disadvantaged in terms of perceived strength benefits. Given that such consumer perceptions can form a barrier to choice when strength benefits are valued, the objective of this chapter is to investigate how packaging design can be used to improve the competitiveness of sustainably packaged products (i.e., those products where the packaging contains sustainability cues). The chapter reports results from three experiments in which laundry detergent packaging was varied in sustainability and gender cues. Findings indicate that although consumers disadvantage sustainably packaged products when they seek out strength benefits, this can be overcome by providing masculinity signals through packaging design. Particularly, packaged products that contain both sustainable and masculine packaging design cues are perceived relatively favorable in terms of perceived strength, gentleness and environment-friendliness. They are more likely to be chosen compared to laundry detergents with conventional, non-gendered packaging designs even in cases where consumers seek out strength (rather than gentleness) benefits. Conversely, sustainable designs are preferred in general when consumers seek gentleness. 
Making it macho

\subsection{Introduction}

Recent research into sustainable marketing highlights that consumers often hold implicit associations whereby products with sustainability attributes are considered as less potent (Lin \& Chang, 2012; Luchs \& Kumar, 2015; Luchs, Swan, \& Creusen, 2016; Luchs et al., 2010; Pancer et al., 2017). Consumers intuitively tend to consider that a product can be either strong or 'green', but not both (Luchs et al., 2010). For example, Lin \& Chang (2012) have shown that consumers consistently use more hand sanitizer when it has an eco-label on the packaging than when it does not, to offset lower perceived ability to combat germs. Conversely, research suggests that sustainable products are valued better in terms of gentleness benefits as sustainability reflects aspects of caring and nurturing (Brough et al., 2016; Luchs et al., 2016).These associations suggest that sustainable alternatives are likely to be valued over conventional products when gentleness is important, yet when consumers (also) seek out strength-related benefits, these associations may prevent consumers from making sustainable purchase decisions.

Packaging design is often used to generate impressions of sustainability (e.g., in terms of graphics, materials and labels) and such design affects consumer sustainability perceptions of the packaging as well as the product contents (Steenis et al., 2017). Packaging design elements also serve as cues for consumers to make other product-related inferences (Fenko et al., 2018; Steenis et al., 2017) and research has attested how packaging design can convey brand personality and product benefits (Orth \& Malkewitz, 2008). Some examples include how packaging design affects price expectations, perceived quality and attractiveness (Orth et al., 2010), and how the shape curvature and color saturation of packaging affects experienced taste (Becker et al., 2011). These influences of packaging design are particularly important when it comes to inferences about sustainability, because sustainability is a credence benefit which cannot be easily perceived or verified by consumers (Vermeir \& Verbeke, 2006). Stereotypical 'green' packaging aesthetics likely also cause consumers to more readily attach a strength penalty to the packaged product, yet there might also be other ways to use packaging designs in order to counteract this penalty.

Although the relationship between sustainability and perceived strength has been attested in prior research, comparatively less attention has been paid to means to counteract the effects of this inference. Most of the prior studied interventions rely on the explicit provision of information to overcome barriers to sustainable 
consumption (Gleim, Smith, Andrews, \& Cronin, 2013), for example by providing claims or a description of the production process that explicitly state that sustainable products are also effective (Lin \& Chang, 2012; Luchs et al., 2010; Newman et al., 2014). In real purchase situations however, consumers likely rely more on visual cues, particularly those from packaging design, rather than detailed explicit information, especially for low-involvement purchases (Hoegg \& Alba, 2011; Petty \& Cacioppo, 1986). Hence the influence of design elements is potentially an important factor regardless of whether explicit information is also present.

The current research contributes to the existing literature on consumer perceptions and preferences for sustainably packaged products by considering the role of packaging design as an intervention, specifically how gender (masculine versus feminine) aesthetics may be used as an implicit signal of strength benefits and as such will counteract the strength penalty related to sustainably packaged products. The use of gender elements in packaging and product design has long been a cornerstone of marketing practice and pertains to the imbuement of gender associations in product offerings (different from positioning strategies that target specific consumer genders). Gendered design has been studied by marketing scholars as a tool to signal specific benefits or brand personality associated with gender stereotypes (Grohmann, 2009; Lieven, Grohmann, Herrmann, Landwehr, \& Van Tilburg, 2015), yet the use of such designs for sustainable offerings has been largely overlooked.

Thus, the current study is centered around two packaging design factors, namely sustainable design (vs. conventional design) and the use of (masculine vs. feminine) gendered design elements. We test the influences of sustainable (vs. conventional) packaging designs on perceived strength and gentleness and downstream effects on choice and purchase intentions. The chapter also investigates how the extent to which the consumers' intended usage scenario calls for either strength- or gentleness benefits affects whether consumers are inclined to choose sustainable or conventional packaged products. We then introduce gendered packaging design variants to consider whether masculine (vs. feminine) packaging aesthetics can be used to improve consumer perceptions and choice for sustainably packaged products, especially when consumers seek out strength benefits in their product usage. 


\subsection{Literature review}

\subsubsection{Sustainability \& packaged product preference}

\section{Sustainability \& compensatory inferences}

Many consumers hold favorable attitudes toward the concept of sustainability (Vermeir \& Verbeke, 2006) as well as sustainable product attributes (Luchs et al., 2010). Consumers for example hold positive attitudes toward sustainable packaging in general (Van Birgelen et al., 2009), and may be willing to pay more for the inclusion of such a sustainable attribute (Steenis, Van der Lans, Van Herpen, \& Van Trijp, 2018). Despite these positive sentiments, actual consumer choices are often less sustainable than would be expected (Vermeir \& Verbeke, 2006). One of the causes of this gap is that the presence of a positively valued sustainability benefit can reduce the perception of other sought-after benefits (Luchs et al., 2010). This has been considered more broadly in terms of consumers' intuitive compensatory inferences, such that a product that is superior on one attribute is expected to be inferior on other attributes (Chernev, 2007; Chernev \& Carpenter, 2001). For example, deliberately more sustainable product offerings can be perceived less favorably because consumers infer that the firm has had to make compromises in quality or pricing, to offset increased production costs due to improved environmentfriendliness (Newman et al., 2014).

\section{Strength \& gentleness inferences in relation to sustainability}

Two potential consumer inferences arising from sustainability cues are inferences related to perceived strength and gentleness (Luchs et al., 2010). Strength is described according to perceived effectiveness, powerfulness and toughness (Lin \& Chang, 2012; Luchs et al., 2010), efficacy (Pancer et al., 2017), potency (Van Rompay, De Vries, Bontekoe, \& Tanja-Dijkstra, 2012), or intensity (Fenko et al., 2018) ${ }^{6}$. Such attributes can include for example a cleaning detergent's ability to kill germs, or a detergent's ability to remove tough stains. Conversely, gentleness can be represented by caring, benevolence, health and safety (Amos, Allred, \& Zhang, 2017;

${ }^{6}$ Although strength is sometimes used interchangeably with the term 'functionality' we consider that the latter term can encompass both strength and gentleness attributes. In some cases, gentleness may be a more functional aspect of product usage than strength, for example when using laundry detergents for delicate fabrics. 
Luchs et al., 2010), for example, the extent to which a soap is not harmful or irritating to the skin.

Due to ingrained lay-beliefs sustainable product attributes have become positively associated with the gentleness dimension (Luchs et al., 2010), and sustainability has come to represent principles of caring, warmth and compassion (Brough et al., 2016; Luchs et al., 2010). For example, on-pack biodegradability labels lead industrial cleaning products to be perceived as safer for consumer health, less toxic, less corrosive and less likely to contain consumer warning labels such as "do not get into eyes" or "keep out of reach of children" (Amos et al., 2017), which would be associated with a low degree of gentleness. In line with this, lay people's product usage itself indicates a negative association between sustainability and strength (Lin \& Chang, 2012; Luchs et al., 2010).

In line with prior research we expect that consumers perceive lower strength and higher gentleness for sustainably packaged products (vs. conventionally packaged ones):

H1a: Sustainably packaged (vs. conventionally packaged) products are perceived to have lower product strength.

H1b: Sustainably packaged (vs. conventionally packaged) products are perceived to have higher product gentleness.

\subsubsection{Effects of consumers' intended usage scenario on choice for sustainable versus conventional alternatives}

A sustainable alternative need not be generally superior or inferior in terms of a consumer evaluation, but rather consumers' eventual preferences and choices are determined by the importance of the benefits that are affected. The sustainabilitylow strength association has been studied for products for which strength-related attributes are important in consumer choice, such as considering antibacterial capabilities of a hand soap when the goal is not to catch a flu (Lin \& Chang, 2012). When consumers seek out gentleness-related attributes (e.g., related to caring, safety and warmth), sustainable products should be preferable. For example, for baby shampoo gentleness is typically valued more than strength, hence preferences for a sustainable baby shampoo exceed preferences for sustainable car shampoo, a product where strength is valued (Luchs et al., 2010). Thus, whether sustainability is 
Making it macho

an asset for increasing consumers' purchase likelihoods or not depends on the relative importance of strength and gentleness benefits.

For many product categories both strength and gentleness are potentially relevant benefits. For example, consumers might be especially inclined to search for a sustainable stain remover when trying to remove a stain from expensive leather upholstery because it may be perceived as the safest way of dealing with the stain without harming the fabric. Conversely, when consumers would try to clean particularly hard to remove stains on a kitchen appliance, they might focus their search on conventional cleaners rather than sustainable ones because potency is a more relevant factor in the decision.

This implies that, in view of compensatory inference-making (Chernev, 2007; Chernev \& Carpenter, 2001; Newman et al., 2014), the use of sustainable packaging designs (vs. conventional ones) does not by definition lead to worse or better consumer purchase behavior but is (co-)determined by whether strength or gentleness is more relevant and important in the intended usage situation. Thus, we hypothesize that the extent to which the desired usage scenario values strength vs. gentleness affects the desirability of sustainable vs. conventional packaged products:

H2: Sustainably packaged (vs. conventionally packaged) products are less preferable when the consumer's intended usage emphasizes strength, and more preferable when the consumer's intended usage emphasizes gentleness.

\subsubsection{Interplay of packaging sustainability \& gender design on consumer preference}

\section{Gendered design \& sustainability}

Positioning strategies for consumer goods frequently associate brands and products with masculine or feminine personality traits (Grohmann, 2009), and marketers have sought to do so in order to imbue their brands with specific personality or to imply that the brand has specific values and benefits. For example, masculinity is marketed as adventurous, aggressive, brave, daring, dominant and sturdy, while femininity is harmonic, subtle, tender, fragile, graceful, sensitive and sweet (Grohmann, 2009; Van Tilburg, Lieven, Herrmann, \& Townsend, 2015). Associating products with gender can be achieved through various means including marketing communications and brand spokespeople (Grohmann, 2009), brand names (Guevremont \& Grohmann, 2015; Lieven et al., 2015) and product and 
packaging design (Creusen \& Schoormans, 2005; Lieven et al., 2015; Van Tilburg et al., 2015). Product and packaging design are a particularly important source of product gender perceptions because they provide relatively direct means of anthropomorphizing inanimate objects; they are analogous to human physical features which can inform a person's gender or other traits (Epley, Waytz, \& Cacioppo, 2007; Van Tilburg et al., 2015).

Prior research indicates that a variety of design elements contribute to a product's perceived masculinity or femininity (Schnurr, 2018). For example, masculine designs include shapes that are straight and angular (vs. round and curvy for feminine ones), and darker colors (vs. lighter hues for feminine designs). Appendix 5.1. presents an overview of the elements of shape, type font, materials, textures and colors that have been shown to influence gender-oriented brand personality.

The use of masculine design elements has for example been shown to increase taste intensity during the consumption of food products and (Becker et al., 2011). Masculine design cues also increase consumer preference in the context of functionally-oriented products (Schnurr, 2018). Additionally, in the presence of lowcompetence cues (e.g., an unproven product), masculine design cues enhance purchase likelihood because they serve as surrogate cues for competence (Hess \& Melnyk, 2014). Since consumers tend to be more uncertain about the performance of sustainable (versus conventional) products (Luchs, Brower, \& Chitturi, 2012), masculine design cues could likewise potentially be used to address this perceived shortcoming.

Sustainable products are typically marketed using sustainable packaging design elements (e.g., green and earth-tone color palettes, natural imagery, frilly fonts, etc.) and the specific use of these aesthetics has often been characterized as feminine rather than masculine which in part may explain why sustainable products are often perceived as low in strength (Brough et al., 2016). The use of masculine packaging design cues can potentially offset lower strength perceptions inferred from sustainability packaging cues, and also may be able to link sustainably packaged products with associations of strength, possibly in addition to gentleness. That is, the presence of both masculinity and sustainability cues may inhibit the degree to which consumers make compensatory inferences, resulting in a packaged product that is perceived relatively favorable in both strength and sustainability (and potentially gentleness). 
We hypothesize that masculine packaging design reduces or removes the strength penalty for the sustainable option. We expect that masculine design increases strength for both conventional as well as sustainably packaged products, but we also more specifically expect the increase in perceived strength to be stronger for the latter. As we predict conventional packaged products to be perceived as relatively higher in strength $(\mathrm{H} 1 \mathrm{a})$, providing masculine design cues may have a somewhat diminished effect in further increasing perceived strength compared to when these masculine design cues are used for sustainably packaged products (which are expected to be lower in perceived strength). Thus, the gap between sustainable and conventional in terms of strength perceptions should be reduced when masculine design cues are applied.

H3a: Using a masculine packaging design (vs. feminine design) increases perceived strength.

H3b: The increase in perceived strength by using a masculine packaging design (vs. feminine design) is stronger for sustainably packaged products compared to conventional alternatives.

Integrating the prior discussions and hypothesis, we posit that higher perceived strength, gentleness and sustainability each are principally desirable product benefits that also mediate the effects of sustainability design (in combination with gender design) on consumer preferences (purchase intentions and choice).

H4: Perceived strength, perceived gentleness, and perceived sustainability mediate the (interactive) effect of sustainability packaging design and gender packaging design on consumer preferences. 


\subsection{Research overview}

Three experiments were conducted to test the hypotheses. The first experiment aimed to verify the assumption that consumers would be less (more) likely to choose a sustainably packaged product (vs. a conventional one) when strength (gentleness) was emphasized in intended product usage. The second experiment introduced gendered sustainable packaging designs to test their effects on consumer choices. The third experiment was a larger-scale study aimed to test the process underlying these choices by investigating the role of perceived strength, gentleness and sustainability constructs in a moderated-mediation model.

\subsection{Experiment I: Choice experiment sustainable vs. conventional packaging design}

Experiment I sought to verify the proposition that sustainability is a liability when strength is sought in consumers' usage scenario, and a benefit when gentleness is sought.

\subsubsection{Method}

The experiment used a $2 \times 2$ within-subjects design with a fictitious fast-moving consumer good (laundry detergent), two usage scenarios (one with a strength emphasis vs. one with a gentleness emphasis), and two packaging design variants (sustainable design vs. conventional design). Participants were 105 Dutch(-speaking) consumers recruited through a professional consumer research panel $\left(M_{\text {age }}=48.66\right.$, $S D_{\text {age }}=16.58,50.5 \%$ male), and received a small financial compensation for participating. Sampling quota were applied such that the sample was equally distributed in terms of gender and contained respondents aged 18+. Participants were selected to either sometimes or regularly purchase and/or use laundry detergents to ensure experience with the product category

\subsubsection{Stimuli}

Laundry detergents were selected because both strength benefits (e.g., ability to clean clothes, remove stains) as well as gentleness benefits (e.g., protecting delicate fabrics) are relevant purchase criteria. Additionally, packaging design plays a major role in generating impressions at the point-of-purchase, as the qualities of the detergent are experience attributes that cannot be examined at this stage. The 
packaging variants (Figure 5.1) were created by a professional graphic packaging designer and differed in terms of color palettes (green for sustainable vs. orange/blue for conventional), materials (sustainable pulp-look vs. conventional plastic look) and symbolic elements (e.g., leaf icon for the sustainable alternative), but explicit (textual) information was kept constant. A fictional, neutral brand name was used ("Wash").

\subsubsection{Procedure \& measures}

Participants were first shown a description of the intended usage scenario (strength-emphasis or gentleness-emphasis; Figure 5.2), and then had to choose between either the detergent with a conventional packaging design and the one that had a sustainable design. The order in which the scenarios were presented was counterbalanced. The two packaging designs images were presented side-by-side on the same page (left- and right position was counterbalanced). Participants were thereafter shown the other scenario description, and again chose between the two alternatives

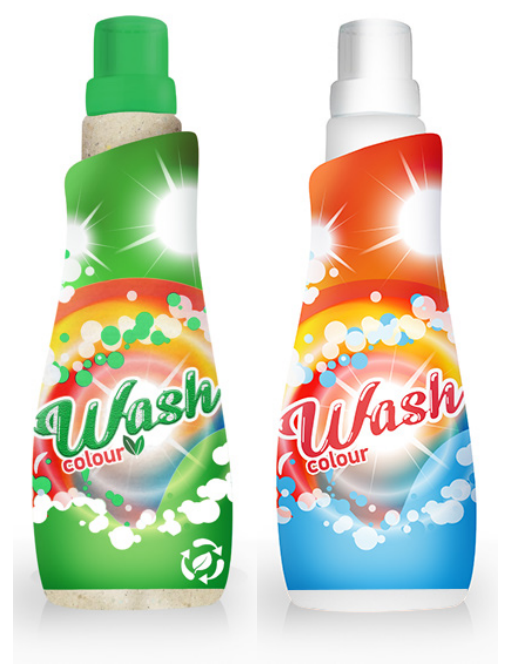

FIGURE 5.1. Experiment I sustainable \& conventional packaging design stimuli.

Following the choices in each of the two conditions, participants were separately shown the two variants in a randomized order, and asked to rate the packaged products on overall attitude (on a 7-pt bipolar adjectival scale with negative/positive 
as end-points), perceived sustainability (which also served as a manipulation check, measured on a 1-100-pt bipolar adjectival slider with totally not environmentfriendly/very environment-friendly as end-points), perceived strength- and gentleness (in two ways: one 100-pt bipolar adjectival item with strength/gentleness as end-points, and two separate items for strength- and gentleness on 7-pt Likert scales). Participants were instructed to make their choices and give their evaluations under the assumption that their usual brands were not available. Perceived attractiveness and perceived category fit of the packaged product were included as background measures. Participants also filled in a number of items measuring their environmental concern (Hawcroft \& Milfont, 2010). Details of scales and items can be found in Appendix 5.2.

\subsubsection{Results}

\section{Manipulation checks and background measures}

To check whether the manipulation of sustainability design was successful, a repeated measures ANOVAs was carried out. Its results showed that the sustainable design was perceived as more sustainable than the conventional one $\left(M_{\text {sustainable }}=\right.$ 71.31 vs. $\left.M_{\text {conventional }}=53.29, F(1,104)=46.80, p<.001, \eta_{p}{ }^{2}=.31\right)$, as intended. Next, to check whether the designs were roughly equivalent on the background measures, similar ANOVAs were carried out for attractiveness and category fit. The conventional design was perceived as relatively more attractive $\left(M_{\text {sustainable }}=5.22\right.$ vs. $M_{\text {conventional }}=$ $\left.5.54, F(1,104)=5.25, p<.05, \eta_{p}^{2}=.05\right)$ and marginally more typical of the category $\left(M_{\text {sustainable }}=5.31\right.$ vs. $\left.M_{\text {conventional }}=5.47, F(1,104)=3.44, p=.067, \eta_{p}^{2}=.03\right)$. However, both these effects were comparatively small.

Strength emphasis:

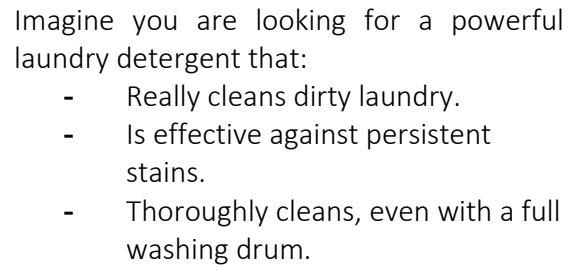

- Really cleans dirty laundry.

- $\quad$ Is effective against persistent stains.

- Thoroughly cleans, even with a full washing drum.

\section{Gentleness emphasis:}

Imagine you are looking for a mild laundry detergent that:

- Does not damage delicate, vulnerable fabrics (such as wool and silk).

- Is suitable for people with sensitive skin.

- Does not contain allergens

FIGURE 5.2. Usage scenario descriptions (labels were not shown to respondents). 


\section{Strength \& gentleness attribute evaluations}

Results from ANOVAs for the two separate strength/gentleness items showed that, in line with expectations, the sustainable design was perceived as less powerful $\left(M_{\text {sustainable }}=5.02\right.$ vs. $\left.M_{\text {conventional }}=5.53, F(1,104)=12.63, p<.05, \eta_{p}{ }^{2}=.11\right)$ and more gentle $\left(M_{\text {sustainable }}=5.08\right.$ vs. $\left.M_{\text {conventional }}=4.53, F(1,104)=8.53, p<.01, \eta_{p}{ }^{2}=.08\right)$ compared to the conventional design. Results were similar for the bipolar adjectival item measuring relative strength/gentleness: the sustainable design was perceived as relatively less powerful/more gentle, compared to the conventional design $\left(M_{\text {sustainable }}=51.66\right.$ vs. $\left.M_{\text {conventional }}=68.78, F(1,104)=23.26, p<.001, \eta_{p}^{2}=.18\right)$. Thus the results supported $\mathrm{H} 1$. No significant order effects of scenario/packaging presentation occurred.

\section{Choices}

In the strength-emphasis condition, $30.5 \%$ of participants chose the sustainable design. In the gentleness-emphasis condition, the pattern switched such a majority of $60 \%$ of the participants chose the sustainable design. These proportions were significantly different from one another (McNemar's test, $\chi^{2}(1)=14.75, p<.001$ ). Thus, results supported $\mathrm{H} 2$ such that sustainable designs were less preferred when the intended usage emphasized strength, compared to when it emphasized gentleness. Conversely, this preference switched in favor of the sustainable alternatives when the intended usage situation emphasized gentleness. The order in which scenarios were randomly presented as well as the alignment of the packaged product presentation had no significant effect on choices.

\section{Attitudes}

In order to explore whether consumers' overall evaluations were significantly in favor of the sustainable/conventional design, a repeated measures ANOVA was conducted with attitude as the dependent variable. Results showed that, on average, both designs were rated the same $\left(M_{\text {sustainable }}=5.56\right.$ vs. $M_{\text {conventional }}=5.56, F(1,104)=$ $\left.0.00, p=1.00, \eta_{p}^{2}=.00\right)^{7}$, indicating that consumers liked both designs equally, but base their choices on usage demands. There were no significant order effects of scenario/packaged product presentation.

${ }^{7}$ Only means were the exact same. The distributions and frequencies of scores varied between the two attitude measurements. 


\subsubsection{Discussion}

Experiment I supported $\mathrm{H} 1$ such that sustainable design leads to lower perceived strength and higher perceived gentleness. Furthermore, respondents' choices imply that whether sustainable packaging cues positively/negatively affect consumer choice depends on the intended usage scenario, in line with $\mathrm{H} 2$. The sustainably packaged variant was preferred when usage emphasized gentleness-related attributes, but in line with the 'sustainability liability' a majority of participants chose the conventionally packaged variant when the usage scenario emphasized strength.

\subsection{Experiment II: Choice experiment with gendered sustainable designs}

Experiment II extends Experiment I by introducing gendered sustainable designs connoting either masculinity or femininity and investigates their effect on consumer choices under the same usage scenarios as in Experiment I.

\subsubsection{Method \& procedure}

The experiment was similar to Experiment I such that it tested consumer response to differently packaged laundry detergents in a within-subjects design with the same two usage scenarios (strength-emphasis vs. gentleness-emphasis; Figure 5.2). The experiment used a Dutch student convenience sample $\left(\mathrm{N}=53, M_{\text {age }}=23.53,89 \%\right.$ female). Participants were presented with three choice sets for each scenario (amounting to a total of six choices), with each choice set containing two differently packaged laundry detergents. For the first choice set, respondents had to choose between the non-gendered sustainable versus conventional packaging, similar to Experiment I. For the second and third choice set, the non-gendered sustainable packaging was replaced with one that contained masculine (feminine) design elements in addition to its sustainability design elements. Thus, the non-gendered, conventional design was the same in all choice sets. The order of the second and third choice set, as well as the order of the scenarios (strength-emphasis, gentlenessemphasis) was counterbalanced. The alignment of the presented stimuli images (left, right) was also counterbalanced. The gendered packaging stimuli (Figure 5.3) were designed by a professional graphic designer and varied in shape (e.g., squared vs. rounded), type-font and color, in line with stereotypical masculine vs. feminine design characteristics. 


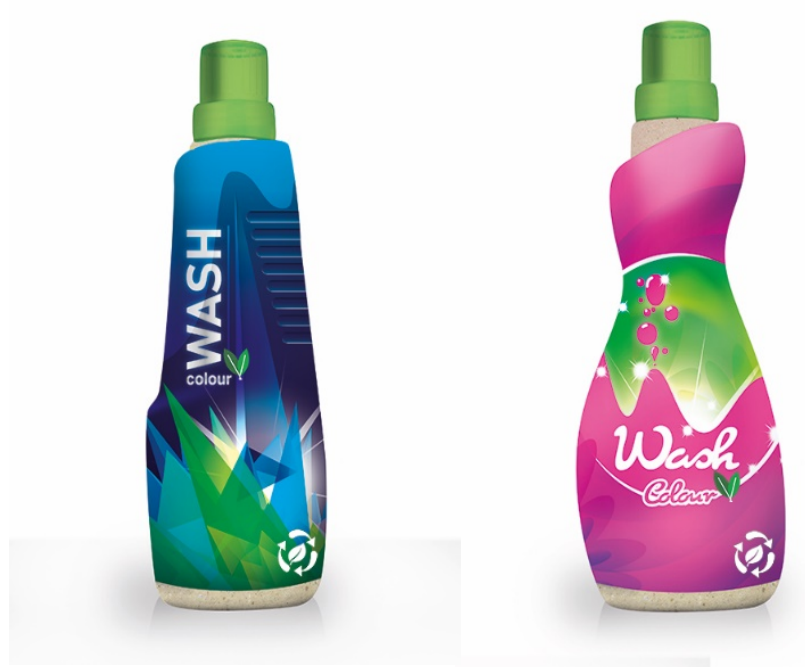

FIGURE 5.3. Masculine and feminine sustainable design stimuli

\subsubsection{Results}

\section{Choice}

Table 5.1 shows the choice distribution per scenario and per choice set.

For the strength scenario, participants chose the conventional design more often $(83 \%)$ than the sustainable one $(17 \%)$ from the first choice set. This was in line with expectations and results from Experiment I. With the second choice set, the pattern reversed such that participants chose the masculine sustainable design (62.26\%) over the conventional design (37.74\%). Lastly, the third choice set revealed that the frequencies for the feminine sustainable vs. the conventional design were the exact same as the first choice, suggesting that the feminine sustainable design was equally not suited for usage that required strength as the non-gendered sustainable design. For the gentleness scenario, consumers chose the sustainable option more frequently than the conventional option for each of the three choices. The choices for the sustainable design however were least favorable for the masculine variant (54.72\%) and most favorable for the non-gendered variant $(81.13 \%)$ with the feminine variant positioned in-between (66.04\%). 


\begin{tabular}{|c|c|c|c|}
\hline & Choice - Sustainable & Choice - Conventional & Sig. \\
\hline \multicolumn{4}{|l|}{ Strength scenario } \\
\hline Sustainable & 9 & 44 & a \\
\hline Sustainable (masculine) & 33 & 20 & $\mathrm{~b}$ \\
\hline Sustainable (feminine) & 9 & 44 & a \\
\hline \multicolumn{4}{|l|}{ Gentleness scenario } \\
\hline Sustainable & 43 & 10 & a \\
\hline Sustainable (masculine) & 29 & 24 & $\mathrm{~b}$ \\
\hline Sustainable (feminine) & 35 & 18 & $a, b$ \\
\hline
\end{tabular}

Next, we tested the difference in choice proportions per choice set across the two usage scenarios (using McNemar's test). Results showed that choice proportions for the first choice set and third choice set in the strength scenario significantly differed from those in the gentleness scenario ( $p$ 's $<.001$ ). Differences for the second choice set were not significant $(p=.59)$. The results for choice set one were in line with Experiment I's findings. For choice set two, the sustainable masculine packaging seemed relatively favorable in both strength and gentleness scenarios although these choices were not significantly different for the strength scenario $(p=.49)$, and marginally for the gentleness scenario $(p=.07)$. The third choice set's comparison showed that the feminine design was chosen most often in the gentleness scenario, while for the strength scenario participants favored the conventional design.

\subsubsection{Discussion}

The experiment replicated Experiment I's results such that consumers tend to choose conventional over sustainable designs when they seek strength, while the opposite happens

when gentleness is sought. Furthermore, the experiment provides evidence for the effects of using gendered sustainable designs. Particularly, a sustainably packaged detergent with masculine design elements is preferred over conventionally packaged (non-gendered) detergent. This is in line with the hypothesis that masculine designs may be used to overcome potential strength penalties. The use of masculine sustainable packaging decreases the suitability for the gentlenessemphasis scenario compared to the non-gendered sustainable packaging, however interestingly the feminine sustainable packaging is also less favored compared to its non-gendered counterpart. 
Making it macho

\subsection{Experiment III: Investigating the process}

Experiment III aimed to test the proposed moderated mediation processes $(\mathrm{H} 4)$ and includes gendered conventional (i.e. non-sustainable) packaging design in addition to the previous stimuli to compare differences in 'gendering' between sustainable and conventional packaging.

\subsubsection{Method}

The experiment consisted of a 2 (packaging sustainability design: sustainable/conventional) $\times 2$ (packaging gender design: masculine/feminine) $\times 2$ (usage scenario: strength-emphasis/gentleness-emphasis) between-subjects design. In the first part of the study, participants were asked to make a choice between two packaging designs (of which one was randomly selected from the four manipulated packaging designs and the other one was the same non-gendered conventional packaging design as was used in Experiment I and II) under consideration of either usage scenario (similar to Experiment I). In the second part, participants were asked to evaluate the same manipulated packaging design more thoroughly. Participants were 750 Dutch(-speaking) consumers recruited from a professional consumer research panel $\left(M_{a g e}=40.89,51 \%\right.$ male), who received a small financial compensation for participating.

\subsubsection{Stimuli \& pre-test}

The stimuli consisted of four laundry detergent packages. Specifically, we used the two gendered sustainable designs (from Experiment II, Figure 5.2) and two gendered conventional designs (Figure 5.4).

The stimuli were pretested to assess their appropriateness for the intended manipulations Participants in the pretest $\left(N=212, M_{\text {age }}=54.35,50 \%\right.$ male) were randomly allocated to one of four experimental conditions in a between-subjects design. They were asked to indicate the degree to which the product's design could best be described as masculine/feminine using two items on a 7-point bipolar adjectival scale with end-points "not masculine/feminine at all" - "very masculine/feminine" (Fugate \& Philips, 2010; Lieven et al., 2015; Schnurr, 2018; Van Tilburg et al., 2015). Additionally, they were asked to assess the sustainability of the design on a 100-point slider scale (similar to Experiment I). 
Results from ANOVAs showed that the masculine designs on average were perceived as more masculine $\left(M_{\text {masculinedesign }}=4.56\right.$ vs. $M_{\text {femininedesign }}=2.60 ; F(1,208)$ $\left.=111.88, p<.001, \eta_{p}^{2}=.35\right)$ and less feminine $\left(M_{\text {masculinedesign }}=3.59\right.$ vs. $M_{\text {femininedesign }}$ $\left.=5.53 ; F(1,208)=112.52, p<.001, \eta_{p}^{2}=.35\right)$ than the feminine designs. Additionally, the sustainable designs on average were perceived as more sustainable than the conventional designs ( $M_{\text {sustainabledesign }} 60.62$ vs. $M_{\text {conventionaldesign }}=51.40 ; F(1,208)=$ $\left.9.74, p<.001, \eta_{p}^{2}=.05\right)$ although not all differences between the four packaging designs were significant. The effect of gender design on perceived sustainability was not significant $\left.(F 1,208)=0.02, p=.89, \eta_{p}{ }^{2}<.001\right)$, as intended. Due to the comparatively smaller effect size of the sustainable design factor on perceived sustainability (relative to effect of gender design on masculinity and femininity), stimuli were adjusted slightly for the main study to include the word "Eco" on the packaging to increase the differences in perceived sustainability for the purposes of the manipulation.

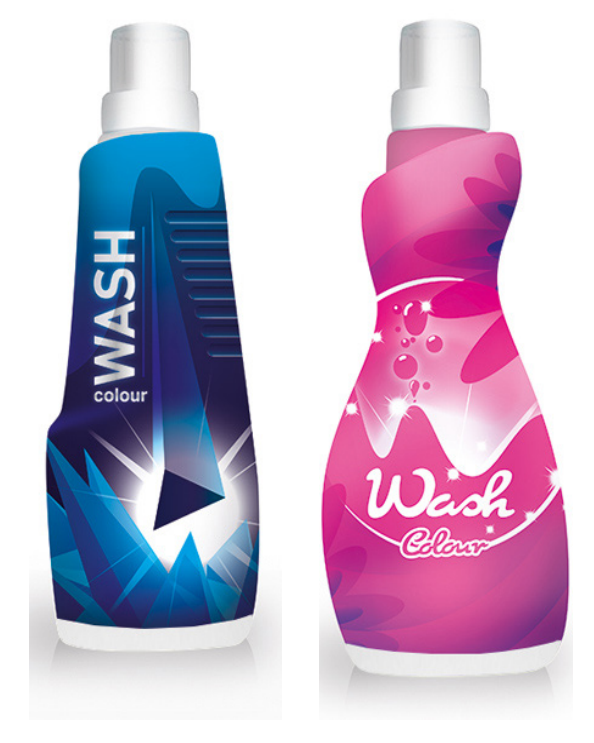

FIGURE 5.4. Masculine and feminine conventional design stimuli 
Making it macho

\subsubsection{Procedure \& measures}

Participants in the main study were shown the description of one of the two (randomly selected) usage scenarios and were asked to choose between a manipulated design (one of four gendered, either sustainable or conventional, packaging designs, depending on the condition) and the conventional, nongendered design (both options presented side-by-side in counterbalanced order). Following this choice, participants were again shown the gendered, either sustainable or conventional, packaging design on a separate page and asked to carefully view this design before answering questions about attitudes towards the laundry detergent and purchase intentions (Dodds, Monroe, \& Grewal, 1991), followed by perceived sustainability, strength and gentleness of the detergent. Subsequently, participants rated items related to the degree of fit between the product and laundry detergent category and to their environmental concern, to be included as covariates. Details of scales and items can be found in Appendix 5.1.

\subsubsection{Results}

\section{Effects of usage scenario and packaging designs on choices}

To analyze the choice data a logistic regression was carried out. Using deviation coding, independent variables were included to estimate the main effects of packaging sustainability design (sustainable, conventional), packaging gender design (masculine, feminine) and the usage scenario (strength, gentleness), as well as their two- and three-way interactions. The dependent variable consisted of choice between the 'baseline' non-gendered conventional packaging and the shown experimental design (where 1 = experimental packaging design, $0=$ non-gendered, non-sustainable packaging).

The logistic regression model was significant $\left(-2 L L=968.30, \chi^{2}(8)=51.62, p<\right.$ .001 , Nagelkerke $R^{2}=.09$ ). Its results (Table 5.2) showed significant effects for sustainability design, usage scenario and the two-way interaction for gender design and usage scenario. The main effect of sustainability design showed that, overall, participants were more inclined to choose gendered sustainability designs, than gendered conventional designs. The main effect of usage scenario showed that the choice for the manipulated designs was on average lower under the strengthemphasis scenario, relative to the gentleness-emphasis scenario. More importantly, the interaction between gender design and usage scenario showed that, in line with expectations, when the scenario emphasized strength, having a masculine instead of 
a feminine design had a more positive effect on the choice probability for the manipulated design than when the scenario emphasized gentleness. This effect was similar for both the sustainable and conventional variants, as the three-way interaction was not significant.

TABLE 5.2. Logistic regression on choices

\begin{tabular}{|c|c|c|c|c|c|}
\hline Predictor & $B$ & $\begin{array}{l}\text { Odds } \\
\text { ratio }\end{array}$ & $S E$ & $\begin{array}{l}\text { Wald } \\
\text { statistic }\end{array}$ & $p$ \\
\hline Constant & -0.63 & 0.54 & 0.08 & 6.64 & $<.05$ \\
\hline Sustainability design (sustainable [1]/conventional [-1]) & 0.34 & 1.40 & 0.08 & 18.80 & $<.001$ \\
\hline Gender design (masculine [1]/feminine [-1]) & -0.10 & 0.90 & 0.08 & 1.79 & .18 \\
\hline Usage scenario (strength [1]/gentleness [-1]) & -0.17 & 0.85 & 0.08 & 4.72 & $<.05$ \\
\hline Sustainability design*Gender design & -0.01 & 1.00 & 0.08 & 0.01 & .97 \\
\hline Sustainability design*Usage scenario & -0.07 & 0.93 & 0.08 & 0.80 & .37 \\
\hline Gender design*Usage scenario & 0.36 & 1.44 & 0.08 & 22.04 & $<.001$ \\
\hline Sustainability design*Gender design*Usage scenario & -0.10 & 0.91 & 0.08 & 1.61 & .20 \\
\hline Gender (covariate) & 0.17 & 1.18 & 0.15 & 1.18 & .28 \\
\hline
\end{tabular}

TABLE 5.3. ANOVA model results per variable

\begin{tabular}{|c|c|c|c|c|c|c|c|c|c|c|}
\hline & \multicolumn{2}{|c|}{$\begin{array}{l}\text { Perceived } \\
\text { strength }\end{array}$} & \multicolumn{2}{|c|}{$\begin{array}{l}\text { Perceived } \\
\text { gentleness }\end{array}$} & \multicolumn{2}{|c|}{$\begin{array}{l}\text { Perceived } \\
\text { Sustainability }\end{array}$} & \multicolumn{2}{|c|}{$\begin{array}{l}\text { Purchase } \\
\text { Intention }\end{array}$} & \multicolumn{2}{|l|}{ Attitude } \\
\hline & $F^{*}$ & $p$ & $F$ & $p$ & $F$ & $p$ & $F$ & $p$ & $F$ & $p$ \\
\hline Sustainability design & 0.76 & .38 & 8.28 & $<.01$ & 244.47 & $<.001$ & 5.24 & $<.05$ & 21.33 & $<.001$ \\
\hline Gender design & 42.40 & $<.001$ & 40.25 & $<.001$ & 4.13 & $<.05$ & 2.82 & .09 & 4.59 & $<.05$ \\
\hline Sustainability design*gender design & 6.77 & $<.01$ & 10.26 & $<.01$ & 0.58 & .45 & 1.93 & .17 & 2.69 & .10 \\
\hline Category fit (covariate) & 152.85 & $<.001$ & 142.06 & $<.001$ & 54.12 & $<.001$ & 152.13 & $<.001$ & 174.22 & $<.001$ \\
\hline Environmental concern (covariate) & 0.40 & .53 & 2.57 & .11 & 2.74 & .10 & 5.67 & .07 & 0.96 & .33 \\
\hline Gender (covariate) & 0.28 & .60 & 6.04 & $<.05$ & 0.73 & .39 & 1.611 & .21 & 5.42 & $<.05$ \\
\hline
\end{tabular}

$* d f(6,745)$ for each model.

**Effects of covariates on dependents did not significantly differ per condition. 
Making it macho

Effects of sustainability and gender design on perceptions, purchase intention and attitude

A series of two-way ANOVAs were conducted to test the effects of packaging sustainability and gender design, as well as the two-way interaction on the proposed mediating constructs (perceived strength- and gentleness and perceived sustainability) and dependent variables (purchase intentions and attitudes). Table 5.3 shows some overall statistics from these analyses. Sustainability design showed significant main effects for perceived gentleness (but not perceived strength), perceived sustainability, attitude and purchase intention. Gender design showed significant main effects for all variables except for purchase intention, where the effect was marginally significant $(p=.09)$. Notably, the two-way interaction was significant for perceived strength and gentleness.

Hypothesis 1a predicted that (without further consideration of effects of gender design) sustainably packaged products would lead to lower perceived strength relative to conventionally packaged products. The lack of a significant main effect of sustainability design does not support the hypothesis. However, the two-way interaction (see Figure 5.5a) revealed that this was due to feminine designs being perceived as equally low in strength regardless of whether the packaging design was sustainable or conventional ( $M_{\text {feminine_sustainable }}=4.60$ vs. $M_{\text {feminine_conventional }}=4.45, p=$ $.38)$, as the masculine conventional design was perceived as higher in strength than the masculine sustainable design $\left(M_{\text {masculine_sustainable }}=4.94\right.$ vs. $M_{\text {masculine_conventional }}=$ $5.24, p<.05)$. Additionally, the main effect of gender design showed that, as expected, masculine designs were rated higher on perceived strength than feminine ones ( $M_{\text {masculine }}=5.09$ vs. $\left.M_{\text {feminine }}=4.52, p<.001\right)$. These outcomes mean that $\mathrm{H3a}$ is supported: using a masculine (vs. feminine) design increased the relative perceived strength as expected $(p<.01)$, however $\mathrm{H} 3 \mathrm{~b}$ is not supported as the effect was still bigger for the conventional (vs. sustainable) packaging as it led to a larger improvement in perceived strength $(p<.001)$. 
For perceived gentleness (Figure 5.5b), in line with $\mathrm{H} 1 \mathrm{~b}$, the results supported the notion that sustainability packaging design led to higher gentleness, relative to conventional designs ( $M_{\text {sustainable }}=4.13$ vs $\left.M_{\text {conventional }}=4.36, p<.01\right)$. The simple effects further indicated that for masculine designs, the sustainable packaging was perceived as more gentle compared to the conventional packaging ( $M_{\text {masculine_sustainable }}$ $=4.28$ vs. $M_{\text {masculine_conventional }}=3.73, p<.001$ ), while for feminine designs there was no significant difference $\left(M_{\text {feminine_sustainable }}=4.57\right.$ vs. $\left.M_{\text {feminine_conventional }}=4.61, p=.82\right)$.

A

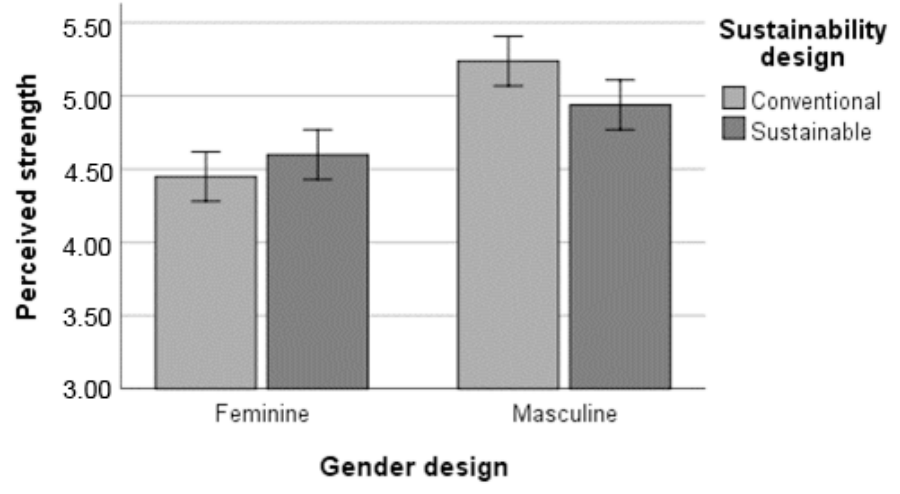

B

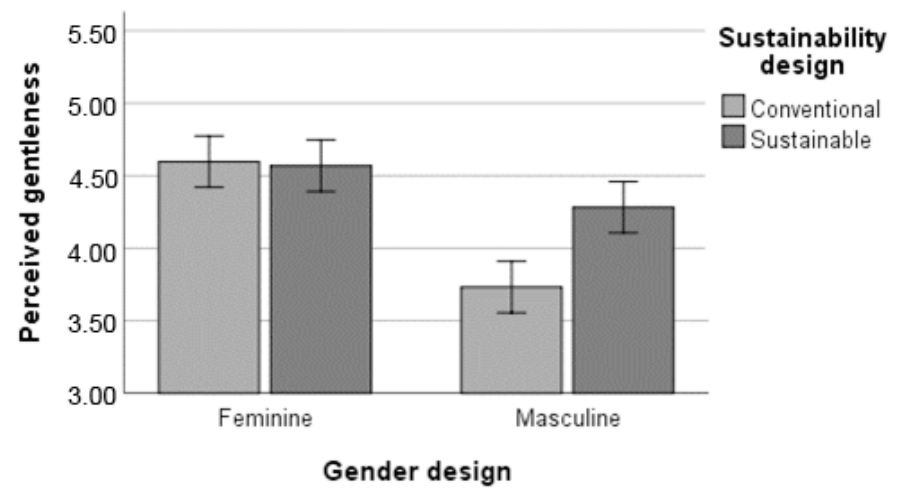

FIGURE 5.5. Effects of sustainability design and gender design on perceived strength (A) and gentleness (B). Error bars represent $95 \% \mathrm{Cl}$.

\section{Perceived sustainability}

The results for perceived sustainability showed that the sustainable designs on average were perceived as significantly more sustainable than their conventional counterparts $\left(M_{\text {sustainable }}=4.84\right.$ vs. $\left.M_{\text {conventional }}=3.52, p<.001\right)$, in line with expectations. There was also a main effect of gender design, such that the masculine 
designs were perceived somewhat more sustainable than the feminine ones ( $M_{\text {masculine }}=4.27$ vs. $\left.M_{\text {feminine }}=4.10, p<.05\right)$. The direction of this effect is somewhat unexpected, given that sustainability has been shown to be associated with femininity (Brough et al., 2016).

\section{Purchase intention \& attitudes}

Next, we analyzed the effects of sustainability design and gender design on purchase intentions and attitudes. The results showed that there was a higher purchase intention for sustainable designs in comparison to conventional designs $\left(M_{\text {sustainable }}=4.38\right.$ vs. $\left.M_{\text {conventional }}=4.16, p<.05\right)$. The marginally significant effect of gender design indicated that masculine designs were preferred somewhat over feminine ones ( $M_{\text {masculine }}=4.35$ vs. $M_{\text {feminine }}=4.19, p=.09$ ). There was a similar effect of sustainability design on attitude $\left(M_{\text {sustainable }}=4.83\right.$ vs. $\left.M_{\text {conventional }}=4.41, p<.001\right)$. There was also a significant, effect of gender design on attitude ( $M_{\text {masculine }}=4.52 \mathrm{vs}$. $\left.M_{\text {feminine }}=4.72, p<.05\right)$, although it was opposite to the effect on purchase intention.

\section{Moderated mediation}

To test $\mathrm{H} 4$, two moderated mediation regression analyses were conducted using PROCESS V3.2 with 10,000 bootstrap samples and $95 \%$ confidence intervals. The first model tested the proposed moderated mediation, that is, whether the (interaction) effect of sustainability and gender design on purchase intention was mediated through perceived sustainability, strength and gentleness. Category fit and environmental concern were entered as covariates. As purchase intentions were elicited without reference to usage scenario (and there were no significant effects of usage scenario on purchase intentions), this model did not include usage scenario as an additional moderator.

The second model used choice as the dependent variable and also included the effect of usage scenario as an additional moderator (moderating the effects of the mediators on choice). Thus, the indirect effects were different from the first model. This second model was defined as a model of dual moderated mediation because the indirect (moderated) effect (tested in the first model) is also dependent on a second moderator (Hayes, 2018).

Bootstrapping results for the first model for purchase intention showed a significant indirect effect of sustainability design through perceived strength for the masculine packaging design ( $B_{\text {Sustainablemasculine }}=-0.05, S E=0.03, C 195[-0.10,-0.01]$ ), but not for the feminine design ( $B_{\text {Sustainablefeminine }}=0.03, S E=0.02, C 195[-0.02,0.74]$ ). 
The difference between these indirect effects was significant (C195-0.15, -0.02]), indicating moderated mediation. The indirect effect of sustainability design through perceived gentleness was similarly significant for the masculine design ( $\left.B_{\text {Sustainablemasculine }}=0.08, S E=0.03, C 195[0.03,0.14]\right)$, yet not for the feminine design ( $\left.B_{\text {Sustainablefeminine }}=-0.01, S E=0.02, C 195[-0.42,0.36]\right)$. Again, the difference between the effects was significant $(C / 950.03,0.16])$. For perceived sustainability, the indirect effects of sustainability design were significant for both designs ( $B_{\text {sustainablemasculine }}=$ $0.37, S E=0.07, C 195[0.24,0.52], B_{\text {Sustainablefeminine }}=0.34, S E=0.07, C 195[0.22,0.47]$, and there was no moderated indirect effect $(C / 955-0.05,0.13])$, which was to be expected as the interaction for perceived sustainability was also not significant. There was no remaining significant direct effect of sustainability design $(B=-0.16, S E=$ $0.10, p=0.13, C 1955-0.37,0.05]$ ) indicating full mediation. Thus, results supported the proposed moderated mediation in $\mathrm{H} 4$, and the hypothesized interaction effects on strength and gentleness significantly contribute to mediated effects on purchase intention.

The second model consisted of a logistic regression with choice as the dependent variable and included the usage scenario factor as an additional moderator (moderating the path from the mediators on choice). Table 5.4 shows the indirect simple effects of sustainability design per level of each moderator, for both the pathways through perceived strength and gentleness. The effects through perceived sustainability were not significant and none of the pairwise contrasts were significant, hence these effects are not further discussed.

To indicate moderated mediation effects (for the pathways through perceived strength and gentleness), we first consider whether there was an overall difference between the indirect effects of sustainability design by gender design across usage scenario, followed by pairwise comparisons (Hayes 2018).

TABLE 5.4. Indirect effects of sustainability design on choice per moderator combination

\begin{tabular}{llllllll}
\hline Moderators & \multicolumn{9}{c}{ Mediators } \\
\hline Usage scenario & Gender design & \multicolumn{4}{c}{ Perceived strength } & \multicolumn{3}{c}{ Perceived gentleness } \\
& & $B$ & SE & C195 & $B$ & SE & CI95 \\
Strength & Masculine & -0.19 & 0.09 & $-0.39,-0.04$ & -0.11 & 0.06 & $-0.24,-0.01$ \\
Strength & Feminine & 0.09 & 0.08 & $-0.7,0.27$ & 0.01 & 0.03 & $-0.05,0.07$ \\
Gentleness & Masculine & 0.03 & 0.03 & $-0.04,0.10$ & 0.27 & 0.09 & $0.12,0.47$ \\
Gentleness & Feminine & -0.01 & 0.02 & $-0.07,0.02$ & -0.02 & 0.07 & $-0.16,0.11$ \\
\hline
\end{tabular}

Note. If a $\mathrm{Cl}$ does not contain the value 0 , then the indirect simple effect is significant 
Making it macho

The differences in the indirect effects of sustainability design for masculine and feminine designs, were different for the two usage scenarios (( $B_{\text {StrengthMasculine }}$ $\left.B_{\text {StrengthFeminine }}\right)-\left(B_{\text {GentlenessMasculine }}-B_{\text {GentlenessFeminine }}\right)=-0.32$, C195-0.66, -0.72$\left.]\right)$. Specifically, within the strength usage scenario, the indirect effect of sustainable design for masculine designs was significantly different from feminine designs $\left(B_{\text {StrengthMasculine }}=-0.19\right.$ vs. $B_{\text {StrengthFeminine }}=0.09$, C195[-0.56, -0.07$\left.]\right)$. Within the gentleness usage scenario, the indirect effect for masculine designs was not significantly different from that for feminine designs ( $B_{\text {GentlenessMasculine }}=0.03$ vs. $\left.\left.B_{\text {GentlenessFeminine }}=-0.01, C / 95-0.05,0.15\right]\right)$. Results for the pathway through perceived gentleness also showed an overall difference for the indirect effect (( $B_{\text {StrengthMasculine }}-$ $\left.B_{\text {StrengthFeminine }}\right)-\left(B_{\text {GentlenessMasculine }}-B_{\text {GentlenessFeminine }}\right)=-0.41$, C195[-0.76, -0.14$\left.]\right)$. Specifically, within the strength usage scenario, the indirect effect of sustainable design for masculine designs was significantly different from feminine designs $\left(B_{\text {StrengthMasculine }}=-0.11\right.$ vs. BstrengthFeminine $=0.01$, C1955-0.28, -0.01$)$. Within the gentleness scenario, the indirect effect was also significantly different ( $B_{\text {strengthMasculine }}$ $=0.27$ vs. $\left.B_{\text {Strengthfeminine }}=-0.02, C / 95[0.10,0.55]\right)$. There was also a remaining direct effect of sustainability design on choice $(B=0.48, S E=0.19, p<.05, C / 95[0.10,0.85])$.

Taken together, results from these models largely support $\mathrm{H} 4$ based on both purchase intentions and choices, and the additional moderating influence of usage scenario. Specifically, the results showed significant dual moderation of the indirect effect pathways through perceived strength and gentleness (but not through perceived sustainability).

\subsubsection{Discussion Experiment III}

Outcomes of the third experiment largely supported the expectations. In line with the hypotheses and results from Experiment I and II, choice is dependent on usage scenarios such that consumers are more likely to pick the masculine designs relative to feminine designs when strength is emphasized, although this effect is similar for both the conventional and sustainable designs. Additionally, the differences in choices can be explained by varying perceptions of laundry detergent strength, which are higher for masculine designs relative to feminine ones. The results also attest that although using masculine design cues improves perceived strength for sustainably packaged products, the masculine conventionally packaged products are still evaluated as higher in strength. This could relate to how consumers' mental sustainability schemata are more difficult to reconcile with concepts of strength compared to packaged products that do not cue sustainability schemata. Conversely, 
both conventional and sustainable feminine designs are perceived equally low on strength and high on gentleness, yet there is a marked difference in the two masculine designs in gentleness perceptions such that the sustainable masculine design is perceived more gentle than the conventional masculine design. Thus, sustainable packaging designs could be made relatively more preferable by adopting masculine aesthetics in the design as these are perceived as relatively powerful, yet are not penalized in terms of gentleness (unlike conventional masculine designs). The results also show that both perceived strength and gentleness mediate the interaction of sustainability design and gender design on consumer purchase intentions and choices embedded within the usage scenario.

\subsection{General discussion}

\subsubsection{Theoretical implications}

The current study includes insights from three consumer experiments investigating the effects of sustainability packaging design and gender design on consumer choices and preferences. These insights contribute to the domain of sustainable marketing and design in various ways. First, we contribute to the literature relating to consumers' mental associative structures and inference-making with regard to sustainability. We show that, in line with previous research, consumers make product-inferences based on packaging appearance such that an overtly sustainable packaging design can be detrimental when consumers look for strengthbenefits (i.e., consumers more often chose the conventional product). On the other hand, this pattern switches such that the sustainable variant is preferred when gentleness is sought as the primary consumer usage benefit.

Second, and more importantly, we investigated how the use of (packaging) gender design elements can be used to improve the competitive position of more sustainably packaged products, in contrast to most prior research whose interventions relied predominantly on the provision of explicit information (e.g., Luchs et al., 2010; Lin \& Chang, 2012, Newman et al., 2014). Particularly, we showed that the use of masculine design elements in a sustainably designed packaging can improve the likelihood that consumers choose the sustainable option (relative to a non-gendered, conventionally packaged product) when consumers seek strength benefits in the product's usage. Consumers perceive sustainably packaged products as less potent, and more gentle compared to conventional alternatives. However, when packaging design elements that connote masculinity are introduced, consumers perceive the detergents as comparatively more powerful. Hence, 
masculine gender elements can be used to offset the strength penalty. That said, results from Experiment III show that the masculine conventional packaging variants still lead to higher perceptions of detergent power, compared to the masculine sustainable packaging. This could be caused due to counter-intuitive signaling (i.e., masculine design is supposed to be sustainable but also powerful), and this may require additional consumer effort to assimilate. It did not appear that the effect was caused due to induced category ambiguity (Pancer et al., 2017), as perceived category fit did not differ per design. Relative to prior work which indicates that consumers may have difficulty in accepting products that excel in both sustainability and potency (e.g., Luchs \& Kumar, 2015; Luchs et al., 2010; Newman et al., 2014; Pancer et al., 2017) the current findings imply that this is an intuitive association, rather than one that is fundamentally irreconcilable.

Third, another interesting finding is that although masculine sustainable packaging is perceived as somewhat less powerful than masculine conventional packaging, the former is still perceived as more gentle. Thus, while a masculine conventional design still leads to the highest strength perceptions, they also have the lowest gentleness scores. Conversely, the masculine sustainable design is perceived as comparatively favorable in both strength and gentleness. Again, this indicates that consumers can to some extent assimilate these mental schemata such that they perceive these packaging designs as representing a product that could (to a large extent) fulfil both strength and gentleness needs. 


\subsubsection{Practical implications}

Firms that offer packaged products with sustainability benefits must overcome various challenges to ensure that their offerings match with consumer demands whilst also generating awareness of the environmental benefits of their packaged products. The findings of this study show that consumers perceive sustainably packaged laundry detergents as suitable for usage scenarios that require gentleness benefits, less so for strength benefits. We have shown that firms can use packaging design to imbue their products with gender in order to overcome these potential barriers. Interestingly, making sustainably packaged products look masculine as well leads to a relatively favorable perception in terms of perceived strength and gentleness benefits of the detergent. This suggests that such designs could be especially viable when highlighting both benefits (e.g., "all-in-one" products) for product categories where both benefits are relevant, and where consumers are unlikely to purchase specialized products for either usage scenario. The use of packaging design aesthetics is a powerful tool in the marketer's toolbox because it often requires little or no functional change in the product's actual performance, making changes comparatively easy to realize. 
Making it macho

APPENDIX 5.1. Influences of packaging/product design elements on perceived masculinity/femininity

\begin{tabular}{llll}
\hline Design element & Masculine design & Feminine design & Source(s) \\
\hline Shape & - Angular, bulky, straight, & - Round, slim, curvy, & - Van Tilburg et al. (2015) \\
& heavy & slender & - Lieven et al. (2015) \\
& & & - Creusen \& Schoormans (2005) \\
Typefont & - Solid, bold-face & - Fine, sleek, elegant, & - Lieven et al. (2015) \\
& - Modern display fonts & serif-type & - Van Tilburg et al. (2015) \\
& (Impact, Agency FB) & - Script fonts & - Shaikh, Chaparro, and Fox \\
& - No frills & (Monotype Corsiva, & (2006) \\
& & Kristen) & - Brough et al. (2016) \\
& & - Frilly & - Van Rompay and Pruyn (2011) \\
Materials \& Textures & - Rough texture & - Smooth texture & - Van Tilburg et al. (2015) \\
& - Hard surface material & - Soft surface & - Creusen \& Schoormans (2005) \\
Colour & - Darker colours & - Lighter colours & - Van Tilburg et al. (2015) \\
& - Dim reflectiveness & - Shiny & Lieven et al. (2015) \\
\hline
\end{tabular}




\section{CHAPTER 5}

APPENDIX 5.2. Study measurements

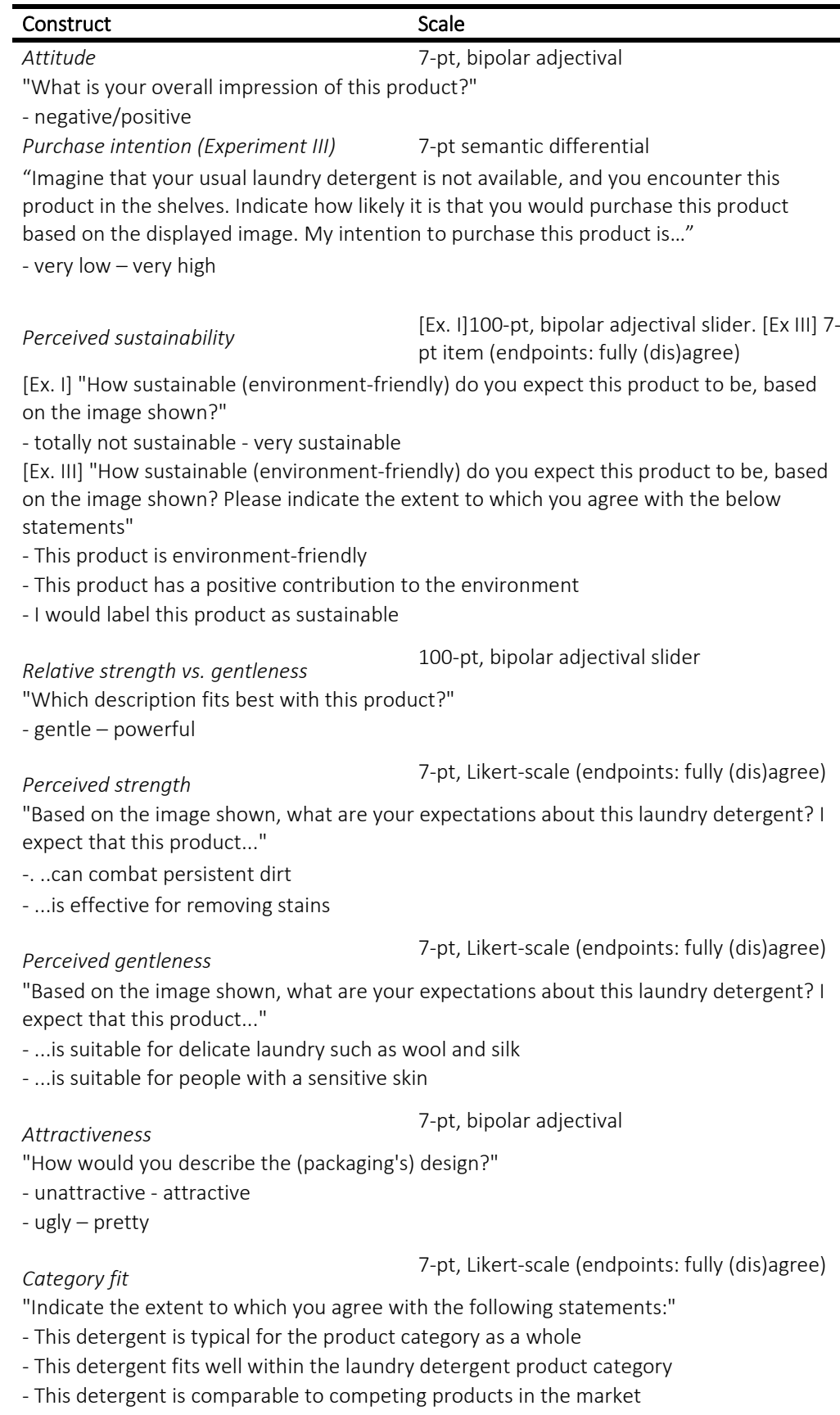

Haws, Winterich and Naylor (2014), Luchs et al. (2010) References

Crites, Fabrigar \& Petty (1994)

Dodds, Monroe \& Grewal (1991) 
Making it macho

APPENDIX 5.2. Study measurements (continued)

\begin{tabular}{lc}
\hline Construct & Scale \\
\hline Environmental concern & \\
"Indicate the extent to which you agree & 7-pt, Likert-scale (endpoints: fully (dis)agree) \\
with the following statements:" & Hawcroft and \\
- Humans are severely abusing the environment & Milfont (2010) \\
- The balance of nature is strong enough to cope with the impacts of modern industrial & \\
nations & \\
- The so-called "ecological crisis" facing humankind has been greatly exaggerated & \\
- If things continue on their present course, we will soon experience a major ecological & \\
catastrophe & \\
- When humans interfere with nature it often produces disastrous consequences & \\
\hline
\end{tabular}




\section{CHAPTER 6 \\ General discussion}


The current thesis investigated consumer response to sustainable packaging design following the overall theoretical framework introduced in Chapter 1. Consumer response was viewed as a subject-object interaction, which depends on both the 'objective' design of packaging and its cues and consumers' subjective processing thereof. Across the empirical chapters, we examined both functional and aesthetical design goals, leading into structural, graphical and verbal cues which in turn affected the consumer inference-making process. Four distinct types of consumer inferences were examined, namely with regard to: (1) packaging sustainability, (2) product (contents) sustainability, (3) other product benefits (besides sustainability) and (4) greenwashing related to firm motives. We subsequently examined how sustainable packaging design affects consumer responses towards the packaged product in terms of attitudes, purchase intentions, willingness-to-pay and choice through these four types of inferences. Contextual influences of product contents sustainability, firms' sustainability claims and advertisement and consumer usage scenarios were also examined to further elucidate the inference-making process.

The empirical investigations first focused on the extent to which consumers perceive and utilize packaging cues based on various (existing) packaging types in order to form a perspective of the 'status quo', and to provide initial evidence for the theorized cue-utilization and subsequent inference-making processes. Next, we investigated how conceptually different sustainable redesign strategies (i.e., sustainability improvements) affect consumer response when framed against conventional packaging designs. Therein, we paid specific attention to consumer inferences, and also considered how combining sustainable redesign strategies leads to perceived diminishing returns. Following this, we investigated contextual factors based on various advertisement claims in conjunction with combined (explicit) packaging and product sustainability ratings. We investigated how discrepancies between firm's sustainability claims and actual packaged product environmental performance can give rise to greenwashing inferences, even if consumers are otherwise positive towards sustainability initiatives. The final empirical chapter investigated how the use of overtly sustainable (versus conventional) packaging aesthetics affects consumer choices depending on whether the consumer usage scenario emphasizes strength or gentleness benefits. Additionally, the chapter investigated how the inclusion of 'gendered' packaging design elements (masculine versus feminine appearance) can be used to improve the competitive position of sustainably packaged products. 


\subsection{Summary of findings and conclusions}

The following section presents the main findings and conclusions of the thesis. These findings are discussed along the theoretical framework, starting with the effects of packaging design on consumer cue perception, followed respectively by the four inference types and related contextual factors.

\subsubsection{Packaging cues and cue perception}

The cue perception process (Chapter 2) shows that the most salient cue perceptions based on the utilization of structural and graphical packaging design cues relate to perceived convenience and perceived sustainability. Importantly, these results indicate that consumers have accessible mental associations between packaging and sustainability, which can be considered a prerequisite for sustainability-oriented inference-making. Additionally, the results also show a low consensus among consumers with regard to the perceived sustainability of packaging designs. This suggests that consumers differ substantially in how sustainable they perceive various designs to be, and/or utilize different cues based on which they form the sustainability inference. The results also show a large gap (a large inverse correlation) between consumer perception of packaging sustainability and life-cycle analysis. This gap could be explained by how life-cycle analysis considers the broad impact of packaging across the entire supply-chain (e.g., including transportation or water- and energy usage during production processes), whereas consumers tend to (overly) rely on visible packaging design cues during those parts of the life-cycle where consumers themselves interact with the packaging.

\subsubsection{Consumer inference-making: perceived packaging sustainability}

Across the chapters, the results consistently show that sustainable packaging design increases perceived packaging sustainability through the processing of structural and graphical packaging cues (Chapter $2 \&$ Chapter 5), as well as on the basis of explicit sustainability information related to packaging (Chapter $3 \&$ Chapter 4). This increased sustainability perception positively mediates the effects of sustainable packaging designs on consumer attitudes, purchase intentions and choices. While Chapter 2 shows that packaging's structural and graphical cues are used by consumers to generate sustainability inferences, the sustainability evaluations based on these inferences are inaccurate (both at the individual 
consumer level, as well as the aggregate) when compared to packaging's environmental impacts as determined by life-cycle analysis. Additionally, when considering the effects of explicit information, Chapter 3 showed that consumer response is also subject to diminishing returns. Increasing the number of sustainable redesign improvements (by combining them) is perceived by consumers to lead to heavily diminished increases in environmental impacts, and do not further contribute to consumers' moral satisfaction derived from 'green' purchases. This means that providing more intensive sustainability redesigns does not necessarily lead to sizeable gains in terms of consumer perception and purchase intentions.

\subsubsection{Consumer inference-making: perceived (packaged) product benefits}

Results of Chapters 2 and 5 show that the use of structural and graphical sustainable packaging design cues lead consumers to infer that the product itself is also more sustainable, and that consumers consistently make inferences relating to various other packaged product benefits. Such inferences can occur when using implicit packaging design cues (Chapters 2 and 5), as well as when explicit packaging sustainability information is provided (Chapter 3 ). The results show that packaging materials and graphics inform consumer inferences towards product content sustainability, which implies that consumers consider the integrated packaged product as one 'whole' (Luchs et al., 2011), rather than intuitively making sharp distinctions between packaging and product contents.

Moreover, the results indicate that consumers rely on associative mental structures such that when packaging acts as a signal for sustainability, consumers make inferences about other (unobservable) benefits of the packaged products. The nature of these inferences can be beneficial or detrimental to consumer outcomes. Cues that are utilized by consumers to indicate higher sustainability also lead to higher perceived healthiness, naturalness and (to a lesser extent) taste, quality. However, they also cause consumers to infer a higher price. Similarly, Chapter 3 showed how such inferences are also made when functional sustainable packaging redesign was communicated by textual descriptions (controlling for differences in packaging appearance) The concept of perceived (packaging) sustainability itself is shown to be positively related to perceived naturalness and functionality, but also to financial and behavioral costs.

More specific inferences of perceived strength and gentleness of laundry detergents are examined in Chapter 5 . This chapter shows that sustainably packaged detergents (based on graphical, structural and verbal cues) are evaluated worse on 
strength benefits yet more positively on gentleness benefits, relative to conventionally packaged detergents. The evaluation of these strength and gentleness benefits in turn has profound impact on consumer packaged product choices, depending on which benefit was valued most in consumers' usage scenario. Additionally, Chapter 5's results demonstrate the effects of gendered packaging designs on consumer choice. Packaging designs incorporating both sustainable and masculine design cues are perceived as relatively favorable in strength, gentleness and sustainability and are more likely to be chosen compared to laundry detergents with conventional, non-gendered packaging designs, even in cases where consumers seek out strength benefits.

\subsubsection{Consumer inference-making: greenwashing (firm motives)}

Results show that consumers make inferences of firm greenwashing, especially when actual sustainability performance of the packaged product does not (fully) match the firm's sustainability claims. This pathway is important for two reasons. First, consumers make inferences that do not pertain to the actual (environmental) performance of packaged products itself, yet that do affect consumer attitudes and purchase intentions towards those packaged products. In other words, these inferences do not necessarily affect the evaluation of the packaged product's benefits, but cause more negative consumer response because consumers are skeptical towards firm motives. Second, these greenwashing inferences cause consumers to become ambivalent toward offerings that offer sustainability benefits, as consumers' positive perception of improved environmental performance may be offset by the firm's marketing communications thereof.

\subsubsection{Contextual factors}

Investigating the roles of product contents in conjunction with firms' sustainability marketing (Chapter 4 ) shows that when firms make generic packaged product sustainability claims, and a high level of packaging sustainability is not fully matched by an equally high level of product contents sustainability (or vice versa), a claim-fact discrepancy occurs to which consumers respond negatively. Greenwashing inferences are the main driver behind this effect, because the packaged product only partially lives up to what is implied by the firm's packaged product sustainability claim. The results of the first experiment also indicate a centrality effect (Gershoff \& Frels, 2015; Sloman et al., 1998). Specifically, a partial discrepancy wherein only packaging (a peripheral attribute) is sustainable but where 
product contents (a central attribute) are not, leads to greater greenwashing perceptions than vice versa. This effect was not explained by mere differences in perceived environmental impacts.

An examination of the moderating role of claim type shows that using puffy claims increases the effects of the sustainable product-packaging combination on perceived sustainability, yet also increases the perceived greenwashing. Perceived sustainability and greenwashing respectively exert positive and negative effects on consumer attitudes and purchase intentions. The increase in the positive effect (due to using puffy claims) through perceived sustainability on consumer purchase intentions, however, does not occur when only the (peripheral) packaging is sustainable (and product contents are not), but does occur in the opposite situation (only product contents sustainable). This indicates a centrality effect such that packaged products where only the peripheral packaging is made sustainable tend to be penalized compared to packaged products where more central product contents are made sustainable. Additionally, the positive effects through increased perceived sustainability is stronger than negative effect through increased greenwashing perception for attitudes, but not for purchase intentions. This may indicate a difference similar to the attitude-behavioral intention gap (Vermeir \& Verbeke, 2006), since consumers respond more positively for attitudes (which are more general and more distant to actual purchases) compared to purchase intentions. The findings also show that using subdued claims, or no claim at all, reduces the expectations that firms generate, subsequently reducing both the respective 'pros and cons' of the effects through perceived sustainability and perceived greenwashing inferences.

In light of consumer inference making with regard to strength and gentleness benefits (Chapter 5), consumers' intended usage scenario acts as a contextual factor because it moderates the relative weight of strength versus gentleness benefits in consumer choices. When the usage scenario emphasizes strength, consumers forego sustainably packaged laundry detergents in favor of conventionally packaged ones. At the same time, consumers favor sustainably packaged detergents when the scenario emphasized gentleness benefits. This type of moderation is conceptually different from Chapter 4's because it does not affect the nature of the inference itself, but affects the relative importance of strength and gentleness benefits (on consumer choice). 


\subsection{Theoretical implications}

\subsubsection{The intersect of packaging design and consumer behavior}

Most of the prior marketing and consumer behavior literature has viewed packaging purely from a consumer signaling point of view, for example by focusing on effects of sustainability claims, advertisements and on-package labels (e.g., Atkinson \& Rosenthal, 2014; Pancer et al., 2017; Walker Naylor \& Trudel, 2012). Most of this research however remains limited in that it mainly considers marketingrelated tools that can only be used as cues for sustainability (e.g., sustainability labels), yet which do not affect functional differences in actual environmental impacts. Consumer research that does study design elements that are likely to affect the true environmental impacts of packaged products often focusses solely on consumer perception (e.g., Seo et al., 2016). Conversely, relevant research in the sustainable (packaging) design domain has predominantly focused on various ecodesign principles and frameworks of sustainable design, such as (design for) circular economies (Bocken et al., 2016; Geissdoerfer et al., 2017) and cradle-to-cradle frameworks (McDonough \& Braungart, 2002). However, consumer response to such functional approaches of redesign is rarely considered or empirically tested, as most eco-design principles do not consider the impact of consumer response, despite this being a key criterion for successful sustainable design (Fletcher \& Goggin, 2001; Ottman, Stafford, \& Hartman, 2010).

The current thesis contributes to the extant literature by investigating consumer inference-making processes and its outcomes based on both functionally and aesthetically oriented goals of sustainable design. This approach directly responds to calls for research that (1) integrates both functional and aesthetical design perspectives, in consideration that consumers engage with integrated packaged products (Luchs \& Swan, 2011), and, (2) considers this in light of consumer sustainability perception and sustainable packaging design principles (Luchs et al., 2016). Sustainability especially has been an aspect that has traditionally been neglected from a design point of view, despite its critical importance (Eppinger, 2011; Luchs et al., 2016). The current thesis showed how specific sustainable design elements affect consumer attitudes (Chapter 2), purchase intentions (Chapter $3 \& 4$ ), willingness-to-pay (Chapter 5), and choices of sustainably packaged products.

More specifically, we contribute to the literature on consumer cue perception of (sustainable) packaging designs (Ampuero \& Vila, 2006; Lindh, Olsson, et al., 2016; Magnier \& Crié, 2015) in two ways. First, we connect consumer inference-making 
based on packaging cues with cue utilization and salience, and show that consumers make a wide variety of benefit inferences based on packaging cue perception. While sustainability cue perceptions are shown to be salient, they only have a relatively modest effect on consumers' overall attitudes. Second, we connect consumer cue perception with expert assessments, showing that consumers' cue based sustainability inferences of packaging designs are (inversely) related to outcomes from life cycle analysis. This implies that the 'object-subject accuracy' (cf. Steenkamp, 1990) is key to understanding sustainability because omitting either side of the coin (expert assessment vs. consumer perception) is likely to generate a biased view.

Furthermore, we bridge the gap between consumer and design literature by examining consumer response to functional sustainable redesign strategies, independent of potential differences in visually ascertainable packaging design cues (Chapter 3). Consumers tend to prefer circular over linear strategies, and biologically circular over technically circular ones. Combining different strategies however does lead to diminished increases in consumer response, as consumers infer heavily diminished increases in perceived sustainability, and derive little additional moral satisfaction from more intensively redesigned packaging. These sustainable redesign strategies are principally focused on achieving functional changes in packaging's environmental impacts, hence studying their effects on consumer response is an effective way to include design alterations that affect both actual and perceived sustainability. Insights into consumer responses towards these functional changes in sustainable packaging design, as well as to the underlying processes, had thus far not been investigated in prior research. Therefore, the study elucidates how functional sustainable redesign strategies relate to consumer perceptions thereof.

\subsubsection{Consumer inference-making processes}

The thesis also emphasized that sustainable packaging design may cause consumers to make inferences pertaining to a much wider variety of consumer benefits than just perceived (packaging) sustainability. The findings of the current research imply that there are 'pros and cons' to signaling sustainability benefits in packaged products. Across the chapters, we show that packaging sustainability is associated positively with perceived naturalness, quality, healthiness and gentleness benefits. At the same time, sustainable packaging is associated more negatively with favorable pricing and perceived strength. This contributes to both the research on consumer inference-making regarding sustainable packaging design (Koenig-Lewis, Palmer, Dermody, \& Urbye, 2014; Magnier \& Schoormans, 2017; Magnier et al., 2016; 
Rokka \& Uusitalo, 2008; Van Birgelen et al., 2009), as well as the growing stream of sustainability literature on consumer inference-making and mental associations surrounding sustainability cues and benefits (Brough et al., 2016; Lin \& Chang, 2012; Luchs et al., 2012; Luchs et al., 2010; Newman et al., 2014; Pancer et al., 2017). Inferences towards other benefits are important because sustainable marketing and design have been criticized for being overly myopic, such that an overemphasis on the environmental qualities of a 'greener' offering risks ignoring other consumer benefits which may be more determinant for consumer purchase decisions (Ottman et al., 2010).

In consideration of these inferences with regard to other benefits (besides sustainability), another contribution relates to the effectiveness of interventions based on aesthetical packaging designs (Chapter 5). By attesting how aesthetical design based on gender cues can be used to counteract specific negative strength inferences consumers make regarding sustainability, we contribute to the literature in (packaging) design aesthetics (Reimann, Zaichkowsky, Neuhaus, Bender, \& Weber, 2010; Van Tilburg et al., 2015), symbolism (Van Ooijen, Fransen, Verlegh, \& Smit, 2017; Van Rompay, Pruyn, \& Tieke, 2009) and metaphors (Fenko et al., 2018). The approach is different from prior proposed interventions because it is based on implicit processing of cues (rather than explicit textual information) and relies on the use of symbolism (i.e., masculine and feminine gender cues) that does not rely on cueing typical sustainability schemata. This latter aspect is important because it implies that design-based interventions against negative consumer inferences can originate from aesthetical design alterations that are independent of sustainable design itself, which also shows how combinations of sustainability and gender cues can be integrated and processed by consumers.

Additionally, the thesis examined consumer inferences pertaining to firm greenwashing, focusing on the discrepancy between firm claims and actual sustainability of packaging and product contents. This approach contributes to the literature regarding packaging-based inference-making by showing that consumers can also take into account elements that are ulterior to the actual (environmental) benefits of the packaged product itself (i.e., firm behaviors). Specifically, we showed that even though consumers can positively value improved sustainability benefits of a packaged product, they might also negatively value the way in which such improvements are marketed by the firm. 


\subsection{Practical implications}

The thesis provides relevant implications for managers, marketers and packaging designers, as well as those who guard sustainability processes within organizations.

Consumers utilize (sustainable) packaging cues to make sustainability inferences of both packaging and the product contained within. Increased perceived sustainability has positive effects on consumer attitudes, purchase intentions and potentially consumer choice, however alterations in packaging design can cause consumers to infer about other benefits as well. Therefore, when firms market packaging that is sustainable (be it functionally, aesthetically or both) they must be careful not to fall victim to green marketing myopia (Ottman et al., 2010), that is, overly assuming that consumers will purchase products simply because they are (perceived to be) more sustainable. The findings suggest that marketers must consider not only the impact on perceptions of sustainability, but take into account a more holistic view of packaged product and brand perception with the notion that consumers may make both positive (e.g., higher naturalness and gentleness) and negative inferences (e.g., higher costs, low strength) based on sustainable packaging cues. The extent to which these inferences lead to positive or negative consumer outcomes also depends on various contextual elements. Particularly, the match between sustainability expectations (based on claims in advertisement) with actual sustainability performance of both packaging and product contents is important, although there are both pros and cons to increasing/decreasing this gap. Additionally, the intended consumer product usage affects the relative importances of (perceived) benefits provided by the packaged product.

Second, practitioners should 'mind the gap' between consumers' sustainability perception and expert-based indications of environmental impacts. Consumers' laybeliefs of packaging types' sustainability does not reflect expert assessments. In order to account for this gap, firms could consider developing (overtly) more sustainable packaging designs for which the gap between consumer perception and life-cycle assessment outcomes is relatively small. Such packaging likely has the additional benefit of being perceived as less deceptive when it is actively marketed as 'sustainable' because it is favored both in consumer perception and actual environmental impacts. Alternatively, firms may frame more sustainable redesigns against current 'status quo' packaging such that it focusses on the relative change in environmental impacts (Chapter 3), hence both the actual environmental impacts as well as consumer sustainability perceptions increase. Long-term solutions however 
call for a better alignment between consumer perception and natural science insights with regards to environmental impacts. This implies that some form of consumer re-education is needed, however there may be significant hurdles in readjusting established consumer beliefs and the way in which these beliefs are formed, specifically because consumers chiefly rely on perceptually salient and sometimes non-diagnostic packaging cues.

A successful implementation of long-term adjustments therefore calls for research to investigate potential avenues of approach with regard to adjusting consumer cue perception and inference-making. This should however also take into account that life-cycle assessment outcomes are not fixed. Technological improvements in packaging production processes, as well as methodological improvements of measuring more objective environmental impacts, are likely to occur, and will subsequently alter outcomes of life-cycle assessments. This could posit an additional challenge as consumer beliefs may not be updated as rapidly or thoroughly as expert insights, and could undermine the perceived trustworthiness of (prior) informational campaigns.

Third, as a continuation of the prior two points raised, packaging designers and marketers should strategically consider the use of overt sustainability signals (which could either be intrinsically connected to the actual environmental impacts, or not). An initial consideration is whether to deliberately signal sustainability benefits in the first place. A sustainable positioning is desirable when its pros outweigh the cons in terms of consumer inference-making, whilst ideally also leading to an actual environmental impact improvement. At the same time an overtly sustainable design and positioning is risky in circumstances where, for example, consumers seek out strength-benefits in the product's use or when the product contents' sustainability does not match the packaging. Due to the gap between consumers' and experts' environmental assessments, taking an overt sustainability positioning is also risky when the packaging is not perceived to be sustainable, even though it would lead to better environmental results from a life-cycle analysis perspective. Various sustainable packaging redesigns can be carried out without significant perceptible changes in packaging cues (e.g., lightweighting). While, without extrinsic cues, such approaches would not improve consumer response through increased sustainability perceptions and various positive benefit inferences, they would also avoid negative inferences with regard to packaged product benefits and greenwashing. Such an approach may therefore be viable if sustainable packaging is expected to diminish brand perceptions. On the other hand, this approach assumes that market push or 
potential legal requirements, rather than consumer pull, are the driving forces behind sustainability initiatives because it presumes that packaging innovations are made without consideration of perceived consumer benefits.

\subsection{Limitations and future research}

The thesis's approach focused on perceptions and preferences regarding packaged products, but we did not consider the retail environment. This highlights two limitations of the current research. First, the experiments used hypothetical settings that were not designed to be representative of a true purchase setting. This limits their external validity in predicting actual consumer purchase behavior, however the experiments may still be similar to consumer-testing phases of new product development activities from a firm perspective (e.g., where consumer response against various packaging prototypes is investigated). Second, with the lack of a surrounding retail environment with competing products we did not test for effects based on attention and product differentiation. Therefore, future research could consider how consumer preferences for sustainable packaging design depends on other packaging designs in the retail environment (Orth \& Crouch, 2014), for example by investigating the extent to which other packaging does (not) provide sustainability cues. This can be viewed from a perspective of attentional and categorization processes (Schoormans \& Robben, 1997), or atypicality in design (Celhay \& Trinquecoste, 2015). For example, one could consider the extent to which sustainable(-looking) designs are perceived as less/more typical for specific product categories. When sustainable packaging is atypical, it would be interesting to see whether such packaging can draw more consumer attention to the packaged product relative to more typical packaged products. Such potential positive attentional effects could be compared against the potential negative effects caused by category ambiguity (Pancer et al., 2017), to see whether risking a less positive product evaluation could be offset by being more differentiated in the retail context.

Furthermore, with regard to the experimental setups and cues used, the methodology was limited to considering visual effects only (i.e., consumers viewed the packaging designs and descriptions from a screen). Future research could also take into account packaging's effects from a more sensory perspective. For example, adopting more sustainable packaging materials (or materials that aim to generate impressions of sustainability) could affect haptics in addition to just its visual appearance (Littel \& Orth, 2013). Research could consider whether haptics-related 
aspects could be designed to evoke sustainability, or consider the congruence between various sensory aspects (e.g., visuals, haptics, taste impressions).

Future research could also investigate more contextual (moderating) influences. Particularly, the current thesis did not consider how individual differences and specific consumer traits could affect cue perception and inference-making processes. Such research could draw from the sustainability literature, for example by more closely investigating the effects of consumers' environmental attitudes (Lin \& Chang, 2012) to consider which design-based interventions would be effective for consumers that are not intrinsically motivated to behave in sustainable manners. Alternatively, research could focus on consumer sensitivity to design (Bloch, Brunel, $\&$ Arnold, 2003), and particularly how this differentially affects the effectiveness of aesthetics to promote sustainable choice.

Another promising area for further research lies in the object-subject accuracy with regard to consumer sustainability perceptions versus actual sustainability. While the current thesis validates the existence of a gap between consumer perception and more objective measures of sustainability, it has not specifically sought out ways to overcome such gaps. The presence of this gap implies that some form of consumer re-education is needed to ensure that consumers do not make misinformed choices, even if they have environmentally friendlier motives. Future research could therefore consider testing the effectiveness of interventions aimed at changing consumer beliefs under uncertain and gradually changing environmental facts about packaging's environmental impacts. Such an approach could draw from work in the CSR domain regarding the provision different types of argumentation and information from different sources (e.g., Atkinson \& Rosenthal, 2014) in consideration of the strength of prior lay beliefs and the size of the gap between consumers and expert assessment. 


\section{REFERENCES}

Adeyeye, K., She, K., \& Baïri, A. (2017). Design factors and functionality matching in sustainability products: A study of eco-showerheads. Journal of Cleaner Production, 142, 4214-4229.

Ajzen, I. (1991). The Theory of Planned Behavior. Organizational Behavior and Human Decision Procesess, 50(2), 179-211.

Allegra, V., Zarbà, A. S., \& Muratore, G. (2012). The post-purchase consumer behaviour, survey in the context of materials for food packaging. Italian Journal of Food Science, 24(4), 160-164.

Amos, C., Allred, A., \& Zhang, L. (2017). Do biodegradable labels lead to an ecosafety halo effect? Journal of Consumer Policy, 40(3), 279-298.

Ampuero, O., \& Vila, N. (2006). Consumer perceptions of product packaging. Journal of Consumer Marketing, 23(2), 100-112.

Anderson, M. (2015). Great things come in innovative packaging: an introduction to PlantBottle(tm) packaging. Retrieved March, 22, 2016, from http://www.cocacolacompany.com/plantbottle-technology/great-things-come-in-innovativepackaging-an-introduction-to-plantbottle-packaging/

Andreoni, J. (1990). Impure altruism and donations to public goods: A theory of warm-glow giving. The Economic Journal, 100(401), 464-477.

Ares, G., \& Deliza, R. (2010). Studying the influence of package shape and colour on consumer expectations of milk desserts using word association and conjoint analysis. Food Quality and Preference, 21(8), 930-937.

Atkinson, L., \& Rosenthal, S. (2014). Signalling the green sell: The influence of ecolabel source, argument specificity, and product involvement on consumer trust. Journal of Advertising, 43(1), 33-45.

Auger, P., Devinney, T. M., Louviere, J. J., \& Burke, P. F. (2008). Do social product features have value to consumers? International Journal of Research in Marketing, 25(3), 183-191. 


\section{REFERENCES}

Bech-Larsen, T., \& Nielsen, N. A. (1999). A comparison of five elicitation techniques for elicitation of attributes of low involvement products. Journal of Economic Psychology, 20(3), 315-341.

Becker, L., Van Rompay, T. J. L., Schifferstein, H. N. J., \& Galetzka, M. (2011). Tough package, strong taste: The influence of packaging design on taste impressions and product evaluations. Food Quality and Preference, 22(1), 17-23.

Bemporad, R., Hebard, A., \& Bressler, D. (2012). Re:Thinking consumption. Consumers and the future of sustainability: BBMG, GlobeScan and SustainAbility.

Binninger, A. S. (2015). Perception of naturalness of food packaging and its role in consumer product evaluation. Journal of Food Products Marketing, 53(3), 1-17.

Bloch, P. H. (1995). Seeking the ideal form: Product design and consumer response. Journal of Marketing, 59(3), 16-29.

Bloch, P. H., Brunel, F. F., \& Arnold, T. J. (2003). Individual differences in the centrality of visual product aesthetics: Concept and measurement. Journal of Consumer Research, 29(4), 551-565.

Bocken, N. M. P., De Pauw, I., Bakker, C., \& Van der Grinten, B. (2016). Product design and business model strategies for a circular economy. Journal of Industrial and Production Engineering, 33(5), 308-320.

Bocken, N. M. P., Farracho, R., Bosworth, R., \& Kemp, R. (2014). The front-end of ecoinnovation for eco-innovative small and medium sized companies. Journal of Engineering and Technology Management, 31, 43-57.

Bohlmann, G. M. (2004). Biodegradable packaging life-cycle assessment. Environmental Progress, 23(4), 342-346.

Boukris, E., Van Gijlswijk, R. N., Ansems, A. M. M. T., \& Jongeneel, L. S. (2014). DoorTAStend, LCA studie van draagtassen. Utrecht: TNO.

Bovea, M. D., Serrano, J., Bruscas, G. M., \& Gallardo, A. (2006). Application of life cycle assessment to improve the environmental performance of a ceramic tile packaging system. Packaging Technology and Science, 19(2), 83-95.

Brisson, I. (1993). Packaging waste and the environment: Economics and policy. Resources, Conservation and Recycling, 8(3/4), 183-192. 
Brockhaus, S., Petersen, M., \& Kersten, W. (2016). A crossroads for bioplastics: exploring product developers' challengers to move beyond petroleum-based plastics. Journal of Cleaner Production, 127, 84-95.

Brough, A. R., Wilkie, J. E. B., Ma, J., Isaac, M. S., \& Gal, D. (2016). Is eco-friendly unmanly? The green-feminine stereotype and its effect on sustainable consumption. Journal of Consumer Research, 43(4), 568-580.

Brunswik, E. (1955). Representative design and probabilistic theory in a functional psychology. Psychological Review, 62(3), 193-217.

Callister, M. A., \& Stern, L. A. (2012). The role of visual hyperbole in advertising effectiveness. Journal of Current Issues \& Research in Advertising, 29(2), 1-14.

Celhay, F., \& Trinquecoste, J. F. (2015). Package graphic design: Investigating the variables that moderate consumer response to atypical designs. Journal of Product Innovation Management, 32(6), 1014-1032.

Chang, C. (2005). Feeling ambivalent about going green. Journal of Advertising, 40(4), 19-32.

Charrad, M., Ghazzali, N., \& Boiteau, A. N. (2014). NbClust: An R package for determining the relevant number of clusters in a data set. Journal of Statistical Software, 61(6), 136.

Chernev, A. (2007). Jack of all trades or master of one? Product differentiation and compensatory reasoning in consumer choice. Journal of Consumer Research, 33(4), 430-444.

Chernev, A., \& Carpenter, G. S. (2001). The role of market efficiency intuitions in consumer choice: A case of compensatory inferences. Journal of Marketing Research, 38(3), 349-361.

Coombs, C. H. (1964). A theory of data. Oxford: Wiley.

Cowley, E. (2006). Processing exaggerated advertising claims. Journal of Business Research, 59(1), 728-734.

Cude, B. J. (1993). Consumer perceptions of environmental marketing claims: an exploratory study. Journal of Consumer Studies and Home Economics, 17, 207-225. 
Dangelico, R. M., \& Pujari, D. (2010). Mainstreaming green product innovation: why and how companies integrate environmental sustainability. Journal of Business Ethics, 95(3), 471-486.

Darke, P. R., \& Ritchie, R. J. B. (2007). The defensive consumer: Advertising deception, defensive processing, and distrust. Journal of Marketing Research, 44(1), 114-127.

De Koeijer, B., Wever, R., \& Henseler, J. (2017). Realizing product-packaging combinations in circular systems: Shaping the research agenda. Packaging Technology and Science, 30(8), 443-460.

De Vries, G., Terwel, B. W., Ellemers, N., \& Daamen, D. D. L. (2015). Sustainability or profitability? How communicated motives for environmental policy affect public perceptions of corporate greenwashing. Corporate Social Responsibility and Environmental Management, 22, 142-154.

Deng, X., \& Srinivasan, R. (2013). When do transparant packages increase (or decrease) food consumption? Journal of Marketing, 77(4), 104-117.

ecoinvent. (2013). ecoinvent Version 3.01.

http://www.ecoinvent.org/database/ecoinvent-version-3/ecoinvent-v30/

Ecover. (2018). Our clean plastic goals. Retrieved 29 March, 2018, from https://www.ecover.com/commitments/

Ellen MacArthur Foundation. (2015). Circular Economy Overview. Retrieved 27 March, 2017, from https://www.ellenmacarthurfoundation.org/circulareconomy/overview/concept

Ellen, P. S., Webb, D. J., \& Mohr, L. A. (2006). Building corporate associations: Consumer attributions for corporate social responsible programs. Journal of the Academy of Marketing Science, 34(2), 147-157.

Epley, N., Waytz, A., \& Cacioppo, J. T. (2007). On seeing human: A three-factor theory of anthropomorphism. Psychological Review, 114(4), 864-886.

Eppinger, S. (2011). The fundamental challenge of product design. Journal of Product Innovation Management, 28(3), 399-400.

Eurostat. (2018). Packaging waste statistics. Retrieved 7 March, 2019, from https://ec.europa.eu/eurostat/statistics-

explained/index.php/Packaging_waste_statistics 
EY. (2013). Unwrapping the packaging industry: Seven factors for success.

Fazio, R. H. (2007). Attitudes as object-evaluation associations of varying strength. Social Cognition, 25(5), 603-637.

Fenko, A., De Vries, R., \& Van Rompay, T. J. L. (2018). How strong is your coffee? The influence of visual metaphors and textual claims on consumers' flavor perception and product evaluation. Frontiers in Psychology, 9, 1-12.

Fishbein, M., \& Ajzen, I. (1975). Belief, attitude, intention, and behavior: An introduction to theory and research. Reading, MA: Addison-Wesley.

Fletcher, K. T., \& Goggin, P. A. (2001). The dominant stances on ecodesign: A critique. Design Issues, 17(3), 15-25.

Folkes, V., \& Matta, S. (2004). The effect of package shape on consumers' judgments of product volume: Attention as a mental contaminant. Journal of Consumer Research, 31(2), 390-401.

Ford, G. T., Smith, D. B., \& Swasy, J. L. (1990). Consumer skepticism of advertising claims: Testing hypotheses from economics of information. Journal of Consumer Research, 16(4), 433-441.

Forehand, M. R., \& Grier, S. (2002). When is honesty the best policy? The effects of stated company intent on consumer skepticism. Journal of Consumer Psychology, 13(3), 349-356.

Friestad, M., \& Wright, P. (1994). The persuasion knowledge model: how people cope with persuasion attempts. Journal of Consumer Research, 21(1), 1-31.

Furst, T., Connors, M., Bisogni, C. A., Sobal, J., \& Winter Falk, L. (1996). Food Choice: A Conceptual Model of the Process. Appetite, 26, 247-266.

Garaus, M., \& Halkias, G. (2019). One color fits all: product category color norms and (a)typical package colors. Review of Managerial Science, 1-23.

Gardner, D. M. (1975). Deception in advertising: A conceptual approach. Journal of Marketing, 39(1), 40-46.

Geissdoerfer, M., Savaget, P., Bocken, N. M. P., \& Hultink, E. J. (2017). The Circular Economy - A new sustainability paradigm. Journal of Cleaner Production, 143, 757768. 
Gelici-Zeko, M. M., Luters, D., ten Klooster, R., \& Weijzen, P. (2012). Studying the influence of packaging design on consumer perceptions (of dairy products) using categorizing and perceptual mapping. Packaging Technology and Science, 26(4), 215-228.

Gershoff, A. D., \& Frels, J. K. (2015). What Makes It Green? The Role of Centrality of Green Attributes in Evaluations of the Greenness of Products. Journal of Marketing, 79(1), 97-110.

Glavič, P., \& Lukman, R. (2007). Review of sustainability terms and their definitions. Journal of Cleaner Production, 15, 1875-1885.

Gleim, M. R., Smith, J. S., Andrews, D., \& Cronin, J. J. J. (2013). Against the green: A multimethod examination of the barriers to green consumption. Journal of Retailing, $89(1), 44-61$.

Goedkoop, M., Huijbregts, M., Schryver, A., De Struijs, J., \& Van Zelm, R. (2013). A life cycle impact assessment method which comprises harmonised category indicators at the midpoint and the endpoint level (1 ed.). The Hague: Ministry of Housing, Spatial Planning and Environment (VROM).

Goldberg, M. E., \& Hartwick, J. (1990). The effects of advertiser reputation and extremity of advertising claim on advertising effectiveness. Journa of Consumer Research, $17(2), 172-179$.

Golder, P. N., Mitra, D., \& Moorman, C. (2012). What Is Quality? An Integrative Framework of Processes and States. Journal of Marketing, 76(4), 1-23.

Grohmann, B. (2009). Gender dimensions of brand personality. Journal of Marketing Research, 46(1), 105-119.

Grunert, K. G. (2005). Consumer behaviour with regard to food innovations: quality perception and decision-making. In W. M. F. Jongen \& M. T. G. Meulenberg (Eds.), Innovation in agri-food systems (pp. 57-85). Wageningen: Wageningen Academic Publishers.

Guevremont, A., \& Grohmann, B. (2015). Consonants in brand names influence brand gender perceptions. European Journal of Marketing, 49(1/2), 101-122.

Haan, P., \& Berkey, C. (2002). A study of the believability of the forms of puffery. Journal of Marketing Communications, 8(4), 243-256. 
Hadjichristidis, C., Sloman, S. A., Stevenson, R., \& Over, D. (2004). Feature centrality and property induction. Cognitive Science, 28, 45-74.

Hayes, A. F. (2006). A primer on multilevel modeling. Human Communication Research, $32(4), 385-410$.

Hayes, A. F. (2018). Partial, conditional, and moderated moderated mediation: Quantification, inference, and interpretation. Communication Monographs, 85(1), 440.

Hayes, A. F., \& Preacher, K. J. (2014). Statistical mediation analysis with a multicategorical independent variable. British Journal of Mathematical and Statistical Psychology, 67(3), 451-470.

Hess, A. C., \& Melnyk, V. (2014). Pink or blue? The impact of gender cues on brand perceptions. European Journal of Marketing, 50(9/10), 1550-1574.

Higgins, E. T. (1996). Knowledge activation: Accessibility, applicability and salience. In E. T. Higgins \& A. W. Kruglanski (Eds.), Social psychology: Handbook of basic principles (pp. 133-168). New York: Guilford Press.

Hoegg, J., \& Alba, J. W. (2011). Seeing is believing (too much): The influence of product form on perceptions of functional performance. Journal of Product Innovation Management, 28(3), 346-359.

Hoogland, C. T., de Boer, J., \& Boersema, J. J. (2007). Food and sustainability: Do consumers recognize, understand and value on-package information on production standards? Appetite, 49(1), 47-57.

llyuk, V., \& Block, L. (2016). The effects of single-serve packaging on consumption closure and judgments of product efficacy. Journal of Marketing, 42(6), 858-878.

Irwin, J. R., \& Spira, J. S. (1997). Anomalies in the values for consumer goods with environmental attributes. Journal of Consumer Psychology, 6(4), 339-363.

Jain, S. P., \& Posavac, S. S. (2001). Prepurchase attribute verifiability, source credibility, and persuasion. Journal of Consumer Psychology, 11(3), 169-180. doi: 10.1207/s15327663jcp1103_03

Kahneman, D., \& Knetsch, J. L. (1992). Valuing public goods: The purchase of moral satisfaction. Journal of Environmental Economics and Management, 22(1), 57-70. 
Kamins, M. A., \& Marks, L. J. (1987). Advertising puffery: The impact of using two-sided claims on product attitude and purchase intention. Journal of Advertising, 16(4), 615 .

Kardes, F. R., Posavac, S. S., \& Cronley, M. L. (2004). Consumer inference: A review of processes, bases, and judgment contexts. Journal of Consumer Psychology, 14(3), 230-256.

Kelley, H. H. (1973). The processes of causal attribution. American Psychologist, 28(2), 107-128.

Kelly, G. A. (1955). The Psychology of Personal Constructs. New York: Norton.

Klewitz, J., \& Hansen, E. G. (2014). Sustainability-oriented innovation of SMEs: a systematic review. Journal of Cleaner Production, 65(15), 57-75.

Koenig-Lewis, N., Palmer, A., Dermody, J., \& Urbye, A. (2014). Consumers' evaluations of ecological packaging: Rational and emotional approaches. Journal of Environmental Psychology, 37, 94-105.

Kopalle, P. K., \& Assunção, J. L. (2000). When (not) to indulge in 'puffery': The role of consumer expectations and brand goodwill in determining advertised and actual product quality. Managerial and Decision Economics, 21(6), 223-241.

Kopalle, P. K., Fisher, R. J., Sud, B. L., \& Antia, K. D. (2017). The effects on advertised quality emphasis and objective quality on sales. Journal of Marketing, 81(2), 114-126.

Kopalle, P. K., \& Lehmann, D. R. (2015). The truth hurts: How customers may lose from honest advertising. International Journal of Research in Marketing, 32, 251-262.

Kuraray (2012). EVAL(TM) Resins - The better barrier for food applications. Pasadena, TX.

Lee, S. Y. (2014). When do consumers believe puffery claims? The moderating role of brand familiarity and repetition. Journal of Promotion Management, 20(2), 219-239.

Li, M., \& Chapman, G. B. (2012). Why do people like natural? Instrumental and ideational bases for the naturalness preference. Journal of Applied Social Psychology, 42(12), 2859-2878.

Lieven, T., Grohmann, B., Herrmann, A., Landwehr, J. R., \& Van Tilburg, M. (2015). The effect of brand design on brand gender perceptions and brand preference. European Journal of Marketing, 49(1/2), 149-149. 
Ligthart, T. N., \& Ansems, A. M. M. T. (2018). EnvPack, an LCA-based tool for environmental assessment of packaging chains: Part 2: influence of assessment method on ranking of alternatives. The International Journal of Life Cycle Assessment, 1-11.

Ligthart, T. N., Velzen, U. T. Van, \& Brouwer, M. (2017 in prep.). LCA-based tool for environmental assessment of packaging chains. Part 1: Scope, methods and inventory of tool.

Lin, Y. C., \& Chang, C.-c. (2012). Double standard: The role of environmental consciousness in green product usage. Journal of Marketing, 76(5), 125-134.

Lindh, H., Olsson, A., \& Williams, H. (2016). Consumer perceptions of food packaging: Contributing to or counteracting environmentally sustainable development? Packaging Technology and Science, 29(1), 3-23.

Lindh, H., Williams, H., Olsson, A., \& Wikström, F. (2016). Elucidating the indirect contributions of packaging to sustainable development: A terminology of packaging functions and features. Packaging Technology and Science, 29(4-5), 225-246.

Littel, S., \& Orth, U. R. (2013). Effects of package visuals and haptics on brand evaluations. European Journal of Marketing, 47(1/2), 198-217.

Luchs, M. G., Brower, J., \& Chitturi, R. (2012). Product choice and the importance of aesthetic design given the emotion-laden trade-off between sustainability and functional performance. Journal of Product Innovation Management, 29(6), 903-916.

Luchs, M. G., \& Kumar, M. (2015). "Yes, but this other one looks better/works better": How do consumers respond to trade-offs between sustainability and other valued attributes? Journal of Business Ethics, 140(3), 568-584.

Luchs, M. G., \& Swan, K. S. (2011). Perspective: The Emergence of Product Design as a Field of Marketing Inquiry. Journal of Product Innovation Management, 28(3), 327345.

Luchs, M. G., Swan, K. S., \& Creusen, M. E. H. (2016). Perspective: A review of marketing research on product design with directions for future research. Journal of Product Innovation Management, 33(3), 320-341. 
Luchs, M. G., Walker Naylor, R., Irwin, J. R., \& Raghunathan, R. (2010). The sustainability liability: Potential negative effects of ethicality on product preference. Journal of Marketing, 74(5), 18-31.

Lupiáñez-Villanueva, F., Tornese, P., Veltri, G. A., \& Gaskell, G. (2018). Assessment of different communication vehicles for providing Environmental Footprint information: European Commission.

Magnier, L., \& Crié, D. (2015). Communicating packaging eco-friendliness: An exploration of consumers' perceptions of eco-designed packaging. International Journal of Retail \& Distribution Management, 43(4/5), 350-366.

Magnier, L., \& Schoormans, J. (2015). Consumer reactions to sustainable packaging: The interplay of visual appearance, verbal claim and environmental concern. Journal of Environmental Psychology, 44, 53-62.

Magnier, L., \& Schoormans, J. (2017). How do packaging material, colour and environmental claim influence package, brand and product evaluations? Packaging Technology and Science, 30(11), 735-751.

Magnier, L., Schoormans, J., \& Mugge, R. (2016). Judging a product by its cover: Packaging sustainability and perceptions of quality in food products. Food Quality and Preference, 53, 132-142.

Manfredi, S., Allacker, K., Chomkhamsri, K., Pelletier, N., \& Souza, D. M. de. (2012). Product Environmental Footprint (PEF) Guide; Consolidated version. Ispra, Italy.

Martinho, G., Pires, A., Portela, G., \& Fonseca, M. (2015). Factors affecting consumers' choices concerning sustainable packaging during product purchase and recycling. Resources, Conservation and Recyling, 103, 58-68.

McDonald, S., \& Oates, C. J. (2006). Sustainability: Consumer Perceptions and Marketing Strategies. Business Strategy and the Environment, 15, 157-170.

McDonough, W., \& Braungart, M. (2002). Cradle to Cradle: Remaking the Way We Make Things. New York: North Point Press.

McQuarrie, E. F., \& Mick, D. G. (1996). Figures of rhetoric in advertising language. Journal of Consumer Research, 22(4), 242-438.

Meyers-Levy, J., \& Tybout, A. M. (1989). Schema Congruity as a Basis for Product Evaluation. Journal of Consumer Research, 16(1), 39-54. 
Mintel. (2018). Global packaging trends 2018. Retrieved 6 April 2018, from http://www.mintel.com/global-packaging-trends/

Mitra, D., \& Golder, P. N. (2006). How Does Objective Quality Affect Perceived Quality? Short-Term Effects, Long-Term Effects, and Asymmetries. Marketing Science, 25(3), 230-247.

Murto, P., Person, O., \& Ahola, M. (2014). Shaping the face of environmentally sustainable products: image boards and early consumer involvement in ship interior design. Journal of Cleaner Production, 75, 86-95.

Newman, G. E., Gorlin, M., \& Dhar, R. (2014). When going green backfires: How firm intentions shape the evaluation of socially beneficial product enhancements. Journal of Consumer Research, 41(3), 823-839.

Nordin, N., \& Selke, S. (2010). Social Aspect of Sustainable Packaging. Packaging Technology and Science, 23(6), 317-326.

Nyilasy, G., Gangadharbatla, H., \& Paladino, A. (2014). Perceived greenwashing: The interactive effects of green advertising and corporate environmental performance on consumer reactions. Journal of Business Ethics, 125(4), 693-707.

Obermiller, C., Spangenberg, E. R., \& MacLachlan, D. L. (2005). Ad Skepticism: The consequences of disbelief. Journal of Advertising, 34(3), 7-17.

Olson, J. C. (1978). Inferential belief formation in the cue utilization process. Paper presented at the Advances in Consumer Research, Aann Arbor, MI.

Olson, J. C., \& Jacoby, J. (1972). Cue utilization in the quality perception process. Paper presented at the The Third Annual Conference of the Association for Consumer Research, Chicago, IL.

Orth, U. R., Campana, D., \& Malkewitz, K. (2010). Formation of consumer price expectation based on package design: Attractive and quality routes. Journal of Marketing Theory and Practice, 8(1), 23-40.

Orth, U. R., \& Crouch, R. C. (2014). Is beauty in the aisles of the retailer? Package processing in visually complex contexts. Journal of Retailing, 90(4), 524-537.

Orth, U. R., \& Malkewitz, K. (2008). Holistic package design and consumer brand impressions. Journal of Marketing, 72(3), 64-81. 
Ottman, J. A., Stafford, E. R., \& Hartman, C. L. (2010). Avoiding Green Marketing Myopia: Ways to Improve Consumer Appeal for Environmentally Preferable Products. Environment: Science and Policy for Sustainable Development, 48(5), 22-36.

Ozaki, R. (2011). Adopting sustainable innovation: What makes consumers sign up to green electricity? Business Strategy and the Environment, 20, 1-17.

Pancer, E., McShane, L., \& Noseworthy, T. J. (2017). Isolated environmental cues and product efficacy penalties: The color green and eco-labels. Journal of Business Ethics, 143(1), 159-177.

Parguel, B., Benoît-Moreau, F., \& Larceneux, F. (2011). How sustainability ratings might deter 'Greenwashing': A close look at ethical corporate communication. Journal of Business Ethics 102(1), 15-28.

Petersen, M., \& Brockhaus, S. (2017). Dancing in the dark: Challenges for product developers to improve and communicate product sustainability. Journal of Cleaner Production, 161, 345-354.

Petty, R. E., \& Cacioppo, J. T. (1986). The elaboration likelihood model of persuasion. Advances in Experimental Social Psychology, 19, 123-205.

Prakash, G., \& Pathak, P. (2017). Intention to buy eco-friendly packaged products among young consumers of India: A study on developing nation. Journal of Cleaner Production, 141, 385-393.

Reimann, M., Zaichkowsky, J., Neuhaus, C., Bender, T., \& Weber, B. (2010). Aesthetic package design: A behavioral, neural, and psychological investigation. Journal of Consumer Psychology, 20(4), 431-441.

Rettie, R., \& Brewer, C. (2000). The verbal and visual components of package design. The Journal of Product and Brand Management 9(1), 56-70.

Richards, J. I. (1990). A "New and Improved" view of puffery. Journal of Public Policy \& Marketing, $9(1), 73-84$.

Richardson, P. S. (1994). Cue effects on evaluations of national and private-label brands. In C. W. Park \& D. C. Smith (Eds.), Marketing Theory and Applications (Vol. 5, pp. 165171). Chicago: American Marketing Association.

Rod, S. (1990). Packaging as a retail marketing tool. International Journal of Physical Distribution \& Logistics Management, 20(8), 29-30. 
Rokka, J., \& Uusitalo, L. (2008). Preference for green packaging in consumer product choices - Do consumers care? International Journal of Consumer Studies, 32(5), 516525 .

Romaniuk, J., \& Sharp, B. (2004). Conceptualizing and measuring brand salience. Marketing Theory, 4(4), 327-342.

Rozin, P., Spranca, M., Krieger, Z., Neuhaus, R., Surillo, D., Swerdlin, A., \& Wood, K. (2004). Preference for natural: instrumental and ideational/moral motivations, and the contrast between foods and medicines. Appetite, 43(2), 147-154.

Schnurr, B. (2018). What's best for whom? The effect of product gender depends on positioning. European Journal of Marketing, 52(1/2), 367-391.

Schoormans, J. P. L., \& Robben, H. S. J. (1997). The effect of new package design on product attention, categorization and evaluation. Journal of Economic Psychology, 18(2/3), 271-287.

Scott, L., \& Vigar-Ellis, D. (2014). Consumer understanding, perceptions and behaviours with regard to environmentally friendly packaging in a developing nation. International Journal of Consumer Studies, 38(6), 642-649.

Seo, S., Ahn, H.-K., Jeong, J., \& Moon, J. (2016). Consumers' attitude toward sustainable food products: ingredients vs. packaging. Sustainability, 8(10), 1073-1092.

Simms, C., \& Trott, P. (2010). Packaging development: A conceptual framework for identifying new product opportunities. Marketing Theory, 10(4), 397-415.

Simonson, I., \& Winer, R. S. (1992). The influence of purchase quantity and display format on consumer preference for variety. Journal of Consumer Research, 19(1), 133-138.

Sloman, S. A., Love, B. C., \& Ahn, W.-k. (1998). Feature centrality and conceptual coherence. Cognitive Science, 22(2), 189-228.

Sonneveld, K., James, K., Fitzpatrick, L., \& Lewis, H. (2005). Sustainable Packaging: How do we Define and Measure It? Paper presented at the 22nd IAPRI Symposium.

Spack, J. A., Board, V. E., Crighton, L. M., Kostka, P. M., \& Ivory, J. D. (2012). It's Easy Being Green: The Effects of Argument and Imagery on Consumer Responses to Green Product Packaging. Environmental Communication, 6(4), 441-458. 
SPC. (2011). Definition of sustainable packaging: GreenBlue. Retrieved 7 March 2019 from: https://sustainablepackaging.org/wp-content/uploads/2017/09/Definitionof-Sustainable-Packaging.pdf

Steenis, N. D., Van der Lans, I. A., Van Herpen, E., \& Van Trijp, H. C. M. (2018). Effects of sustainable design strategies on consumer preferences for redesigned packaging. Journal of Cleaner Production, 205, 854-865.

Steenis, N. D., Van Herpen, E., Van der Lans, I. A., Ligthart, T. N., \& Van Trijp, H. C. M. (2017). Consumer response to packaging design: The role of packaging materials and visuals in sustainability perceptions and product evaluations. Journal of Cleaner Production, 162, 286-298.

Steenkamp, J.-B. E. M. (1990). Conceptual model of the quality perception process. Journal of Business Research, 21(4), 309-333.

Steenkamp, J.-B. E. M., Van Trijp, H. C. M., \& Ten Berge, J. M. F. (1994). Perceptual mapping based on idiosyncratic sets of attributes. Journal of Marketing Research, $31(1), 15-27$.

Steptoe, A., Pollard, T. M., \& Warde, J. (1995). Development of a measure of the motives underlying the selection of food: The food choice questionnaire. Appetite, 25(3), 267284.

TerraChoice. (2010). The sins of greenwashing: Home and family edition. Retrieved 26 October 2017 from: http://sinsofgreenwashing.com/index35c6.pdf

Tirole, J. (1989). The theory of industrial organization. Cambridge, MA: MIT Press.

Tobler, C., Visschers, V. H. M., \& Siegrist, M. (2011). Eating green. Consumers' willingness to adopt ecological food consumption behaviors. Appetite, 57, 674-682.

Toncar, M., \& Fetscherin, M. (2012). A study of visual puffery in fragrance advertising: Is the message sent stronger than the actual scent? European Journal of Marketing, 45(1/2), 55-72.

Torelli, C. J., Monga, A. B., \& Kaikati, A. M. (2012). Doing poorly by doing good: Corporate social responsibility and brand concepts. Journal of Consumer Research, 38(5), 948963. 
Underwood, R. L. (2003). The communicative power of product packaging: Creating brand identity via lived and mediated experience. Journal of Marketing Theory and Practice, 11(1), 62-76.

Underwood, R. L., Klein, N. M., \& Burke, R. (2001). Packaging communication: Attentional effects of product imagery. Journal of Product \& Brand Management, 107), 403-422.

UNEP. (2005). Talk the walk: Advancing sustainable lifestyles through marketing and communications. Retrieved 16 January, 2016, from http://www.unep.fr/shared/publications/pdf/DTIx0763xPA-TalkWalk.pdf

Unilever. (2015). A small can, a big impact. Retrieved 22 March, 2016, from http://www.compresseddeodorants.com/assets/content/uk/Compressed_white_pap er_22-02-2016.pdf

Van Birgelen, M., Semeijn, J., \& Keicher, M. (2009). Packaging and proenvironmental consumption behavior: Investigating purchase and disposal decisions for beverages. Environment and Behavior, 41(1), 125-146.

Van Dam, Y. K. (1996). Environmental assessment of packaging: The consumer point of view. Environmental Management, 20(5), 607-614.

Van Ooijen, I., Fransen, M. L., Verlegh, P. W. J., \& Smit, E. G. (2017). Signalling product healthiness through symbolic package cues: Effects of package shape and goal congruence on consumer behaviour. Appetite, 109(1), 73-82.

Van Rompay, T. J. L., De Vries, P. W., Bontekoe, F., \& Tanja-Dijkstra, K. (2012). Embodied product perception: Effects of verticality cues in advertising and packaging design on consumer impressions and price expectations. Psychology \& Marketing, 29(12), 919-928.

Van Rompay, T. J. L., Deterink, F., \& Fenko, A. (2016). Healthy package, healthy product? Effects of packaging design as a function of purchase setting. Food Quality and Preference, 53, 84-89.

Van Rompay, T. J. L., Pruyn, A. T. H., \& Tieke, P. (2009). Symbolic Meaning Integration in Design and its Influence on Product and Brand Evaluation. Design \& Emotion, 3(2), 19-25. 
Van Rompay, T. J. L., \& Veltkamp, M. (2014). Product packaging metaphors: Effects of ambiguity and explanatory information on consumer appreciation and brand perception. Psychology \& Marketing, 31(6), 404-415.

Van Tilburg, M., Lieven, T., Herrmann, A., \& Townsend, C. (2015). Beyond "Pink it and shrink it" perceived product gender, aesthetics, and product evaluation. Psychology \& Marketing, 32(2), 422-437.

Vermeir, I., \& Verbeke, W. (2006). Sustainable food consumption: Exploring the consumer "attitude-behavioral intention" gap. Journal of Agricultural and Environmental Ethics, 19(2), 169-194.

Vos, J. (2009). Actions speak louder than words: Greenwashing in corporate America. Notre Dame Journal of Law, Ethics \& Public Policy, 23, 673-697.

Wagner, T., Lutz, R. J., \& Weitz, B. A. (2009). Corporate hypocrisy: Overcoming the threat of inconsistent corporate social responsibility perceptions. Journal of Marketing, 73(6), 77-91.

Walker Naylor, R., \& Trudel, R. (2012). Is Less More When Communicating Sustainability? Consumer Response to Ambiguous Versus Detailed Sustainability Product Labels. Paper presented at the Advances in Consumer Research, Duluth, MN.

Williams, A. A., \& Langron, S. P. (1984). The use of free-choice profiling for the evaluation of commercial ports. Journal of the Science of Food and Agriculture, 35(5), 558-568.

Zeithaml, V. A. (1988). Consumer perceptions of price, quality, and value: A means-end model and synthesis of evidence. Journal of Marketing, 52(3), 2-22.

Ziem, S., Chudziak, C., Taylor, R., Bauen, A., Murphy, R., Guo, M., \& Akhurst, M. (2013). Environmental assessment of Braskem's bio-based PE resin: summary of the life cycle assessment, land-use change and water footprint reports: E4tech \& LCAworks. 


\section{SUMMARY}

The design of more sustainable packaging is an important step towards reducing packaging's environmental impacts. Packaging however also serves important role as a 'silent salesman' as it provides many cues which consumers may use to make inferences about the packaged product's expected benefits. Successful sustainable packaging should therefore not only be better for the environment, but should also be an attractive option for consumers. Across four empirical chapters, this thesis examines sustainable packaging design in terms of both functional and aesthetical design goals, leading into structural, graphical and verbal packaging cues. Consumer response is studied along four distinct types of consumer inferences, namely with regard to: (1) packaging sustainability, (2) product (contents) sustainability, (3) other product benefits (besides sustainability) and (4) greenwashing related to firm motives.

An analysis of consumer cue perceptions relating to 'status quo' tomato soup packaging options available in the marketplace (Chapter 2 ) reveals that consumers have accessible mental associations between packaging and sustainability, and readily utilize packaging cues to make inferences related to (product) sustainability as well as other benefits. Sustainable packaging design leads to inferences of higher naturalness, healthiness and quality but also causes consumers to infer a higher price and lower convenience (Chapter $2 \& 3$ ). Furthermore, sustainable packaging design cues can also lead to inferences of lower product strength and higher gentleness (Chapter 5). Moreover, there is a significant overall inverse correlation between consumer perception of packaging sustainability and life-cycle analysis outcomes (Chapter 2). This gap is likely caused in part due to consumers' emphasis on using visible packaging cues whereas life-cycle analysis takes a more holistic view.

When it comes to actively redesigning packaging to be functionally more sustainable (Chapter 3), consumers tend to react most positively toward biologically circular redesign strategies (e.g., biodegradability) followed by technically circular (e.g., recyclability) and linear strategies (e.g., lightweighting), respectively. While any sustainability redesign is perceived relatively favorable compared to a conventional status quo packaging, combining multiple redesign strategies into a single packaging does not substantially increase consumer purchase intentions, and is perceived by consumers to lead to heavily diminished increases in environmental impacts. This effect is explained by a lack of increase in consumers' moral satisfaction obtained from the more sustainable alternative. Thus, the presence of at least one 
sustainability improvement takes precedent over developing more intensive redesigns.

Investigating the aesthetical aspects of (sustainable) packaging redesign using laundry detergents (Chapter 5 ) shows that while overtly sustainable packaging cues do cause consumers to infer lower detergent strength and higher gentleness, these inferences can be influenced by also including aesthetical (masculine/feminine) gender cues in the packaging's design. Specifically, packaged products that contain both sustainable and masculine packaging design cues are perceived as relatively favorable in terms of perceived strength, gentleness and environment-friendliness. Consumer usage scenario moderates the effect of the strength and gentleness inferences. Sustainable packaging designs in general are chosen less when consumers seek out strength-benefits in detergent usage, but the use of masculinity cues compensates this disadvantage. Conversely, sustainable designs are preferred in general when consumers seek gentleness benefits during usage. The usage of aesthetical gender cues indicates that designers and marketers need not always rely exclusively on cues that connote sustainability in order to improve sustainable choice likelihood.

The thesis also investigates greenwashing inferences in consideration of product and packaging combinations and firms' sustainability communications (Chapter 4). Consumers are more likely to infer that the firm is attempting to greenwash when it provides environmental claims for packaged products for which only either packaging or product contents are truly sustainable (compared to when both are sustainable). In such cases, there is a claim-fact discrepancy wherein the firm implies 'full' sustainability, but the actual product-packaging combination is only partially sustainable. This causes consumers to become ambivalent as they positively value the (partial) sustainability improvement, but negatively value the deceitful actions of the firm. This process is further moderated by the type of sustainability claim. Using highly puffy claims increases the pros (improved sustainability perception) and cons (higher perceived greenwashing) whereas not providing any claims reduces them. Based on centrality theory, findings also indicate that when only a peripheral attribute (packaging) is made sustainable, consumers perceive a higher degree of greenwashing than when only central attributes (product contents) are made sustainable. 
Overall, this thesis shows that making packaging more sustainable and/or using packaging sustainability cues does not merely change consumers' (potentially inaccurate) view of that packaging's environmental qualities, but causes consumers to make various types of other inferences as well. Consumers infer about other benefits of the packaged product as well as firm intentions in relation to potential deceit. Successful sustainable packaging design should seek to reinforce those consumer inferences with positive effects and/or inhibit inferences with potential negative effects to ensure an overall attractive packaged product proposition. 


\section{ACKNOWLEDGEMENTS}

\section{DANKWOORD}

It's been a long (and sometimes strange) journey. Of course, the PhD process would not be complete without some big ups and downs, major changes in my personal life, lucky breaks, sleepless nights and, in the end, a bunch of personal growth. While this journey has been an experience in and of itself, I've at last arrived at my destination by completing the PhD thesis. Looking back at these past four-plus years, I want to take the time to thank the people who have made that completion possible.

Allereerst wil ik mijn dank uitspreken voor mijn promotor Hans van Trijp en copromotors Erica van Herpen en Ivo van der Lans. Bedankt voor de energie die jullie in dit proefschrift hebben gestoken, zonder jullie hulp was ik er niet gekomen. Hans, jou wil ik in het bijzonder bedanken voor je brede conceptuele skills en oplossingsgerichtheid. Zelfs wanneer het lastig leek bepaalde concepten logisch met elkaar te verbinden, kon je me altijd weer inspireren om een andere kijk op dingen te nemen. Verder zullen de Hans-modellen me altijd bijblijven, waaronder natuurlijk het pijltjes-en-blokmodel en de grafieken, maar ook de zeldzamere 'experimental design kubus'. Bij voorkeur uitgetekend op de achterkant van een draft proposal bladzijde, financieel overzicht of projectplanning van onbekende oorsprong. Erica, jou wil ik in bijzonder bedanken voor je kritische oog op de details en alle hulp met het doordenken en opzetten van de experimenten. Daarnaast waardeer ik dat zelfs als je het erg druk had, je alsnog mijn stukken aandachtig wist door te nemen en van feedback te voorzien. Ivo, bij jou kon ik natuurlijk altijd terecht met de (meest obscure) statistische vraagstukken, was het niet via afspraak dan wel ergens tussendoor tijdens de uren MCB-30306 practicals. Daarnaast waardeer ik je oprechtheid, geduld en je nuchterheid in alle (wetenschappelijke) zaken en konden we altijd goede (en soms eventueel nuttige) discussies over van alles en nog wat te voeren, ook al was het puur om er over te discussiëren. Dat ga ik zeker missen!

I would also like to express my gratitude to the committee members, professors Gert Spaargaren, Edith Smit, Jan Schoormans and Jorg Henseler, for their time and effort spent in reading and evaluating my $\mathrm{PhD}$ thesis and attending the defence ceremony.

Ook wil ik alle (andere) stafleden en administratieve support van MCB bedanken voor hun betrokkenheid en inputs gedurende mijn tijd bij MCB. In het bijzonder wil ik 
Ellen Vossen bedanken voor haar toewijding om me te helpen met de administratieve taken van het $\mathrm{PhD}$ werk.

Dan mogen natuurlijk al mijn PhD mede-lotgenoten niet ontbreken. Te beginnen met mijn (ex)kamergenoten, Peter en Kristina. Peter P., met jou in de kamer was het nooit saai (op de kamer of de gehele afdeling), en je eindeloze Peter-capriolen waren een grote bron van vermaak. Kristina "Subaru" Supertova, we had some great times inside and outside of room 5014 (including regular intervals of smoking breaks), through ups and downs. I presume my absence has left a gaping void that can never be truly filled, but l'll be sure to check up every now and then with a beverage or two to alleviate the symptoms. Also thank you for all the times I borrowed your WUR card for coffee.

Dat brengt me tot mijn andere MCBuddies: Robert en Lisanne. Robbie, wat een knakenharde, radical avonturen hebben wij samen meegemaakt (ook al vrijwel altijd eindigend met een kater die dag erna). Vanaf het begin van de $\mathrm{PhD}$, tot op de Steamboat Natchez en gedurende de Villa Mokerhard era met $C B$, en uiteindelijk helemaal tot het afronden van onze proefschriften, was ik altijd siked voor onze hangouts (met of zondere andere locals). $\mathrm{lk}$ zeg, laten we die steez er in de toekomst inhouden, bij voorkeur in de achterste hoek van de bar (of op een willekeurige maandagmiddag in de Spot). LvG, bedankt voor de goede gesprekken omtrent het wereldverbeteraarschap en het PhD-leven maar ook vooral voor het standaard geouwehoer. Laten we vooral niet nog een keer naar een optreden van Kraantje Pappie gaan (verder ben je wel cool hoor).

Kunalai, I think I will end up missing our fun casual conversations about the most obscure mediation analysis problems - at least we did sometimes manage to help each other out, or alternatively refer ourselves to Ivo. Luz, thanks for the good conversations we've had over the years and also the free snacks I've scooped up from your office. Also thank you for providing me with preliminary insights as to how babies work (plus I will never forget the Robert x baby interaction). Colin en Aleks, ook jullie wil ik bedanken voor de tijd waar we samen bij MCB zaten. Ik kan me nog goed herinneren toen ik net soort-van was aangenomen dat ik per abuis bij jullie in de lift terecht kwam. Jullie vroegen of ik "die nieuwe PhD was", gevolgd door een lading vol gelach en lol richting de $5^{\mathrm{e}}$ (not sure why). Dat zette denk ik wel de toon voor onze toekomstige interacties. I would also like to express my thanks to all the 
other MCB PhD's whom l've gotten to know over the years. Particularly, Katerina, Naomí, Xin and Giulia. It was great getting to know you and I wish you all the best.

De boys (en girls) uit Ede - jullie weten wie jullie zijn. Bedankt voor de vaak benodigde afleiding van het PhD-leven en de vele avonturen die we de afgelopen jaren hebben meegemaakt. Ik dacht aan bijvoorbeeld die ene keer dat we (ik?) zo nodig een bepaald kustgebergte moesten beklimmen in Colombia, de Aguardiente night (never forgetti), en het nooit behaalde doel om een luiaard te aaien. Daarnaast herinner ik me ook (deels) de vele avonden in de illustere uitgaansgelegenheden Tapperie "The Jug" en de Primer. Laten we er nog vaak ééntje met de boys doen.

Annemieke, super bedankt voor je steun en liefde. Zelfs als ik weer eens lekker onrustig stond te ijsberen of een destructieve bui had wist jij me altijd te kalmeren. Ik weet nog steeds niet hoe je het doet. Zonder jou was mijn leven gedurende het laatste deel van het PhD-traject allemaal echt een behoorlijk stuk minder soepel en vooral minder vrolijk verlopen.

Last but not least wil ik mijn familie bedanken voor al hun steun tijdens deze niet altijd even makkelijke jaren. Pa en ma, bedankt voor hotel Steenis en voor het altijd klaar staan om me met wat-dan-ook te helpen zelfs als ik me gedroeg als sarcastische wijsneus. Mitch, ook zonder jouw hulp was dit boekje er niet zo gekomen. Bedankt voor het ontwerpen van de kaft en voor je rol als proefkonijn voor mijn experimenten. Opa Ronnie en oma's Anita en Margriet, hartstikke bedankt voor al het (indo)food en noodpakketen over de jaren heen. Ook zeker bedankt voor de financiële stimulanspakketen deze laatste maanden. Bovenal bedankt voor alle gezelligheid en betrokkenheid. Ik ben blij dat jullie mijn promotie kunnen meemaken. 


\section{ABOUT THE AUTHOR}

Nigel Desmond Steenis was born in Den Helder on July 11th, 1991. He received his Master's degree in Management, Economics \& Consumer Studies (specializing in Consumer Behavior) from Wageningen University in 2014.

Shortly after finalizing (and later publishing) his MSc thesis on consumer attitudes towards nanotechnology-based product attributes at the Marketing and Consumer Behaviour Group, Nigel started his PhD at the same department. During his $\mathrm{PhD}$, he was involved with the Netherlands Institute for

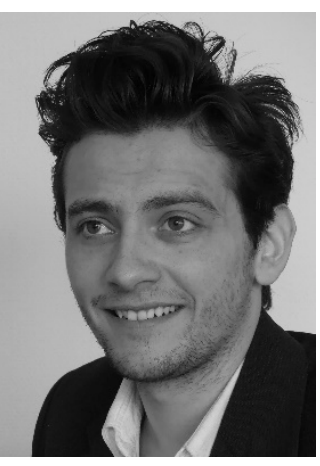
Sustainable Packaging \& Top Institute Food and Nutrition (TiFN) as part of the scientific research programme on sustainable packaging. In this multidisciplinary project, Nigel was responsible for research on consumer purchase behaviors and inference-making processes related to sustainable packaging design. During his PhD, Nigel published several academic papers, attended advanced research methodology courses and presented his work at (inter)national conferences as well as industry events.

Currently, Nigel is looking for opportunities to combine marketing practice with science in a world of many voices but not nearly as many truths. 
Nigel D. Steenis

Wageningen School of Social Sciences (WASS)

Completed Training and Supervision Plan

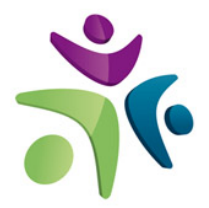

Wageningen School

of Social Sciences

\begin{tabular}{|c|c|c|c|}
\hline Name of the learning activity & Department/Institute & Year & ECTS* \\
\hline \multicolumn{4}{|l|}{ A) Project related competences } \\
\hline PhD Research proposal & MCB/WASS & 2015 & 4 \\
\hline $\begin{array}{l}\text { Quantitative Data Analysis: Multivariate Techniques } \\
\text { (YRM-50806) }\end{array}$ & WUR & 2016 & 2 \\
\hline $\begin{array}{l}\text { Masterclass psychology of health and } \\
\text { environmental behaviour: Priming and } \\
\text { Categorisation and Evaluation }\end{array}$ & WUR & 2015 & 1 \\
\hline STEP Summer School & STEP & 2015 & 2 \\
\hline Developing a teaching package & University of Twente & 2017-2018 & 3 \\
\hline $\begin{array}{l}\text { Behavioural and Experimental Economics (ECH- } \\
\text { 51306) }\end{array}$ & $\mathrm{ECH}$ & 2016 & 6 \\
\hline $\begin{array}{l}\text { Data analysis and programming in } \mathrm{R} \text { (various } \\
\text { courses) }\end{array}$ & Data Camp & $2015-2018$ & 4 \\
\hline \multicolumn{4}{|l|}{ B) General research related competences } \\
\hline Introduction course & WASS & 2015 & 1 \\
\hline Scientific Writing & WGS & 2015 & 1.8 \\
\hline EDEN Doctoral Seminar on Consumer Research & EIASM & 2017 & 4 \\
\hline $\begin{array}{l}\text { 'Consumer response to packaging design The role } \\
\text { of packaging materials and visuals in sustainability } \\
\text { perceptions and product evaluations' }\end{array}$ & $\begin{array}{l}\text { SABE/IAREP Conference } 2016 \\
\text { (Wageningen, NL) }\end{array}$ & 2016 & 1 \\
\hline $\begin{array}{l}\text { 'Consumentenperceptie van } \\
\text { verpakkingsduurzaamheid' }\end{array}$ & $\begin{array}{l}\text { PEFC Nederland Jaarbijeenkomst } \\
\text { (Driebergen, NL) }\end{array}$ & 2016 & 1 \\
\hline $\begin{array}{l}\text { 'Circular packaging (re)design and its effects on } \\
\text { consumer preferences' }\end{array}$ & $\begin{array}{l}\text { KIDV/TIFN Jaarbijeenkomst (Den Haag, } \\
\text { NL) }\end{array}$ & 2017 & 1 \\
\hline WGS Workshop Carousel & WGS & 2016 & 0.3 \\
\hline \multicolumn{4}{|l|}{ C) Career related competences/personal development } \\
\hline Competence Assessment & WGS & 2015 & 0.3 \\
\hline Career Orientation & WGS & 2018 & 1.5 \\
\hline Interpersonal Communication for PhD Candidates & WGS & 2016 & 0.6 \\
\hline Course assistant MCB-30306 & MCB & $2015-2019$ & 4 \\
\hline Total & & & 38.5 \\
\hline
\end{tabular}


This research was funded by Top Institute Food and Nutrition (TiFN), a public-private partnership on pre-competitive research in food and nutrition, and the Dutch Knowledge Institute for Sustainable Packaging (KIDV) under grant SD002 Sustainable Packages. The studies presented in this thesis were performed within the framework of TiFN.

Financial support from Wageningen University \& Research for printing this thesis is gratefully acknowledged.

\section{Cover design:}

Mitch \& Nigel Steenis

\section{Publisher:}

Digiforce / Proefschriftmaken.nl, Vianen 
